\title{
Contributions to the knowledge of Formicidae (Hymenoptera, Aculeata): a new diagnosis of the family, the first global male-based key to subfamilies, and a treatment of early branching lineages
}

\author{
Brendon E. BOUDINOT \\ Department of Entomology/Nematology, Briggs Hall, Rm. 381 \\ University of California, Davis, U.S.A. \\ boudinotb@gmail.com
}

urn:Isid:zoobank.org:author:919F03B0-60BA-4379-964D-A56EB582E16D

\section{Table of contents}

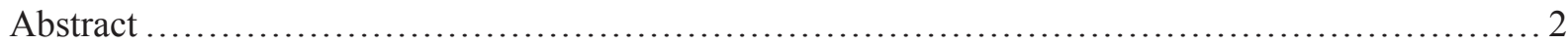

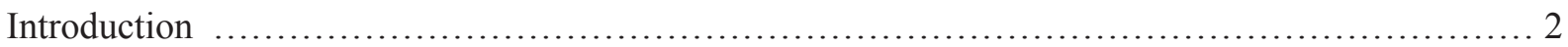

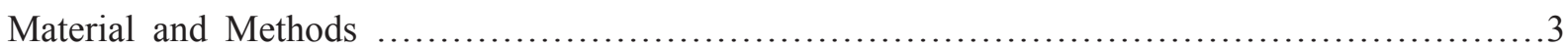

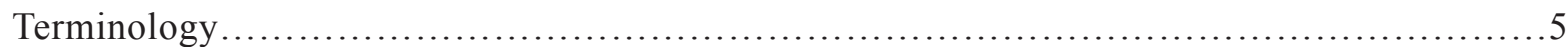

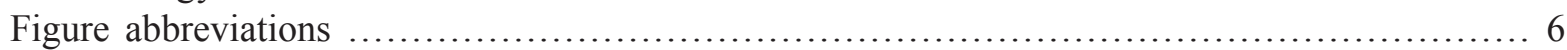

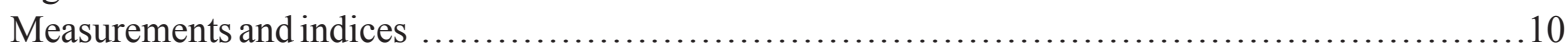

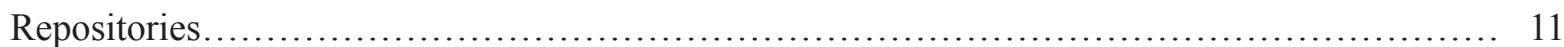

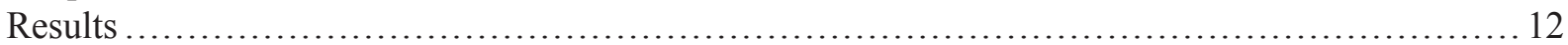

Family Formicidae Latreille, 1809 ..................................................... 12

Key to global subfamilies, based on extant males ........................................ 14

Treatments of focal taxa ........................................................... 17

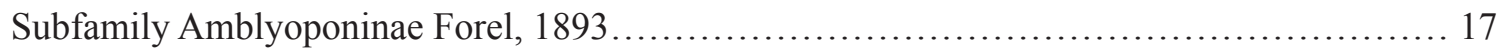

Genus Apomyrma Brown, Gotwald Jr. \& Lévieux, 1971 .............................. 22

Apomyrma stygia Brown, Gotwald Jr. \& Lévieux, 1971 ............................... 24

Apomyrma CD01 ....................................................... 24

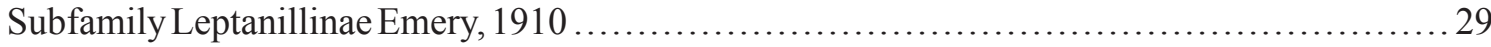

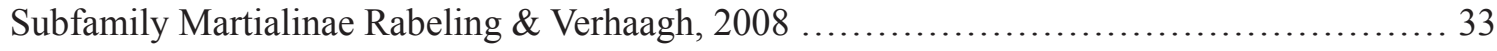

Genus Martialis Rabeling \& Verhaagh, 2008 ........................................ 37

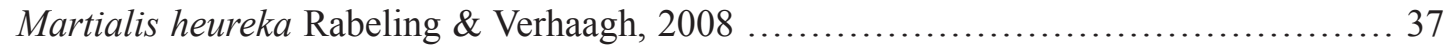

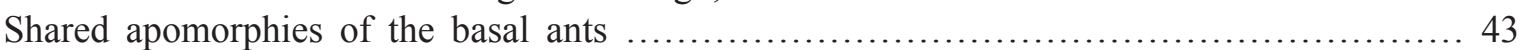

Brief global diagnoses of subfamilies, based on males ................................... 46

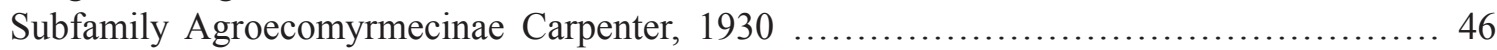

Subfamily Paraponerinae Emery, 1901 ............................................... 47

Subfamily Ponerinae Lepeletier de Saint-Fargeau, 1835 ................................... 47

Subfamily Proceratiinae Emery, 1895 .............................................. 48

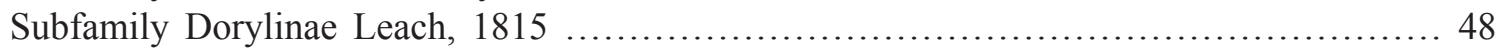

Subfamily Myrmeciinae Emery, 1877 ............................................. 49

Subfamily Pseudomyrmecinae M.R. Smith, 1952 ................................. 49 
Subfamily Aneuretinae Emery, 1913 ................................................... 49

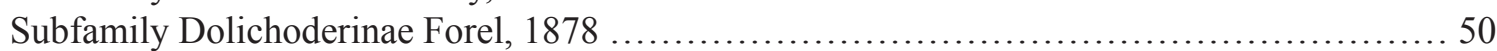

Subfamily Formicinae Latreille, 1809 ................................................ 51

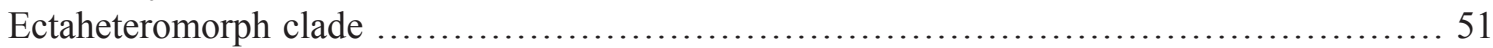

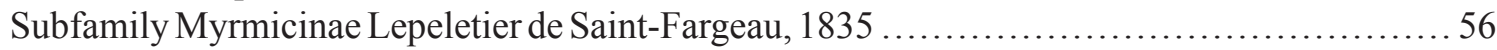

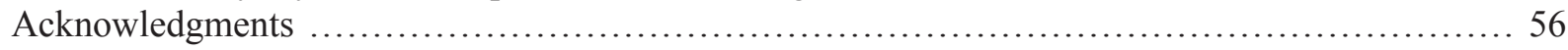

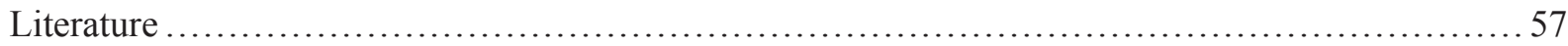

Abstract. The diagnosis of the Formicidae is revised, including five new, unreversed apomorphies, of which one is a unique synapomorphy. The first global male-based key to all subfamilies is provided and illustrated, and all ant subfamilies are diagnosed for males on a global scale for the first time. Three lineages of "basal ants" are assessed in detail: the Amblyoponinae, Leptanillinae, and Martialinae. The males of Martialis heureka (Martialinae) and Apomyrma (Amblyoponinae) are described. The Martialinae and Leptanillinae are diagnosed based on males, and additional diagnostic traits for the male of Amblyoponinae and worker of Martialis are provided. The placement of Scyphodon and Noonilla in the Formicidae and Leptanillinae is confirmed. Morphological characters of the Amblyoponinae, the Leptanillinae, and the Martialinae are contrasted, and potentially homologous apomorphies are signaled.

Keywords. Formicoidea, taxonomy, apomorphies, mesosoma morphology, coxal morphology

Boudinot B.E. 2015. Contributions to the knowledge of Formicidae (Hymenoptera, Aculeata): a new diagnosis of the family, the first global male-based key to subfamilies, and a treatment of early branching lineages. European Journal of Taxonomy 120: 1-62. http://dx.doi.org/10.5852/ejt.2015.120

\section{Introduction}

Ants are a globally diverse and dominant lineage of eusocial aculeates. As posited by Bolton (1994), "it is a truism that [ants] occupy a position among the terrestrial invertebrates equivalent to that occupied by our species among the vertebrates". The higher taxonomy and internal phylogeny of the Formicidae has stabilized significantly in the past few decades due to the active study of ant systematics at the macro scale (Baroni Urbani et al. 1992; Bolton 1994, 2003; Moreau et al. 2006; Brady et al. 2006; Ward et al. 2010; Schmidt 2013; Schmidt \& Shattuck 2014; Brady et al. 2014; Ward et al. 2015), spurred by the pioneering morphological studies of the family by Bolton (1990a, 1990b, 1990c, 1994, 2003). The relationship of the Formicidae with other aculeate families is still rather liquid (see references in Ward 2014), but a recent phylogenomic study supports a sister-group relationship with the Apoidea (Johnson et al. 2013). Bolton $(1994,2003)$ authoritatively diagnosed the family and its subfamilies and provided worker-based keys to the subfamilies and genera (Bolton 1994).

Here, the diagnosis of the Formicidae is updated based on study of all adult castes. Five new unreversed apomorphies are presented, one of which is a synapomorphy unique among the Hymenoptera. The remainder of the paper focuses primarily on male ants. To date the vast majority of myrmecological research has been based on workers due to their abundance and conspicuousness. The sexual dimorphism of ants (and Hymenoptera in general) renders male-worker associations very challenging to make, and has led to major taxonomic bias. Of the $\sim 12,800$ valid extant ant species, males are described for only $\sim 3,450$, or $27 \%$ of the total, and males are unknown for almost a quarter of the genera. Very little synthetic work has been done on males; indeed, bioregional male-based keys to subfamily are available only for North America (Smith 1943), the Palearctic (Western Europe, Bernard 1967; Armenia, Arakelian 1994; European Russia, Arnol'di \& Dlussky 1978; southern Siberia, Radchenko 1994; North Korea, Radchenko 2005; there are several European country-specific treatments), Japan (Yoshimura \& Onoyama 2002), New Zealand (Brown 1958), and Madagascar (Yoshimura \& Fisher 2007). To stimulate 
research on and collection of male ants, and to ease the task of associating males and females, the first global male-based key to subfamilies is presented.

All subfamilies keyed herein are provided with brief global male-based diagnoses. Three of these subfamilies, Amblyoponinae, Leptanillinae, and Martialinae, are treated in more detail due to their important phylogenetic position, as lineages near the base of the tree. The male of the "Martian ant", Martialis heureka - the sole representative of the Martialinae - is described and diagnosed. As in the worker, the male of Martialis displays a unique mixture of pleisiomorphic and derived traits. The discovery of the male of Martialis highlights the value of alternative myrmecological sampling techniques, as only one undamaged worker of Martialis is known, while 25 males were found from one jar of unsorted Amazonian Malaise trap residues. Another male is described herein, that of an Apomyrma (Amblyoponinae) morphospecies. The male of Apomyrma was previously incompletely described from pupae (Brown et al. 1971). The Leptanillinae are re-diagnosed, clarifying the boundaries of this clade, and the "mysterious" male taxa Noonilla and Scyphodon are confirmed as leptanillines.

\section{Material and Methods}

Specimens were examined with several microscopes, but primarily with a Wild M5 stereo microscope with $50 \mathrm{x}$ maximum magnification. Stacked photomicrographs were captured and montaged via AutoMontage Pro (Synoptics Ltd., Cambridge, England) with a JVC KY-F57U camera mounted on a Leica MZ 16A stereo microscope. All images were edited in Adobe Photoshop CS5, including those used from AntWeb (2014) with permission, and all figures were compiled using Adobe Illustrator CS6 (Adobe Systems Inc., California, U.S.A.). Dissections were carried out in watchglasses (Syracuse staining dishes) filled with 95\% ethanol and under either the Leica or the Wild microscopes mentioned above. Genitalia were removed from the metasoma using size 1 entomology pins and size 3 forceps and were immobilized for imaging and examination with ethanol-immersed Blu-Tack (Bostik, Indianapolis, U.S.A.). Pleisiomorphic conditions were inferred from a synoptic examination of extant and extinct Formicidae, and/or were understood from the work of Bolton (1990a, 1990b, 1990c, 2003). Taxonomic catalog resources were from AntCat by Bolton (2014). Some specimens examined have alphanumeric codes associated with them (i.e., CASENT\#, INB\#, INBIOCRI\#, and UCRENT\#) which uniquely identify the specimens for databasing purposes.

\section{Taxa examined}

To ascertain specificity of characters provided in the diagnosis of the Formicidae (below), representatives of all major aculeate lineages, and some "Parasitica" and "Symphyta", were examined. The higher classification of the Aculeata follows Pilgrim et al. (2008). While not all are listed, particular taxa examined include:

"Symphyta"

Cephoidea: Cephidae.

Megalodontoidea: Pamphilidae (Pamphilius pacificus).

Orussoidea: Orussidae (Orussus sp.).

Tenthredinoidea: Argidae; Tenthredinidae.

"Parasitica"

Ceraphronoidea: Megaspilidae.

Chalcidoidea: Chalcididae; Encyrtidae; Eucharitidae; Eurytomidae; Perilampidae; Pteromalidae.

Cynipoidea: Cynipidae; Eucoliidae; Figitidae.

Evanioidea: Aulacidae; Gasteruptiidae.

Ichneumonoidea: Braconidae; Ichneumonidae.

Platygastroidea: Platygastridae; Scelionidae. 
Proctotrupoidea: Diapriidae; Proctotrupidae.

Trigonalyoidea: Trigonalyidae (Trigonalys melanoleuca).

Aculeata

Apoidea: Ampulicidae (Ampulex sp.); Crabronidae; Nyssonidae (Bembicinae, Bembix); Pamphredonidae; Philanthidae (Philanthinae); Sphecidae (Ammophilinae, Sphecinae). Anthophila: Andrenidae; Apidae; Megachilidae; Halictidae.

Chrysidoidea: Bethylidae; Chrysididae (Chrysidinae, Cleptinae); Dryinidae; Embolemidae (Embolemus nearcticus); Plumariidae.

Formicoidea: Formicidae (see below).

Pompiloidea: Mutillidae (Sphaeropthalminae); Myrmosidae (Myrmosinae); Pompilidae (Pepsinae); Sapygidae (Sapyginae).

Scolioidea: Bradynobaenidae (Bradynobaenus gayi); Scoliidae (Campsomeris pilipes).

Tiphioidea: Sierolomorphidae (Sierelomorpha similis).

Thynnoidea: Chyphotidae (Chyphotes spp.); Thynnidae (Anthoboscinae, Anthobosca insularis).

Vespoidea: Rhopalosomatidae (Rhopalosoma nearcticum); Vespidae (Eumeninae, Masarinae, Vespinae).

Ant taxa were examined and evaluated either from physical specimens or high quality images available from AntWeb (2014). Taxa examined during this study cover slightly over $75 \%$ of the extant generic diversity of the family, with males examined for $70 \%$ of the total. Parentheses indicate the number of examined valid extant genera out of the total number of valid extant genera for each subfamily followed by the total number of genera for which males were examined $(\mathrm{x} / \mathrm{y} ; \mathrm{z}$, where $\mathrm{x}=$ total examined, $\mathrm{y}=$ total valid, $\mathrm{z}=$ male examined total). For each genus caste is indicated in brackets if only male $\left({ }^{\lambda}\right)$ or female castes $(+)$ were examined. Workers and gynes are treated together for the purposes of this work as the female castes are overall more similar to each other than to males.

Formicidae $(245 / 320 ; 225)$ :

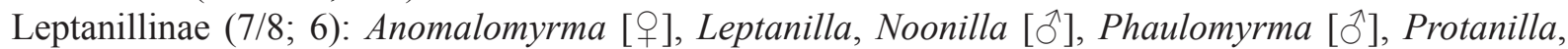

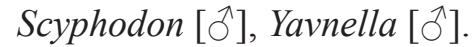

Martialinae (1/1): Martialis.

Agroecomyrmecinae $(2 / 2 ; 1)$ : Ankylomyrma [o], Tatuidris.

Amblyoponinae (13/13; 10): Adetomyrma, Amblyopone, Apomyrma, Bannapone [o], Concoctio [o], Myopopone, Mystrium, Onychomyrmex, Opamyrma [+]], Paraprionopelta, Prionopelta, Stigmatomma, Xymmer.

Paraponerinae (1/1): Paraponera.

Ponerinae (32/47): Anochetus, Belonopelta, Brachyponera, Centromyrmex, Cryptopone, Diacamma, Dinoponera, Dolioponera, Ectomomyrmex, Emeryopone, Harpegnathos, Hypoponera, Leptogenys, Mayaponera, Megaponera, Mesoponera, Myopias, Neoponera, Odontomachus, Odontoponera, Ophthalmopone, Pachycondyla, Paltothyreus, Phrynoponera, Platythyrea, Plectroctena, Ponera, Psalidomyrmex, Pseudoponera, Rasopone, Simopelta, Thaumatomyrmex.

Proceratiinae (3/3): Discothyrea, Probolomyrmex, Proceratium.

Dorylinae (18/18; 17): Acanthostichus, Aenictogiton, Aenictus, Amyrmex, most "Cerapachys" clades [우 or §`], Cheliomyrmex, Cylindromyrmex, Dorylus, Eciton, Labidus, Leptanilloides, Neivamyrmex, Nomamyrmex, Simopone, Sphinctomyrmex sensu lato and sensu stricto, Tanipone, Vicinopone [q].

Myrmeciinae (2/2): Myrmecia, Nothomyrmecia.

Pseudomyrmicinae (3/3): Myrcidris, Pseudomyrmex, Tetraponera.

Aneuretinae (1/1): Aneuretus.

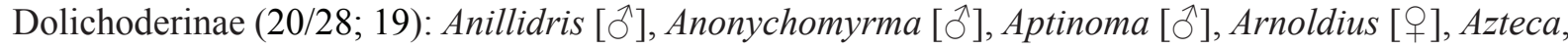
Bothriomyrmex, Dolichoderus, Dorymyrmex, Forelius, Iridomyrmex, Leptomyrmex, Linepithema, Liometopum, Ochetellus, Papyrius, Philidris, Ravavy [ô], Tapinoma, Technomyrmex, Turneria. 
BOUDINOT B.E., Contributions to the Formicidae

Formicinae (49/51; 41): Acropyga, Agraulomyrmex, Anoplolepis, Aphomomyrmex, Bajcaridris, Brachymyrmex, Bregmatomyrma [o], Calomyrmex, Camponotus, Cataglyphis, Cladomyrma, Echinopla, Euprenolepis [o]], Forelophilus, Formica, Gesomyrmex [ㅇ], Gigantiops, Iberoformica [+], Lasiophanes, Lasius, Lepisiota, Melophorus, Myrmecocystus, Myrmecorhynchus, Myrmelachista, Myrmoteras, Notoncus [ठ], Notostigma, Nylanderia, Oecophylla, Overbeckia, Paraparatrechina, Paratrechina, Petalomyrmex, Phasmomyrmex, Plagiolepis, Polyergus, Polyrhachis, Prenolepis, Proformica, Prolasius, Pseudolasius, Pseudonotoncus [o], Rossomyrmex [], Santschiella [o], Stigmacros, Tapinolepis, Teratomyrmex [+], Zatania.

Ectaheteromorph clade (7/7; 6): Acanthoponera, Aulacopone [Q], Ectatomma, Gnamptogenys, Heteroponera, Rhytidoponera, Typhlomyrmex.

Myrmicinae (86/140; 83):

Myrmicini (2/2): Manica, Myrmica.

Pogonomyrmecini (2/2): Hylomyrma, Pogonomyrmex sensu stricto and angustus clade.

Stenammini (7/7): Aphaenogaster sensu stricto and phalangium clade, Goniomma, Messor sensu stricto, Novomessor, Oxyopomyrmex, Stenamma, Veromessor.

Solenopsidini (13/20): Adelomyrmex, Bariamyrma, Cryptomyrmex, Dolopomyrmex, Kempfidris, Megalomyrmex, Monomorium sensu stricto and groups of antarcticum, denticulatum, and latastei, Myrmicaria, Oxyepoecus, Rogeria, Solenopsis, Stegomyrmex, Tropidomyrmex,

Attini sensu lato (38/45): Acanthognathus, Acromyrmex, Allomerus, Apterostigma, Atta, Basiceros, Blepharidatta, Cephalotes, Cyatta, Cyphomyrmex sensu stricto and strigatus and wheeleri clades, Daceton, Diaphoromyrmex, Eurhopalothrix, Kalathomyrmex, Lachnomyrmex, Lenomyrmex, Microdaceton, Mycetagroicus, Mycetarotes, Mycetophylax, Mycetosoritis, Mycocepurus, Myrmicocrypta, Ochetomyrmex, Octostruma, Paramycetophylax, Phalacromyrmex, Pheidole, Procryptocerus, Protalaridris, Pseudoatta, Rhopalothrix, Sericomyrmex, Strumigenys, Talaridris, Trachymyrmex, Tranopelta, Wasmannia.

Crematogastrini $(28 / 64 ; 25)$ : Acanthomyrmex, Atopomyrmex, Calyptomyrmex, Cardiocondyla, Carebara, Cataulacus, Crematogaster, Dacetinops, Formicoxenus, Harpagoxenus, Indomyrma, Leptothorax, Melissotarsus, Meranoplus, Myrmecina, Nesomyrmex, Perissomyrmex [o], Podomyrma, Pristomyrmex, Proatta [+], Recurvidris [+], Rhopalomastix, Temnothorax, Terataner, Tetramorium, Trichomyrmex, Vollenhovia, Xenomyrmex.

\section{Terminology}

Terminology follows Harris (1979) for sculpture; Wilson (1955) for setational stature; Boudinot (2013) for genitalia; Brown \& Nutting's abscissa-oriented nomenclature (1949) for wing venation; Yoshimura \& Fisher (2011) for cellular terminology with the modifications proposed in Boudinot et al. (2013); Keller (2011) and Boudinot et al. (2013) for the head capsule; and Keller (2011) for sundry morphological concepts, including helcial axiality (e.g., axial, supraaxial, and infraaxial). The wing venation typification system presented by Ogata (1991) is used as valuable short-hand for venational patterns.

Mesosomal terms are described here, as several of those used herein are not in standard use in the majority of myrmecological works (Figs 1-2). These terms are preferred, as they refer to previously unappreciated structures, and clarify interfamilial homologies. Terms explicitly relating to the alinota (meso- and metanota) specifically apply to males and gynes, while terms of the meso- and metapecta apply for all adult castes with two exceptions noted below. The mesonotum is comprised of the anterior mesoscutum and posterior mesoscutellum which are divided by the transverse transscutal line. The anterior mesoscutal margin often bears notauli, or anterior lateromedian sulci, which extend posteriorly toward the transscutal line. Two fine posterior lateromedian sulci are present, termed the parapsidal 
lines, which extend anteriorly from the transscutal line. Bordering the posterolateral mesoscutal margins are parascutal carinae, which separate the dorsal mesoscutal disc from the lateral preaxilla. Posterad the transscutal line is the mesoscutellum, which is traversed by the scutoscutellar suture. This suture divides the lateral mesoscutellar portions into the anterior axilla and posterior axillula, and anteriorly delimits the mesoscutellar disc. Often the scutoscutellar suture is impressed, forming the scutoscutellar sulcus. Bounding the axillula ventrolaterally is the mesoscutellar arm. In Hymenoptera, the mesoand metapleurae are completely fused with their respective sterna; thus, the terms mesopectus and metapectus are appropriate to use, although the margin between the metapleuron and metasternum may be arbitrarily determined by presence of the coxal foramina. An oblique mesopleural furrow or sulcus (Yoshimura \& Fisher 2007) divides the mesopleural area into the lower katepisternum and upper anepisternum. The term "oblique mesopleural sulcus" is preferred over "anapleural sulcus", as the sulcus has evolved several times independently in the Hymenoptera and is probably not homologous with the sulcus corresponding to the anapleural suture joining the expanded katapleural and anapleural arches of other pterygota. Above the anepisternum may occur a broad sulcus corresponding to the subalar area. Posterodorsad this area is a ridge which is homologous with the mesepimeron; the mesepimeron does not extend anterad beyond the mesopleural wing process. Worker mesepimera are not differentiated and should be considered lost due to fusion of the mesopleuron and mesonotum; similarly, the subalar area is not developed in the worker caste. The metapleural spiracle may be covered by the supramesopleural sclerite (Vilhelmsen et al. 2010), which for ease is referred to as the spiracular sclerite here. This structure has previously been termed the "basalar lobe" (Deyrup \& Cover 2004; MacGown et al. 2014) and the "epimeral lobe" (Yoshimura \& Fisher 2007). Finally, the metapleural area is divided into the lower and upper metapleuron by a sulcus.

Terminology of the coxae is as follows (Fig. 3): Each coxa is divided into a basicoxa and disticoxa by a basicoxal suture, which occurs near the coxal articulation with the mesosoma. Although not emphasized here, each basicoxite bears lateral and medial coxal-pectal fossae, which articulate with the lateral condyle of the pleuron and the medial condyle of the sternum, respectively. The disticoxite bears the anterior and posterior trochanteral-coxal fossae with which the anterior and posterior trochanteral condyles articulate. Two foramina occur on each coxa, a basicoxal and a disticoxal foramen; both bear intersegmental membranes. The disticoxal foramen is enclosed by the flexor (ancestrally lateral) and extensor (ancestrally medial) margins.

\section{Figure abbreviations}

To maximize size of the figures and to reduce redundancy, abbreviations for figures $1,2,3,9$, and 12 are listed below.

Fig. 1: $A n e p=$ anepisternum, $A x=$ axilla, $A x u=$ axillula, Ktep $=$ katepisternum, $L m p l=$ lower metapleuron, $M e p m=$ mesepimeron, $M s m t p s=$ mesometapleural suture, $M s n t=$ mesonotum, $M s p p=$ mesopleural pit, Mssctla = mesoscutellar arm, Mssctld = mesoscutellar disc, Mssctm = mesoscutum, $M t s c t t=$ metascutellar trouch, $M t p d s=$ metapleuropropodeal suture, Not $=$ notaulus, Oms $=$ oblique mesopleural sulcus, $P l=$ parapsidal line, $P p d=$ propodeum, $P p d l=$ propodeal lobe,$P p d s p=$ propodeal spiracle, $\operatorname{Prax}=$ preaxilla, Prnt $=$ pronotum, Prntl $=$ pronotal lobe, $P s c=$ parascutellar carina, $S a a=$ subalar area, $S c s c s=$ scutoscutellar suture, $S p s c=$ spiracular sclerite, $S s s=$ scutoscutellar sulcus, $T g=$ tegulum, $T_{s c l}=$ transscutal line, $U m p l=$ upper metapleuron.

Fig. 2: AsII= abdominal sternum II, Lcpmsp = lateral coxal articular process of the mesopleuron, Lcpmtp $=$ lateral coxal articular process of the metapleuron, $M c p m s p=$ medial coxal articular process of the mesopectus, $M c p m t p=$ medial coxal articular process of the metapectus, $M s d=$ mesodiscrimen, $M s p=$ mesopectus, $M s c f=$ mesocoxal foramen, $M s p f p=$ mesoprefurcal pit, $M t c f=$ metacoxal foramen, $M t p=$ metapectus, $M t p f p=$ metaprefurcal pit, $\operatorname{Prn}=$ pronotum, $V l m s p l=$ ventrolateral mesopectal line. 
BOUDINOT B.E., Contributions to the Formicidae

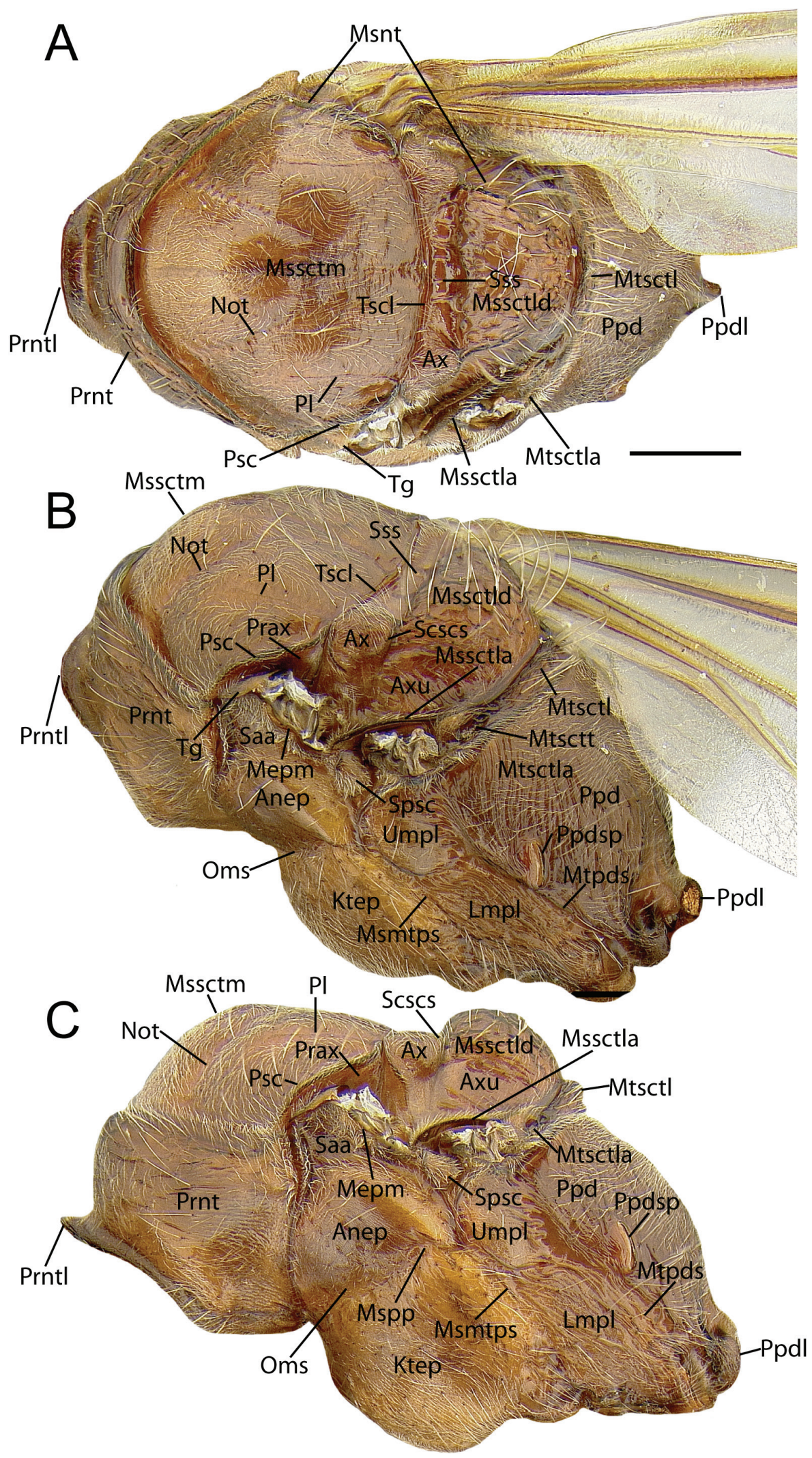

Fig. 1. Mesosoma of Paraponera clavata male (Paraponerinae, Formicidae). A. Dorsal view. B. Dorsal posterolateral oblique view. C. Lateral view. Scale bar $=1.0 \mathrm{~mm}$. Abbreviations: see Material and Methods. 

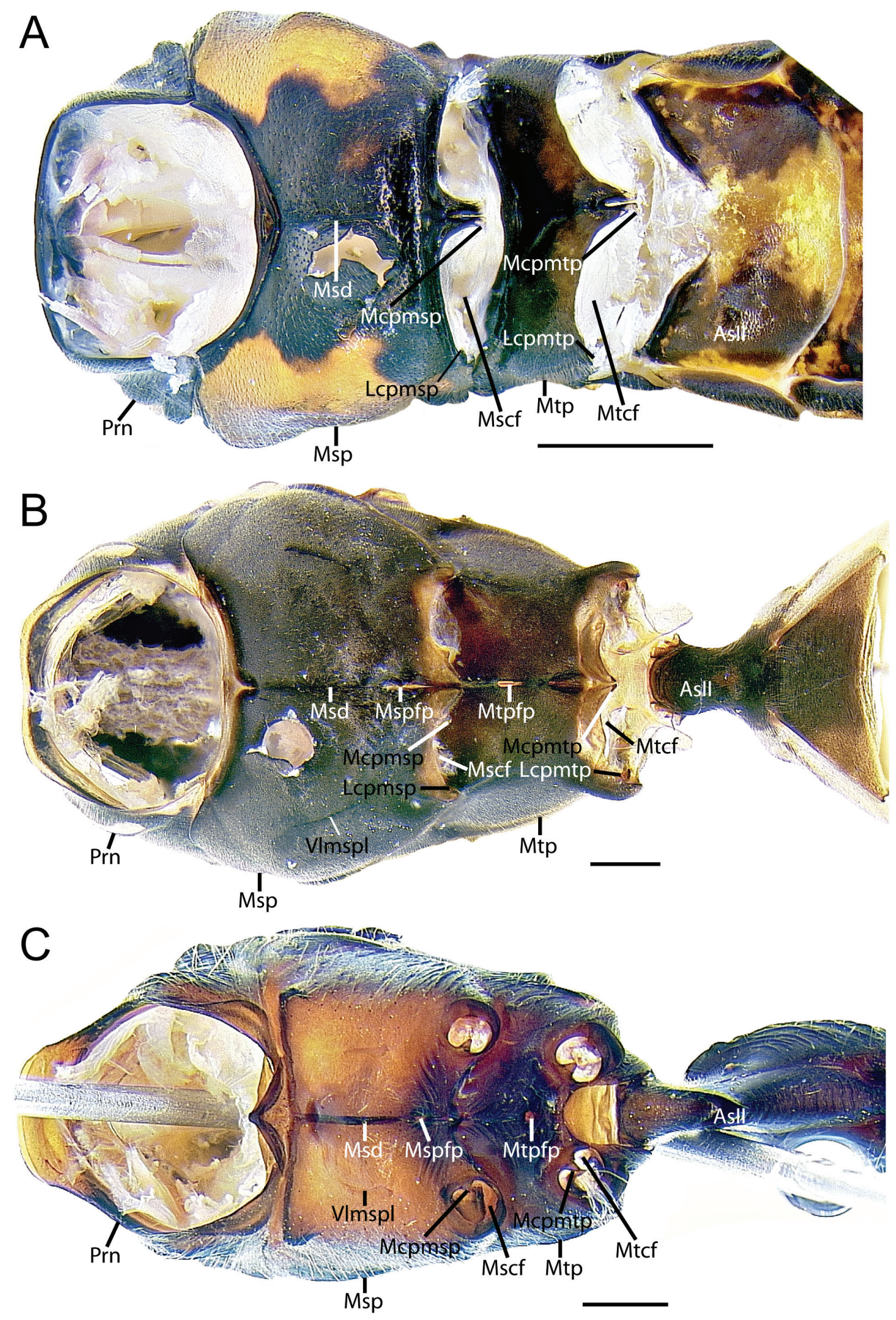

Fig. 2. Pterothoracic venter morphology of representative hymenopterans. A. Tenthredinidae, female. B. Polistes (Vespidae), worker. C. Paraponera clavata gyne (Paraponerinae, Formicidae). Scale bars = $1.0 \mathrm{~mm}$. Abbreviations: see Material and Methods. 

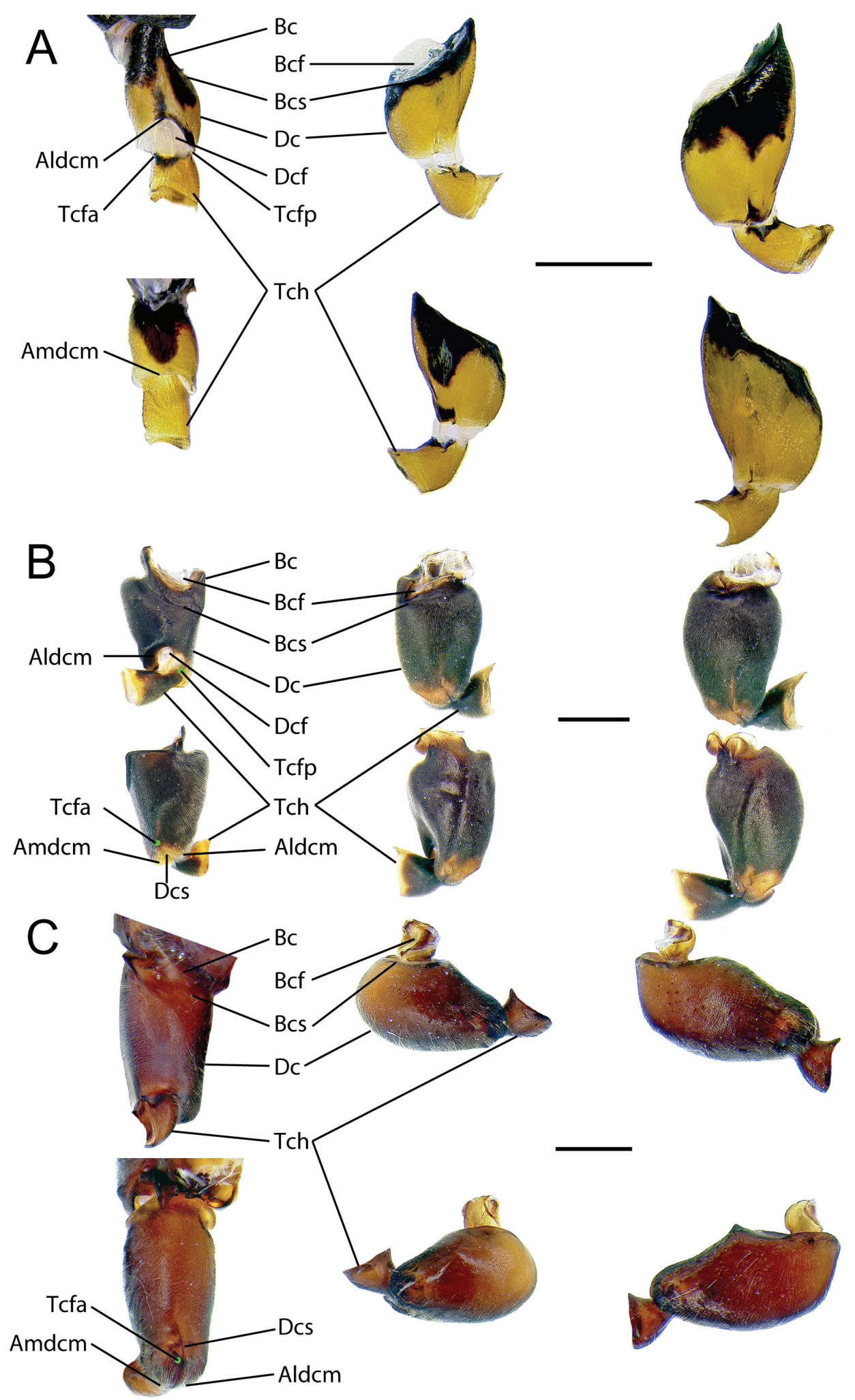

Fig. 3. Coxal morphology of representative hymenopterans: right procoxae, left column; right mesocoxae, middle column; right metacoxae, right column; top procoxa lateral view, bottom procoxa medial view; top meso- and metacoxae anterior view, bottom meso- and metacoxae posterior view. A. Tenthredinidae. B. Polistes sp., Vespidae. C. Paraponera clavata gyne (Paraponerinae, Formicidae). Scale bars $=1.0 \mathrm{~mm}$. Abbreviations: see Material and Methods. 
Fig. 3: $\mathrm{Aldcm}=$ apicolateral disticoxal margin; $A m d c m=$ Apicomedial disticoxal margin; $B c=$ basicoxa; $B c f=$ basicoxal foramen; $B c s=$ basicoxal suture; $D c=$ disticoxa; $D c f=$ disticoxal foramen; $D c s=$ disticoxal suture; $T c f a=$ trochanteral-coxa fossa, anterior; $T c f p=$ trochanteral-coxa fossa, posterior; $T c h$ $=$ trochanter. Green dot indicates concealed articulation.

Figs 9, 12: Wing abbreviations: $\mathrm{C}=$ Costal vein, $\mathrm{Sc}=$ Subcostal vein, $\mathrm{R}=$ Radial vein, $\mathrm{Rs}=$ Radial sector, $\mathrm{M}=$ Medial vein, $\mathrm{Cu}=\mathrm{Cubital}$ vein, $1 \mathrm{~A}=$ first Anal vein, $\mathrm{CC}=$ costal cell, $\mathrm{BC}=$ basal cell, $\mathrm{SMC}=$ submarginal cell, $\mathrm{MC1} / \mathrm{MC}=$ marginal cell $1, \mathrm{SBC}=$ subbasal cell, $\mathrm{SDC} 1 / \mathrm{SDC}=$ subdiscal cell 1. Genital abbreviations: $\mathrm{Bm}=$ basimere; $\mathrm{Bv}=$ basivolsella; $\mathrm{Cu}=$ Cupula in Fig. 9D, 9F, and cuspis in Fig. 9E, 9G (cuspis absent in Martialis); $\mathrm{Di}=$ digitus; $\mathrm{Fg}=$ foramen genitale; $\mathrm{Pm}=$ paramere; $\mathrm{Pv}=$ penisvalva; $\mathrm{Sp}=$ spiculum; $\mathrm{Vc}=$ valviceps; $\mathrm{Vu}=$ valvura.

\section{Measurements and indices}

Male morphometrics practiced herein are improved by carefully attempting to render maximum replicability. Specific improvements include measurement of antenna characters in medial view, and determination that the anteriormost point of the axillae are superior landmarks for measuring mesoscutal and mesoscutellar length, as the transscutal line may be difficult to ascertain in dorsal view. Abdominal segment III and more-posterior segments were not measured due to the weak sclerotization of Martialis males, which caused crumpling during the drying process. The wings are not measured, as accurate metrics would require slide mounting. Numerous indices are supplied, as these calculations provide proportionality information.

\section{Male measurements}

$\mathrm{HL}=$ Head Length, maximum length of head in full-face view from anterior clypeal margin to posterior head margin between lateral ocelli, ignoring distance which ocelli project and regardless of whether occipital carina or vertex is posteriormost

HW1 $=$ Head Width 1, maximum width of head excluding eyes in full-face view

HW2 = Head Width 2, maximum width of head including eyes in full-face view

MAL = Malar Area Length, minimum distance between compound eye and lateral point of mandibular insertion

$\mathrm{MDL}=$ Mandible Length, chord length of mandible from medial point of insertion to apex

$\mathrm{SL}=$ Scape Length, maximum length of scape in medial view, excluding condylar neck

$\mathrm{PDL}=$ Pedicel Length, maximum length of pedicel in medial view

$\mathrm{A} 3 \mathrm{~L}=$ Antennomere 3 Length, maximum length of antennomere 3 in medial view

$\mathrm{AAL}=$ Apical Antennomere Length, maximum length of apicalmost antennomere in medial view

EL = Eye Length, maximum diameter of eye with head positioned in profile view such that anterior and posterior eye margins are in same plane of focus

EW $=$ Eye Width, maximum width of eye at an axis orthogonal to Eye Length with head oriented as above

OOD = Ocular-Ocellus distance, minimum distance between lateral ocellus and compound eye

LOD = Lateral Ocellus Length, maximum diameter of lateral ocellus with head oriented such that anterior and posterior lateral ocellus margins are in same plane of focus

MOD $=$ Median Ocellus Length, maximum diameter of median ocellus in full-face view

$\mathrm{ML}=$ Mesosoma Length, maximum diagonal length of mesosoma in profile view from inflection point of anterior pronotal declivity (between pronotal neck and anteromedian face) to propodeal lobe, or if propodeal lobe absent then to juncture of lateral and dorsal margins of petiolar foramen 
MLL = Mesoscutellum Length, maximum length of mesoscutellum in dorsal view with anterior mesoscutal and posterior mesoscutellar margins in same plane of focus, measured from anteriormost points of axillae to posterior mesoscutellar margin

MLW = Mesoscutellum Width, maximum width of mesoscutellum with specimen oriented as for MLL

MTL = Mesoscutum Length, length of mesoscutum in dorsal view with specimen oriented as in MLL, measured from anterior mesoscutal margin to anteriormost points of axillae

MTW $=$ Mesoscutum Width, maximum width of mesoscutum measured with specimen oriented as in MTL

$\mathrm{PFL}=$ Profemur Length, maximum length of profemur in posterior view

$\mathrm{MFL}=$ Metafemur Length. Maximum length of metafemur in anterior view

$\mathrm{PTH}=$ Petiole Height, dorsoventral height of petiole in profile view, from node dorsum to ventral-most point orthogonal to Petiole Length measurement

PTL = Petiole Length, length of petiole in profile view along anteroposterior axis from inflection point of petiolar presclerites (the articulatory surfaces) to posteriormost point of posterior margin

\section{Indices}

$\mathrm{CI}=$ Cephalic Index HW1/HL $\times 100$

$\mathrm{CS}=$ Cephalic Size $(\mathrm{HW} 1+\mathrm{HL}) / 2$

SEI $=$ Scape-Eye Index EL $/ \mathrm{SL} \times 100$

SI $=$ Scape Index SL $/$ HW $1 \times 100$

$\mathrm{EI}=$ Eye Index $1 \mathrm{EW} / \mathrm{EL} \times 100$

$\mathrm{EYE}=$ Eye Index $2(\mathrm{EL}+\mathrm{EW}) / \mathrm{CS} \times 100$

MDI $=$ Mandible Index MDL $/ \mathrm{HL} \times 100$

OBI $=$ Ocular Bulge Index HW1/HW2 $\times 100$

$\mathrm{OMI}=$ Oculomandibular Index EL/MAL $\times 100$

MNI $=$ Mesonotum Index $($ MTL + MTW $) /($ MLL + MLW $)$

MTI $=$ Mesoscutum Index MTW/MTL $\times 100$

$\mathrm{FI}=$ Femora Index PFL/MFL $\times 100$

PTI $=$ Petiole Index PTH $/$ PTL $\times 100$

\section{Repositories}

Primary reference repositories for this work are as follows:

BEBC $=$ Brendon E. Boudinot personal collection, Davis, California, U.S.A.

CASC $=$ California Academy of Sciences Collection, San Francisco, California, U.S.A.

INPA $=$ Instituto Nacional de Pesquisas da Amazônia, Manaus, Amazonas, Brazil

JTLC $=$ John T. Longino personal collection, Salt Lake City, Utah, U.S.A.

MCZC $=$ Museum of Comparative Zoology, Cambridge, Massachusetts, U.S.A.

MZLU = Lund Zoological Museum, University of Lund, Sweden

MZSP $=$ Museu de Zoologia da Universidade de São Paulo, São Paulo, Brazil

PSWC $=$ Philip S. Ward personal collection. University of California, Davis, CA, U.S.A.

UCDC $=$ R.M. Bohart Collection, University of California, Davis, U.S.A.

Additional repositories from which material was examined to construct the key to subfamilies are as follows:

ABS $=$ Archbold Biological Station, Lake Placid, Florida, U.S.A.

CMWC $=$ Christopher M. Wilson personal collection, Sam Houston State University, Huntsville, Texas, U.S.A. 


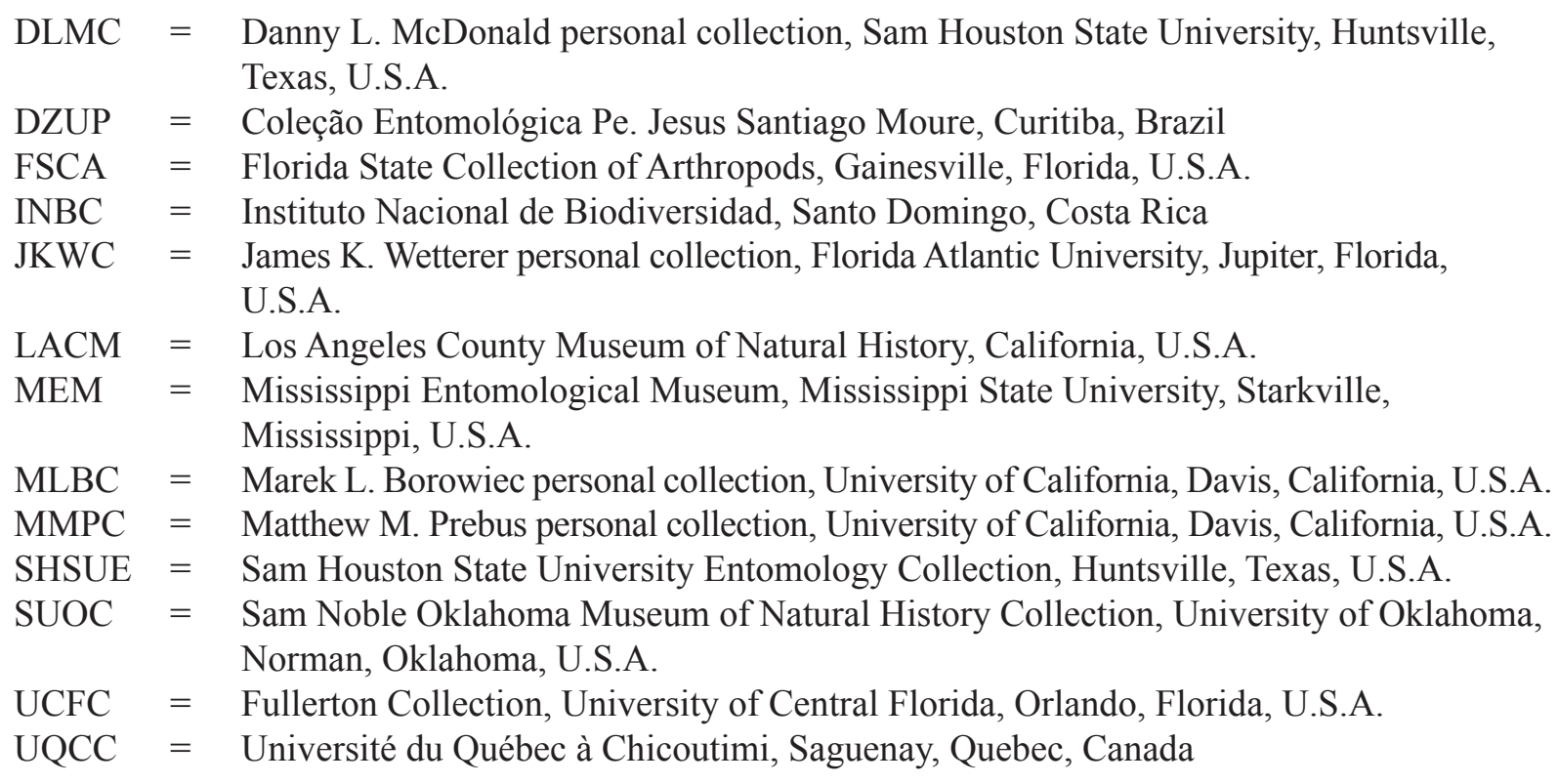

\section{Results}

Class Hexapoda Blainville, 1816

Order Hymenoptera Linnaeus, 1758

Suborder Apocrita Latreille, 1810

Infraorder Aculeata Latreille, 1802

Superfamily Formicoidea Latreille, 1804

Family Formicidae Latreille, 1809

\section{Diagnosis}

Aculeate Hymenoptera with the following apomorphies:

1. Eusocial, wingless worker caste present, colonies perennial (note 1).

2. Sexuals with synchronous nuptial flights (note 2)

3. Head capsule prognathous (worker, gyne) (note 1).

4. Infrabuccal sac present between labium and hypopharynx (note 1).

5. Antenna geniculate between long scape and funiculus (worker, gyne) (notes 1,3).

6. Disticoxal foramen directed laterally and completely enclosing protrochanteral base, including protrochanteral condyles, such that all disticoxal membrane concealed (all castes, Fig. 3C) (note 4).

7. All meso- and metacoxal cavities small, circular, monocondylic, ventrally-directed, and disticoxae strongly produced laterally (all adult castes, Fig. 3C) (note 5).

8. Metapleural gland present (adult castes, but see note 6).

9. Propodeal spiracle located on lateral propodeal face distant from the anterodorsal propodeal corner, often near propodeum midlength (all adult castes) (note 7).

10. Wings of alate gyne deciduous, being shed after copulation (note 1).

11. Forewing 3rs-m and $2 \mathrm{~m}$-cu absent (note 1 ).

12. Hindwing $\mathrm{C}$ not extending along anterior margin, even spectrally (note 8).

13. Hindwing basal/radial cell not produced distally (alate castes) (note 9).

14. Metasoma petiolate (abdominal segment II differentiated from segment II,I which is strongly constricted between the pre- and postsclerites) (all castes), extremely rarely ( $\sim 1$ species) abdominal segment III not constricted between pre- and postsclerites (notes 1 and 10). 
Additional, non-synapomorphic characters of value for diagnosis and identification include: Antenna with 4-12 antennomeres (female) or 5-13 antennomeres (male) (note 11). Bulbus neck (= radicle) and scape with common axis. Epicnemium extremely reduced, not visible in situ (note 12). Abdominal segment II with sternum and tergum equally sclerotized. Pterostigma present or absent (note 13). Wing venation variable, may be extremely reduced, with at minimum no closed cells (note 14). Jugal lobe present or absent; abdominal sternum IX may be complex and modified apically (including prongs, teeth, and lobes).

\section{Notes}

1. Noted as apomorphic by Bolton (2003).

2. Bolton (2003) indicated that "sexuals with mass nuptial flight" was an apomorphy of the Formicidae. Although mass flights do occur in several lineages of ants, it is not clear if the ancestral condition for the Formicidae is to release large quantities of sexuals. The wording has been specifically rephrased here to account for this uncertainty.

3. Males of many species have derived geniculate antennae with elongate scapes, including numerous Myrmicinae, most Formicinae, and Tapinoma (Dolichoderinae). Most males, including poneroids and numerous formicoids, however, have antennae which are not geniculate and have very short scapes.

4. The procoxa of Formicidae is characteristically modified. The trochanteral foramen (situated apically on the procoxa) is directed laterally and entirely enclosed, revealing no membrane in undamaged specimens (Fig. 3C, left column, top row). Medially, the foramen is closed by an unfused seam of the anterior and posterior apical coxal lobes, which completely surround the anterior trochanteral process. The axis of coxal-trochanteral articulation, rather than being lateromedial as in Symphyta (Fig. 3A), or rotated obliquely as in many Aculeata (Fig. 3B), is almost entirely anteroposterior. Leg adduction and abduction occurs along this anteroposterior axis in more-or-less one plane of motion, with the trochanter rotating within the closed disticoxal foramen. The coxae and their articulations with the mesosoma and trochanters are poorly studied and show promise for valuable systematic characters. Previous work on hymenopteran coxae include Johnson (1988), which solely focused on the basicoxite and its musculature, Michener (1981), which focused on the meso- and metacoxae of the Apoidea, and Vilhelmsen et al. (2010), which operationalized several coxal characters. This character is unique to the Formicidae.

5. The meso- and metacoxal foramina are monocondylic, bearing only the medial coxal articular processes and lacking the lateral coxal articular processes of the meso- and metapleurae. Lateral condyles are lacking in the examined species of Chyphotinae, Bradynobaenidae s. str., Mutillidae, and Myrmosidae.

6. The metapleural gland, so distinctive of the female castes, is variably developed in males and has been lost in various taxa.

7. The "high and far forward" placement of the propodeal spiracle remarked upon by Bolton (2003) as a plesiomorphy for the Formicidae is actually an apomorphy for the family. In non-formicid Aculeata (including Apoidea, Scoliidae, and Bradynobaenidae s. str.) the propodeal spiracle is usually situated at the extreme anterodorsal corner of the propodeum, usually within a propodeal spiracle length from the metanotum, and often on the dorsal propodeal face. Some Pompilidae and Tiphiidae (Tiphiinae) have the spiracle situated more posteriorly. Although the propodeal spiracle of $\dagger$ Sphecomyrma freyi is situated high — but laterally—and rather anteriorly (Wilson et al. 1967), it is clearly not at the extreme of other Aculeates. Other $\uparrow$ Sphecomyrma species have more posteriorly situated spiracles which are clearly situated laterally (Wilson 1985; Engel \& Grimaldi 2005). The potential male of $\uparrow$ Sphecomyrma identified by Grimaldi et al. (1997) has a low spiracle situated at about segment midlength.

8. Reduction of the hindwing costal vein occurs sporadically in other aculeate families. 
9. The basal/radial cell has been convergently reduced or lost in several ant subfamilies, and has been lost in Mutillidae, Myrmosidae, Bradynobaenidae s. str., and Chyphotidae. The generality of this trait in these families was not evaluated.

10. The male of an unidentified Protanilla (Leptanillinae) from Thailand has secondarily lost petiolation, where the third abdominal segment is no longer constricted between the pre- and postsclerites (Fig. 10A). These males are still recognizable as ants by the closed apical procoxal foramen, ventrallydirected meso- and metacoxal cavities, and low and lateral propodeal spiracle. Other Protanilla species (even in sympatry) retain the constriction, while yet others have petiolation of the third abdominal segment (Fig. 10B). Some males of the Dolichoderinae (e.g., Azteca) and other unidentified males of the Leptanillinae have very reduced petioles, but these are still distinctly differentiated from the third abdominal segment and are slightly posteriorly constricted.

11. Antennomere count for males usually 13, less often 8-12 (count of 8 observed in Acropyga and Stenamma; counts of $10+$ more common). Antennomere counts may be extremely reduced in inquilines, for example in Pheidole acutidens, which occasionally have an antennomere count of 5, although this is variable infraspecifically, and indeed may vary between the left and right antennae.

12. Brothers (1975) contends that the form of the formicid epicnemium is unique, being highly reduced, fused to and extending over the height of the mesepisternum, and obscured by the pronotum. This putative homology was not evaluated in the present work.

13. The pterostigma is lost in most Leptanillinae, some myrmicine genera, and some species of Leptomyrmex (Dolichoderinae).

14. No closed cells are observed in some males of Leptanillinae and Myrmicinae.

\section{Remarks}

The Formicidae is an unequivocally monophyletic group, previously defined by Bolton $(1994,2003)$ as eusocial, sexually dimorphic aculeate Hymenoptera bearing metapleural glands and geniculate antennae, among other characters. Several previously unreported synapomorphies exist for the family, including a suite of adaptations for terrestrial locomotion (characters 6 and 7). The "low and lateral" propodeal spiracle placement may also be an adaptation for terrestrial locomotion, as it may reduce the distance oxygen would need to diffuse to leg locomotor muscles. While this does not clarify whether the ancestral ant was hypogaeic or epigaeic, it does indicate that terrestrial locomotion was a crucial transition for the Formicidae, as these apomorphies are present in all adult castes of the family. Previous diagnoses of the family (Brothers 1975; Gauld \& Bolton 1988; Goulet \& Huber 1993) were significantly improved by Bolton (1994, 2003). Characters indicated in the family diagnosis by Bolton (2003) and above will be valuable to evaluate for critical fossil taxa such as $\uparrow$ Armania Dlussky and other fossils assigned to the $\uparrow$ Armaniidae whose relationship to the Formicidae is uncertain (see Dlussky 1975: $\uparrow$ Archaeopone, $\uparrow$ Dolichomyrma, $\uparrow$ Poneropterus, $\uparrow$ Pseudarmania; Dlussky 1983: $\uparrow$ Armaniella; Dlussky 1999: $\uparrow$ Khetania; Dlussky et al. 2004: $\uparrow$ Orapia; also see discussion in LaPolla et al. 2013).

\section{Key to global subfamilies, based on extant males}

Notes: It may be expected that some taxa will fail this key, as males of at least 70 genera are undescribed and/or uncollected (see subfamily diagnoses for specific genera). This key treats alate males only, because ergatoid males are identifiable similarly to the workers. Ergatoid males generally bear shorter scapes and more antennomeres than the female, and are known for about a dozen genera.

1 Apicolateral corners of abdominal sternum IX pronged or toothed (even if minutely) (Fig. 4A-B)... 2

- Apicolateral corners of abdominal sternum IX lobed or rounded (Fig. 4C) $\ldots \ldots \ldots \ldots \ldots \ldots \ldots \ldots \ldots$ 
2 Petiole hatchet-shaped in profile view, with distinct peduncle, and node with distinct anterodorsal angle in profile view (Fig. 4D). Clypeus well-developed, with conspicuous convex median disc. Pretarsal claws cleft. Pygostyles present. Neotropical................ Paraponerinae (Paraponera)

- Petiole nodiform, fusiform, subrectangular, or cylindrical in profile view, with or without a distinct peduncle, and node without anterodorsal angle in profile view (Fig. 4E). Clypeus poorly developed, more-or-less linear, without conspicuous convex median disc. Pretarsal claws not cleft; claws edentate or toothed. Pygostyles absent. Global........ Dorylinae (part, excluding Leptanilloides genus group)

3 Wing venation reduced to extremely reduced, with at most only Sc+R+Rs, Rsf1, Mf1, M+Cu, and 1r-rs+Rsf4-6 tubular, at most only three closed cells present (costal, basal, subbasal) (Fig. 4F) and propodeal lobes very inconspicuous or absent (Fig. 4G). Old World.................. Leptanillinae

- Wing venation more complete, often more than three closed cells present or propodeal lobes conspicuous and present (Fig. 4H). Global................................................ 4

4 Abdominal segment III strongly reduced and differentiated from abdominal segment IV (Fig. 5A, B) and antennal toruli separated from anterior clypeal margin by at least one antennal socket diameter and terminal abdominal tergum never produced as spine .......................... 5

- Abdominal segment III not reduced relative to abdominal segment IV or somewhat reduced, but not differentiated from abdominal segment IV (Fig. 5C) or antennal toruli separated from anterior clypeal margin by less than one antennal socket diameter or terminal abdominal tergum posteriorly produced as spine....

8

5 Metatibia with 2 ventroapical spurs (anterior spur may be reduced in size) $\ldots \ldots \ldots \ldots \ldots \ldots \ldots \ldots \ldots$

- Metatibia with at most 1 ventroapical spur............................................. 7

6 Jugal lobe present. Frontal carinae usually robust and conspicuous (Fig. 5D). Cuticle very thick and usually coarsely sculptured. Australia ................. Myrmeciinae, part (Myrmeciini: Myrmecia)

- Jugal lobe absent. Frontal carinae fine, inconspicuous, or absent (Fig. 5E). Cuticle thin and usually finely to not sculptured. New World; African, Asian, Australian Pseudomyrmecinae

7 Abdominal tergum IV strongly and evenly convex in profile view and much longer than abdominal sternum IV (Fig. 5F, black lines). Helcium supraaxial: Anteroposterior axis of helcium situated well above anteroposterior axis of abdominal segment III postsclerites, such that poststernite with very dorsoventrally tall anterior face relative to anterior face of posttergite (Fig. 5F, dark green lines along anterior faces of abdominal segment III). Spiracle of abdominal tergum IV located in extreme anteroventral corner (within at least five spiracular diameters) ......... Agroecomyrmecinae(Tatuidris)

- Abdominal tergum IV weakly or unevenly convex in profile view and about as long as abdominal sternum IV (Fig. 5G, black lines). Helcium axial: Anteroposterior axis of helcium situated at about midheight of abdominal segment III postsclerites, such that anterior faces of postsclerites roughly equivalent, or anterior face of posttergite somewhat longer than that of poststernite (Fig. 5G, green lines). Spiracle of abdominal tergum IV located distant from anteroventral corner (distant by at least ten spiracular diameters).

Myrmicinae

8 Abdominal segment IV with cinctus (constriction) between the pre- and postsclerite (Fig. $5 \mathrm{H}$ ) or jugal lobe present or oblique mesopleural sulcus absent or indistinct.......................... 9

- Abdominal segment IV without a cinctus (Fig. 5I) and jugal lobe absent and oblique mesopleural sulcus always present.................................................... 19

9 Antennal toruli situated anteriorly, abutting, very nearly abutting, or overhanging anterior clypeal margin; toruli less than one antennal socket diameter from anterior clypeal margin in frontal view (Fig. 6A) 
- Antennal toruli situated posteriorly; toruli distant from anterior clypeal margin by at least one antennal socket diameter in full-face view (Fig. 6B) .................................... 12

10 Abdominal segment IV with distinct cinctus between pre- and postsclerites. Oblique mesopleural sulcus present (Fig. 6D) or absent...................................... 11

- Abdominal segment IV without cinctus between pre- and postsclerites. Oblique mesopleural sulcus absent (Fig. 6C) ..................... Dorylinae (part, Leptanilloides genus group)

11 Oblique mesopleural sulcus present (Fig. 6D). Mandibles triangular.

Proceratiinae (part)

- Oblique mesopleural sulcus absent (Fig. 6C). Mandibles nearly linear

Ponerinae (Ponerini part, Dolioponera)

12 Mandibles triangular, worker-like, with distinct and elongate masticatory margin (Fig. 6E)... 13

- Mandibles reduced, linear, spatulate, or falcate, without distinct masticatory margin (Fig. 6B, F-G)

13 Abdominal segment IV without cinctus between pre- and postsclerites (Fig. 5C). Petiolar tergum and sternum completely fused in anterior third, without visible suture (Fig. 6H). Mandibular teeth robust............ Myrmeciinae, part (Prionomyrmecini: Nothomyrmecia)

- Abdominal segment III with cinctus between pre- and postsclerites (Fig. 5H). Petiolar tergum and sternum not insensibly fused in anterior third; if fused, suture visible along entire petiolar length (Fig. 6I). Mandibular teeth absent, fine, or robust.....

14 Metatibia with one ventroapical spur or prora thin and anteriorly directed, extending beneath helcium

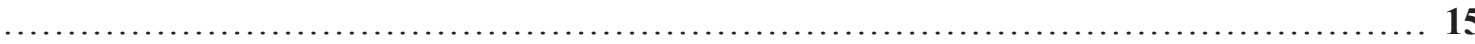

- Metatibia with two ventroapical spurs and prora absent or thick and directed ventrally, not extending beneath helcium. Ponerinae (Platythyreini: Platythyrea)

15 Crossvein $1 \mathrm{~m}$-cu present, thus discal cell 1 closed (Fig. 7A). Mandibles dentate; at least two teeth present on masticatory margin.

Ectaheteromorph clade

- Crossvein 1m-cu absent, thus discal cell 1 open (Fig. 7B). Mandibles edentate or masticatory margin produced apically as single tooth.... Proceratiinae (part, Discothyrea)

16 Mandibles falcate (Fig. 6G) to narrowly linear (Fig. 11A-B). 17

- Mandibles nub-like (Fig. 6F), spiniform (Fig. 6B), or spatulate (broad in profile view).......... 18

17 Petiolar tergum and sternum clearly delineated. Anterior clypeal margin with (Fig. 6G) or without pegs. Abdominal segment III about same size as segment IV, metasoma after petiole well-sclerotized. Global. Amblyoponinae (excluding Apomyrma)

- Petiolar tergum and sternum smoothly fused (similar to Fig. 6H, but along entire petiolar length; note that longitudinal line on petiole in Fig. $11 \mathrm{C}$ is a carina unassociated with sclerotic margins). Anterior clypeal margin without pegs (Fig. 11A-B). Abdominal segment III slightly reduced relative to segment IV, although metasoma after petiole weakly sclerotized (Fig. 11C). Endemic to Amazon basin. Martialinae (Martialis)

18 Mesosoma anteriorly elongated: Mesonotum almost twice as long as broad in dorsal view, and lateral pronotal face longer in profile view than head in full-face view (Fig. 7C). Pterostigma absent. Petiole broadly attached to abdominal segment III, node weak. Afrotropical Amblyoponinae (part, Apomyrma)

- Mesosoma not anteriorly elongated: Mesonotum much less than twice as long as broad in dorsal view, and lateral pronotal face in profile view shorter than to as 
long as head length in profile view (Fig. 7D). Pterostigma present or absent. Petiole very narrowly attached to abdominal segment III, node strong, except Simopelta (Neotropical) Ponerinae (Ponerini part)

19 Basimere strongly developed; distinct from and usually much larger than telomere. Telomere restricted to posterior apex of basimere, not or only slightly extending anteroventrally beneath basimere (Fig. 7E). Petiole narrowly or broadly attached to abdominal segment III. Masticatory margin of mandible often finely serrate. Antenna with 11-13 antennomeres..... Dolichoderinae

- Basimere weakly developed; usually indistinct from and usually about the same size as telomere. Telomere extending anteroventrally beneath basimere almost to base of paramere (Fig. 7F). Petiole narrowly attached to abdominal segment III. Masticatory margin of mandible never serrate. Antenna with $8-13$ antennomeres.

20 Forewing venation nearly complete: Mf3-4 and 2rs-m present, thus submarginal cell 2 closed (Fig. 7A, SMC2). Marginal cell 1 extremely long, at least one-third chord length of wing. Petiolar peduncle long and slender; node short, dorsoventral height somewhat less than maximum diameter of posterior petiolar foramen (Fig. 15C). Sri Lanka. Aneuretinae (Aneuretus)

- Forewing venation reduced: Mf2-4 and 2rs-m absent, thus submarginal cell 2 open (Fig. 7B). Marginal cell 1 length less than one-third chord length of wing. Petiolar peduncle short to absent (Fig. 16B), not particularly slender when developed; node variable. Global.

Formicinae

\section{Treatments of focal taxa}

Amblyoponinae Forel, 1893

Fig. 6G

Amblyoponinae Forel, 1893: 195 (as subfamily of Formicidae). Type genus: Amblyopone.

For taxonomic synopsis of Amblyoponinae, see AntCat (2014).

\section{Synapomorphies}

The Amblyoponinae was diagnosed by Bolton (2003) based primarily on the female castes, while more recently Yoshimura \& Fisher (2012a) diagnosed the males for the Malagasy region. Apomyrma and Opamyrma violate most of these characters; these violations are noted below. Synapomorphies of the Amblyoponinae from the two aforementioned resources are as follows, with respective pleisiomorphies presented in brackets:

1. Dentiform clypeal setae present on anterior clypeal margin (all adult castes) (note 1). [Dentiform clypeal setae absent.]

2. Metapleural gland orifice directed more-or-less posterodorsally (female castes) (note 2). [Metapleural gland orifice directed laterally.]

3. Helcium supraaxial, thus petiole situated high on abdominal segment III, petiole without distinct posterodorsal face and abdominal tergum III without distinct anterodorsal face (all adult castes) (note 3). [Helcium infraaxial.]

4. Petiole very broadly attached to abdominal segment III (all adult castes) (note 4). [Petiole narrowly attached to abdominal segment III.]

5. Helcial sternite very wide (all adult castes) (note 4). [Helcial sternite narrow.]

6. Abdominal segment IV tergosternal fusion present (all adult castes) (note 5). [Abdominal segment IV tergosternal fusion absent.]

7. Basivolsella with ventroapical process, near bases of cuspis and digitus (male) (note 6). [Apical process of basivolsella absent.] 

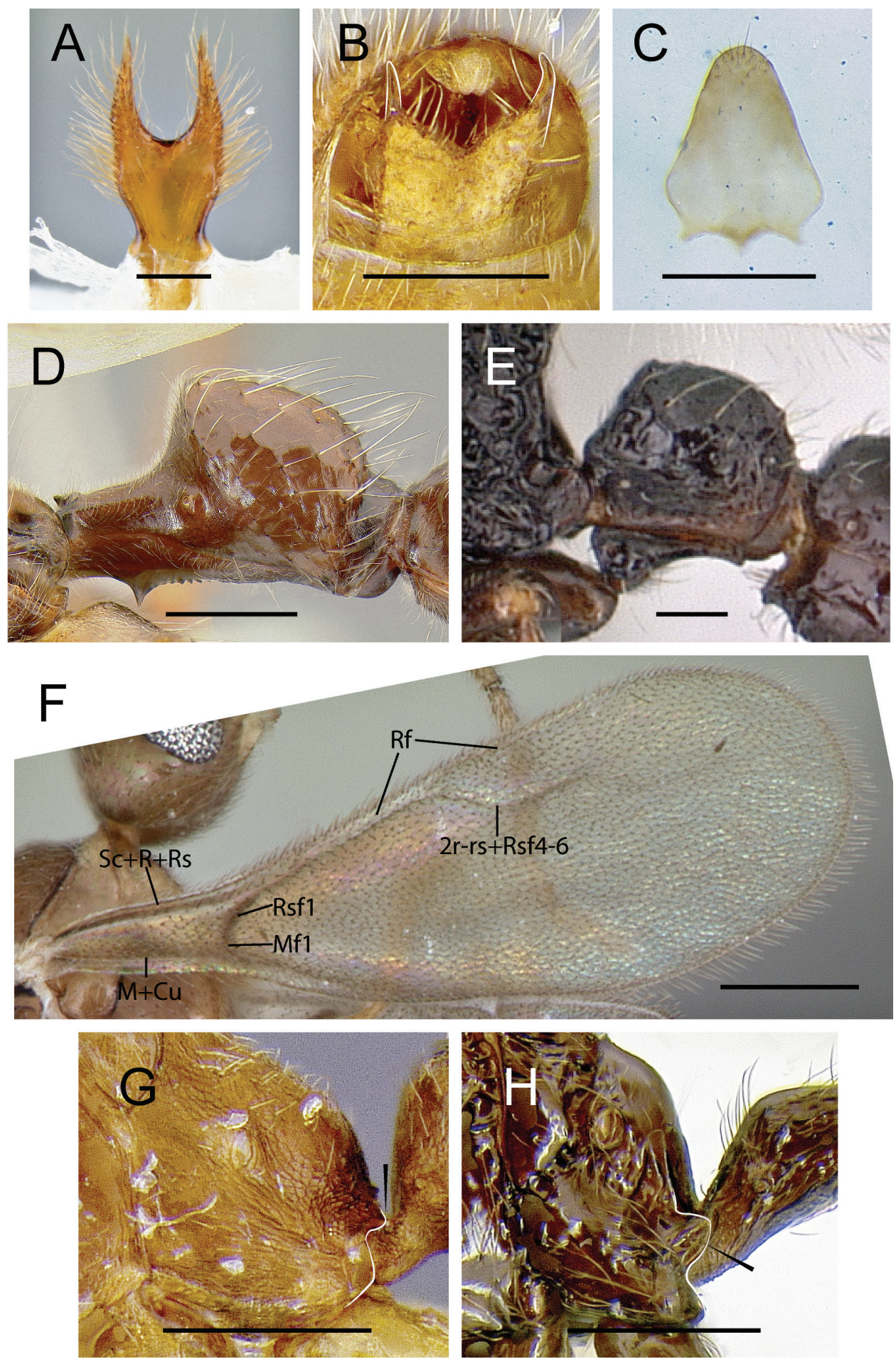

Fig. 4. Male morphology. A-C. Abdominal sternum IX in ventral view. B. Oblique. D-E. Petiole in lateral view. F. Forewing in dorsal view. G-H. Propodeum in lateral view. - A. Aenictogiton indet. (Zambia, CASENT0106126, M. Branstetter). B. Cerapachys "parasyscia" lineage (Kenya, B. Boudinot). C. Emeryopone buttelreepeni (Thailand, CASENT0278779, B. Boudinot). D. Paraponera clavata (?Panama, B. Boudinot). E. Cerapachys lividus (Madagascar, CASENT0138502, D. Raharinjanahary). F. Phaulomyrma indet. (Thailand, UCRENT150358, A. Nobile). G. Leptanillinae indet. (Thailand, CASENT0156249, B. Boudinot); arrow indicates dorsal margin of petiolar foramen. H. Adelomyrmex dentivagans; arrow indicates propodeal lobe. All scale bars $=0.2 \mathrm{~mm}$, except D-E $=1.0 \mathrm{~mm}$. 

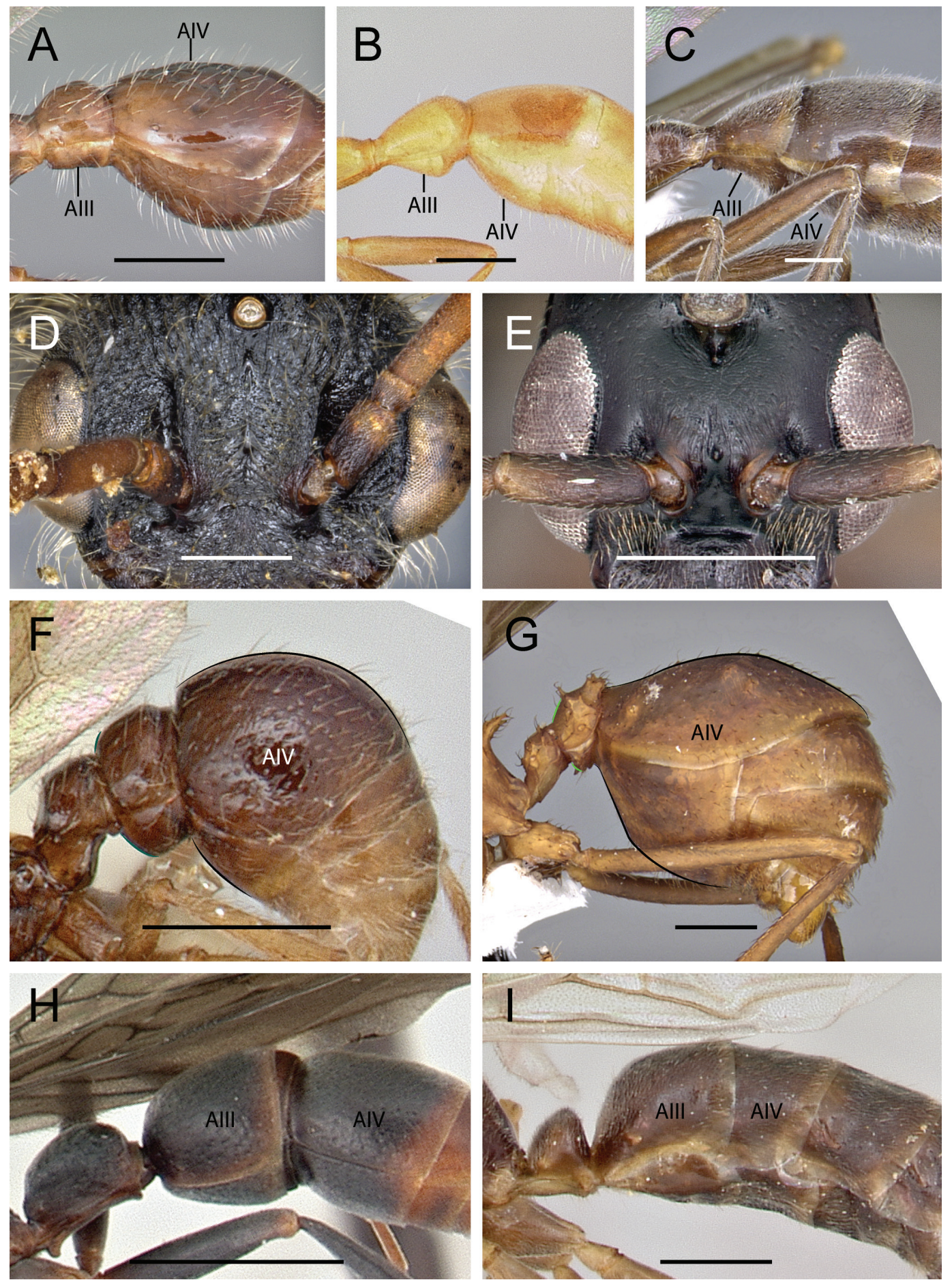

Fig. 5. Male morphology. A-C, F-I. Metasoma, lateral view. D-E. Head capsule, frontal view. A. Myrmica latifrons (U.S.A., CASENT0104816, A. Nobile). B. Pseudomyrmex indet. (Mexico, CASENT0103327, A. Nobile). C. Nothomyrmecia macrops (Australia, CASENT0902784, Z. Lieberman); note that abdominal segment III is reduced relative to, but not differentiated from segment IV. D. Myrmecia pilosula (Australia, CASENT0902800, Z. Lieberman). E. Tetraponera indet. (Madagascar, CASENT0053316, A. Nobile). F. Tatzuidris tatusia (Panama, CASENT0178870, E. Prado). G. Acromyrmex volcanus (Costa Rica, INBIOCRI001283114, E. Ortega). H. Platythyrea arthuri (Mayotte, CASENT0132466, E. Prado). I. Formica pallidefulva (U.S.A., CASENT0172882, A. Nobile). Scale bars: A-F $=0.5 \mathrm{~mm}, \mathrm{G}-\mathrm{I}=1.0 \mathrm{~mm}$. 

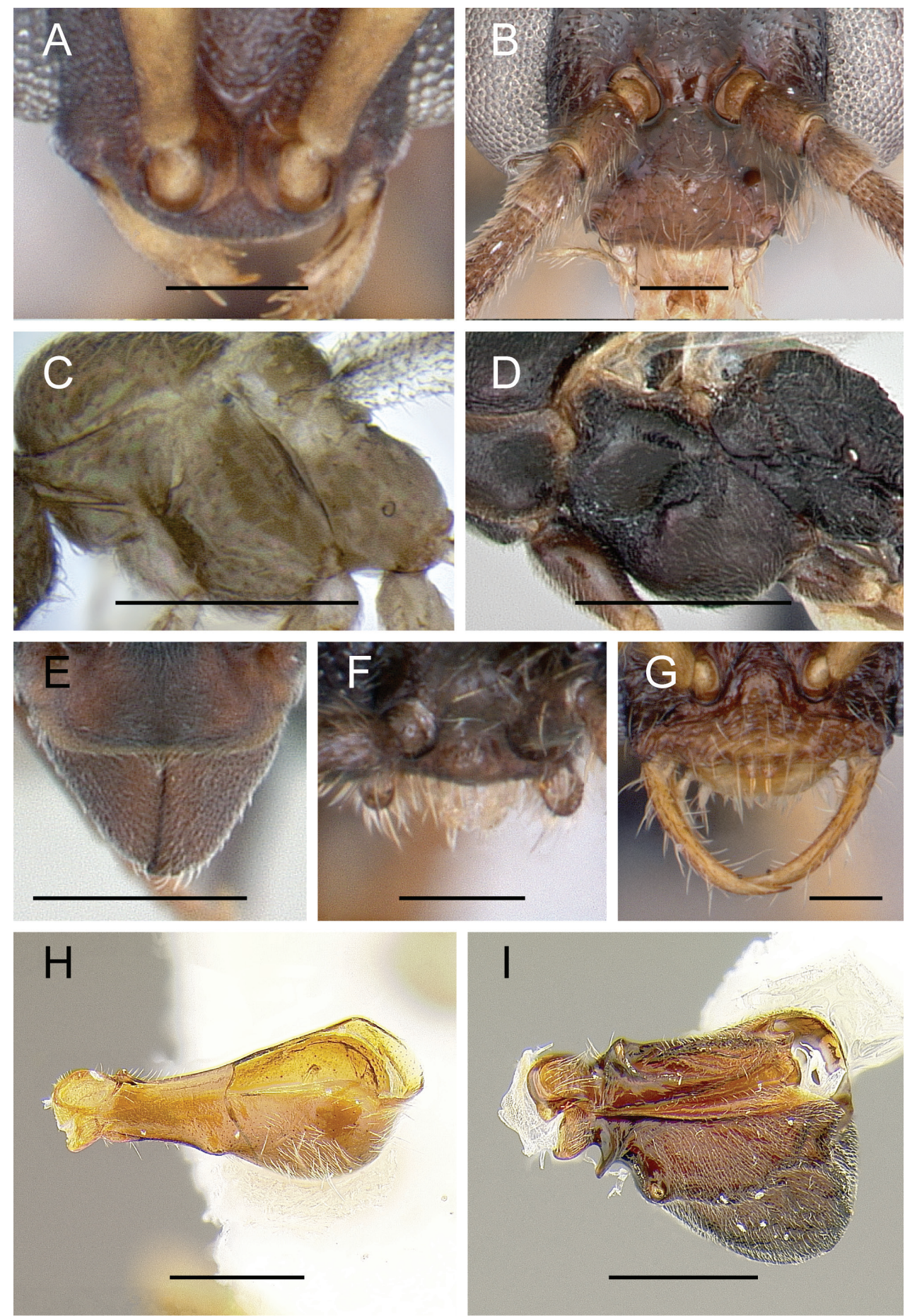

Fig. 6. Male morphology. A-B, E-G. Head capsule in frontal view. C-D. Mesosoma, lateral view. H-I. Petiole, ventrolateral view. - A. Probolomyrmex indet. (Madagascar, CASENT0080551, A. Nobile). B. Anochetus boltoni (Madagascar, CASENT0063847, A. Nobile). C. Leptanilloides gracilis (Guatemala, CASENT0234561, M. Borowiec). D. Odontomachus simillimus (Seychelles, CASENT0172666, A. Nobile). E. Platythyrea arthuri (Mayotte, CASENT0132466, E. Prado). F. Protanilla indet. (Thailand, CASENT0119776, A. Nobile). G. Stigmatomma indet. (Madagascar, CASENT0007087, E. Prado). H. Nothomyrmecia macrops (Australia, B. Boudinot). I. Neoponera cf. apicalis (Honduras, B. Boudinot). Scale bars: A, $\mathrm{F}-\mathrm{G}=0.1 \mathrm{~mm}, \mathrm{~B}=0.2 \mathrm{~mm}, \mathrm{C}=0.25 \mathrm{~mm}, \mathrm{E}, \mathrm{H}-\mathrm{I}=$ $0.5 \mathrm{~mm}, \mathrm{D}=1.0 \mathrm{~mm}$. 


\section{BOUDINOT B.E., Contributions to the Formicidae}
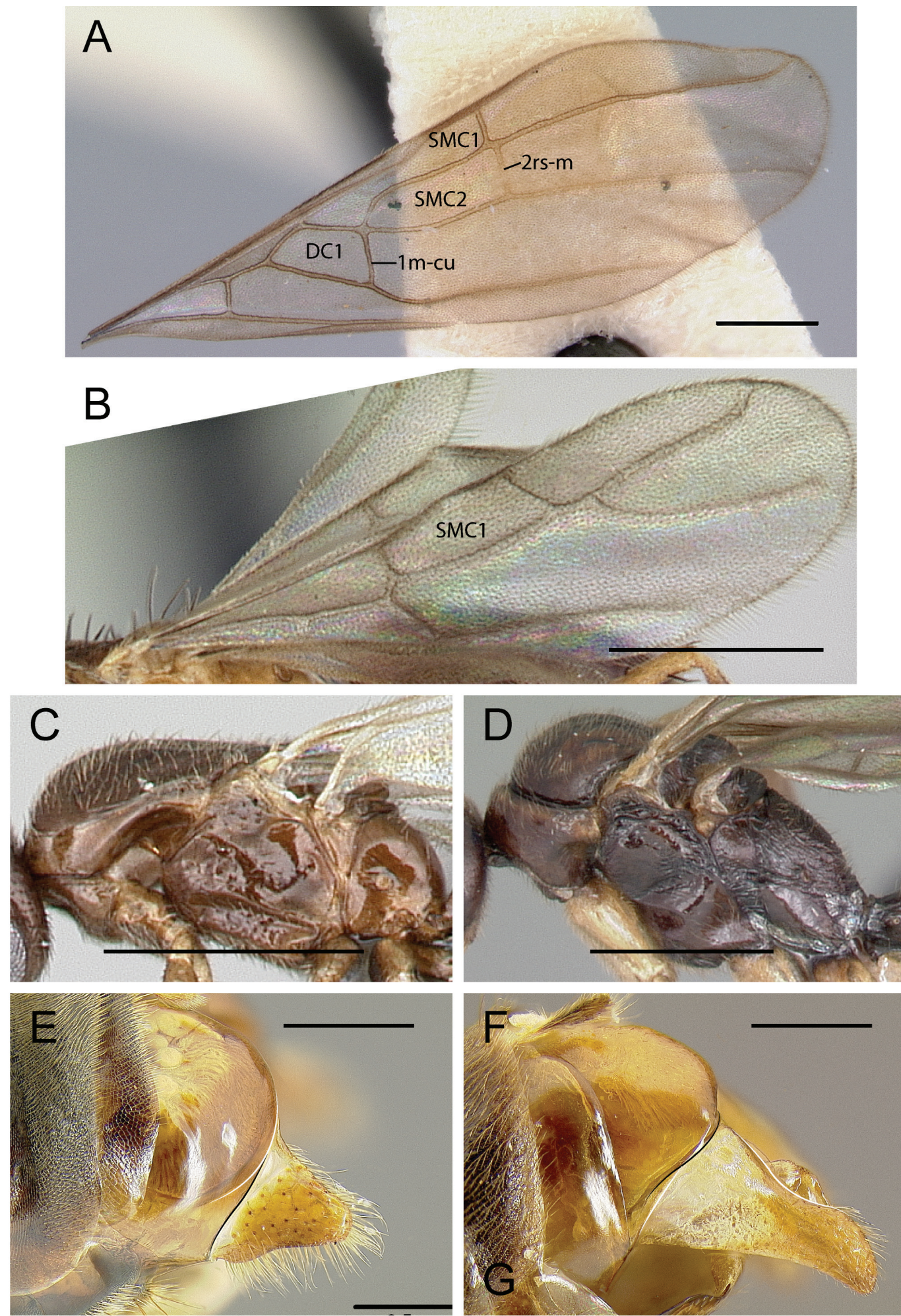

Fig. 7. A-B. Forewing. A. Ventral view, gyne. B. Dorsal view, male. C-D. Mesosoma, lateral view, male. E-F. Paramere, lateral view, male. - A. Aneuretus simoni (Sri Lanka, CASENT0172259, A. Nobile). B. Nylanderia vividula (U.S.A., CASENT0058918, A. Nobile). C. Apomyrma stygia (Central African Republic, CASENT0086073, E. Prado). D. Anochetus boltoni (Madagascar, CASENT0063847, A. Nobile). E. Dolichoderus validus (Costa Rica, INB0003662427, B. Boudinot). F. Formica pacifica (U.S.A., JTLC000006350, B. Boudinot). Scale bars: A-C, E-F = $0.5 \mathrm{~mm}, \mathrm{D}=1.0 \mathrm{~mm}$. 


\section{Notes on synapomorphies}

1. Generally present in males, although these setae may be difficult to ascertain or absent in very small species. Not present in any other extant ant taxon, although present in most $\dagger$ Sphecomyrminae. Apomyrma and Opamyrma workers and Apomyrma males lack dentiform clypeal setae (the male of Opamyrma is unknown); rather, the workers have dentiform setae on the labrum. The male of Apomyrma has a very reduced labrum which lacks dentiform setae.

2. Males with or, more often, without metapleural gland orifice. The metapleural gland of Apomyrma was not evaluated in this study due to insufficient magnification.

3. This corresponds to the third, fifth, and sixth amblyoponine synapomorphies of Bolton (2003). Apomyrma workers and males have infraaxial helcia, while the worker of Opamyrma has an axial helcium.

4. Petiole very narrowly attached in worker Apomyrma and Opamyrma. The petiolar conformation of the male of Apomyrma, though broad, still differs from that observed in Amblyoponinae (see note 5).

5. Reversed in Adetomyrma female castes and variable in males (Yoshimura \& Fisher 2012a).

6. Character from Yoshimura \& Fisher (2012a) and confirmed here via dissection of Amblyopone, Myopopone, Onychomyrmex, Paraprionopelta, and New World Stigmatomma.

\section{Comments}

The supraaxial helcium serves to distinguish both female and male Amblyoponinae, excluding Apomyrma and Opamyrma, from the majority of the Formicidae. Besides occurrence in the amblyoponines, the supraaxial state of the helcium is only developed in Acanthostichus (Dorylinae) and male Proceratium (Proceratiinae), and weakly in the workers of Martialis (Martialinae) and the male of Tatuidris (Agroecomyrmecinae). Males of three amblyoponine genera (Bannapone, Concoctio, and Opamyrma) remain unknown.

The Amblyoponinae was only recently split from the Ponerinae sensu lato (Bolton 2003) and has been recovered in all molecular phylogenies as poneroids, with uncertain relationship to the Proceratiinae and the remainder of the group (Brady et al. 2006; Moreau \& Bell 2013; Ward 2014). Two main clades are recovered in the Amblyoponinae, termed the XMAS (Xymmer, Myopias, Adetomyrma, Stigmatomma) and OCP (Onychomyrmex, Concoctio, Prionopelta) clades (Yoshimura \& Fisher 2012a). Apomyrma, in its original description (Brown et al. 1971), was proposed to be closely related to the Amblyoponinae (then Amblyoponini), a contention supported by Wheeler \& Wheeler (1985) and Hölldobler \& Wilson (1990). Other authors demurred, placing the genus in its own tribe (Apomyrmini) in the Ponerinae sensu lato (Dlussky \& Fedoseeva 1988) and in the Leptanillinae (Bolton 1990b; Kugler 1992), and eventually in its own subfamily, Apomyrminae (Baroni Urbani et al. 1992; Bolton 1994, 2003). The "Apomyrma" sequences used by Saux et al. (2004) were contaminated (P.S. Ward, pers. comm.), but fortuitously their transfer of Apomyrma to the Amblyoponinae was supported by subsequent studies (Brady et al. 2006; Moreau \& Bell 2013). This classification is followed here.

Apomyrma Brown, Gotwald Jr. \& Lévieux, 1971

Apomyrma Brown, Gotwald \& Lévieux, 1971: 259. Type-species: Apomyrma stygia, by original designation. Monotypic.

\section{Apomorphies of Apomyrma}

Note: Characters here indicated are apomorphic for the Formicidae generally, given Bolton's (2003) synthesis of plesiomorphies and novel observations. 
1. Raised clypeal disc between antennae lateromedially compressed, forming wedge-shaped process in anterolateral view, posterolateral clypeal margins distant from antennal toruli (female castes) (note 1). [Clypeal disc broad, uncompressed.]

2. Axillae enlarged, meeting medially (male). [Axillae small, not meeting medially.]

3. Transverse sulcus posterior to helcial sternite present (female castes). [Transverse sulcus posterior to helcial sternite absent.]

4. Abdominal segment III posttergites unfused (all castes).

5. Spiracles of abdominal segment III enlarged and situated at extreme anterior margin of tergum in profile view (female castes) (note 2). [Spiracle smaller, situated distant from anterior tergal margin in profile view.]

6. Penisvalvae dorsally fused for most of length, and anterodorsally fused with basimeres (male). [Penisvalvae unfused dorsally, unfused with basimere.]

7. Anterior base of penisvalvar lateral apodeme strongly produced laterally, forming a helmet- or cowry-like bulbous structure. [Lateral apodeme nearly flush with to slightly raised from valviceps.]

\section{Notes on apomorphies}

1. Clypeus also lateromedially compressed in Leptanilla.

2. Although adduced as the sole synapomorphy for Apomyrma + Leptanillinae by Bolton (1990a), this may be a convergence, as the third abdominal spiracle of Opamyrma is considerably posterior to the anterior tergal margin in profile view.

\section{Comments}

The infraaxial helcium of the worker and male may be apomorphic, depending on placement of the genus.

\section{Male diagnosis}

Male Apomyrma are recognizable by the combination of nub-like mandibles, anteriorly elongate mesosoma, reduced wing venation (marginal, costal, discal, basal, subbasal cells closed; subdiscal cell 1 open; submarginal 1 closed or open; pterostigma absent; 2r-rs situated in basal half of wing), and small, wedge-shaped petiole which is broadly and infraaxially attached to abdominal segment III.

1. Alate (Fig. 8B-C).

2. Mandalus somewhat enlarged, but clearly ringed by sclerotized mandibular cuticle in dorsal view (Fig. 8A).

3. Mandibles strongly reduced, nub-like, lacking teeth (Fig. 8A).

4. Labrum strongly reduced, subrectangular.

5. Palpal formula 2,1, palps strongly reduced in size.

6. Antenna 13-merous; funiculus filiform.

7. Occipital carina absent (Fig. 8B-C).

8. Eyes situated anteriorly, malar area visible in profile view (Fig. 8B).

9. Oblique mesopleural sulcus absent (Fig. 8B).

10. Subalar sulcus broadly enlarged, larger than lower metapleural area (Fig. 8B).

11. Epimeron narrow, lamellar (Fig. 8B).

12. Metapleural spiracular plate absent (Fig. 8B).

13. Mesoscutum anteriorly elongated, with concomitant elongation of lateral pronotal face (Fig. 8B-C).

14. Notauli fine, shallowly impressed, nearly meeting at midline (Fig. 8B-C).

15. Axillae enlarged, meeting medially (Fig. 8C).

16. Scutoscutellar sulcus exceedingly fine (Fig. 8C).

17. Metapleural gland orifice conspicuous (Fig. 8B). 
18. Propodeum small, convex (Fig. 8B).

19. Propodeal spiracle small, circular, situated in anteroventral sector of lateral propodeal face (Fig. 8B).

20. Propodeal lobe absent (Fig. 8B).

21. Ventrolateral meso- and metapleural margins ecarinate (Fig. 8B).

22. Velum of calcar absent.

23. Forewing lacking membrane anterior to costal vein (Fig. 9A).

24. Forewing venation Ogata type IVa: Submarginal cell, marginal cell 1, and discal cell 1 closed; subdiscal cell 1 open (Fig. 9A).

25. Forewing costal vein present, reaching 2r-rs (Fig. 9A).

26. Hindwing venation reduced, only $\mathrm{R}+\mathrm{Rs}$ tubular (Fig. 9B).

27. Jugal lobe absent (Fig. 9B).

28. Petiole subsessile, conical, broadening posteriorly; posterior face weak; anterior and posterior foramina oriented along main body axis (Fig. 8B).

29. Petiolar tergum lacking anterior parabolic carina (basipetiolar carina).

30. Subpetiolar process absent (Fig. 8B).

31. Helcium infraaxial (Fig. 8B), broad in dorsal view.

32. Prora of abdominal sternum III absent (Fig. 8B).

33. Abdominal segment III undifferentiated from IV (Fig. 8B).

34. Cinctus between abdominal segment IV pre- and postsclerites absent (Fig. 8B).

35. Abdominal tergum VIII posterior margin parabolic, unmodified (Fig. 8B).

36. Abdominal sternum VIII visible in situ.

37. Abdominal sternum IX unmodified; neither pronged nor toothed (Fig. 9C).

\section{Distribution of Apomyrma}

Afrotropical, confirmed from: Côte d'Ivoire, Ghana, Benin, Nigeria, Cameroon, Central African Republic, Democratic Republic of the Congo (new record), and South Africa.

Apomyrma stygia Brown, Gotwald Jr. \& Lévieux, 1971

Apomyrma stygia Brown, Gotwald Jr. \& Lévieux, 1971: 264, figs. 1-19 (worker, queen, male). CÔTE D'IVOIRE, Lagunes: Station d'Ecologie de LAMTO, near Toumodi, $6^{\circ} 13^{\prime} \mathrm{N} 5^{\circ} 02^{\prime} \mathrm{W}, 75-120 \mathrm{~m}$ elevation, 16 Apr. 1968 (J. Lévieux) [UCDC paratype worker CASENT0260454 examined] [Original label reads: "IVORY COAST Lamto, Toumodi, 16.iv.68 J. Levieux"].

\section{Apomyrma CD01}

Figs $7 \mathrm{C}, 8-9$

\section{Non-type material examined (male)}

DEMOCRATIC REPUBLIC OF THE CONGO, Bandundu: Wamba, Kikongo Mission, $4^{\circ} 15^{\prime} \mathrm{S} 17^{\circ} 10^{\prime} \mathrm{E}$, 350-500 m elevation, Jul. 2008, Malaise trap (T. Chapman), 20 Apr. 2008, forest Malaise trap (S.L. Heydon \& S.E. Stevenson), 30 Mar.-5 Apr. 2006, Malaise trap in riparian forest (S.L. Heydon \& S.E. Stevenson) and 24 Apr. 2006, Malaise trap in riparian forest (S.L. Heydon); Wamba, Nsheshe Forest NE of Kikongo Mission, 21-28 Jul. 2008, Malaise trap in primary forest (T. Chapman). [Wamba is the name of the river running to the east of the georeference point.]

\section{Male description}

Measurements ( $\mathrm{n}=3$ ). HL $0.36-0.41$, HW1 $0.32-0.38$, HW2 0.45-0.51, MAL 0.06, MDL 0.03-0.04, SL 0.06-0.07, PDL 0.05-0.06, A3L 0.06-0.08, AAL 0.11-0.14, EL 0.22-0.26, EW 0.18-0.21, OOD 0.09-0.10, LOD 0.06-0.07, MOD 0.06-0.08, ML 0.78-0.95, MLL 0.22-0.25, MLW 0.17-0.20, MTL 0.46-0.57, MTW 0.33-0.40, PFL 0.29-0.36, MFL 0.30-0.37, PTH 0.13-0.16, PTL 0.12-0.16. 
INDICES. CI 0.89-0.93, CS 0.34-0.40, SEI 356-427, SI 18.2-19.2, EI 77.4-82.5, EYE 118-120, MDI 8.2-10.5, OBI 70.4-74.6, OMI 3.71-4.50, MNI 2.05-2.14, MTI 126-144, FI 93.6-98.9, PTI 97.9109.1. Small, mesosoma bulky and elongate; wings situated in posterior half of mesosoma (Fig. 8B).

HEAD (Fig. 8A). In full-face view head slightly longer than broad excluding eyes, broader than long including eyes. Palpal formula 2,1; palps short, not reaching hypostomal margin. Stipes with carina along medial margin. Labrum extremely reduced, very narrow and weakly convex, glabrous; lacking dentiform setae; lateral margins nearly contacting medial mandibular base. Mandibles strongly reduced, nub-like, edentate; mandalus enlarged but still ringed by sclerite in dorsal view. Clypeus well-developed; anterior margin weakly emarginate; medial clypeal portion maximum anteroposterior length between 1.5-2 maximum antennal socket diameters; posterior clypeal margin extending slightly between antennal toruli. Supraclypeal area indistinct. Antennal toruli situated distant from anterior head margin; anterior tentorial pits located anterior to lateral torular arches. Frons and ocellar area bulging. Occipital carina absent, occiput obscured by vertex in full-face view. Compound eyes bulging; medial and posterior margins weakly convex; compound eye slightly narrower posteriorly than anteriorly. Ocelli small, situated distantly from compound eye. Hypostomal margin reduced, medial hypostoma narrowly carinate. Antenna 13-merous; scape overall smaller than pedicel; pedicel subspherical, slightly shorter than antennomere 3 ; funiculus filiform, not elongate, reaching propodeum when laid posteriorly against mesosoma.

Mesosoma (Fig. 8B-C). Pronotal neck very short, discontinuous laterally with remainder of sclerite in dorsal view; pronotum weakly musculated, anteromedian face linear and appressed to mesoscutum; dorsoventral height of anteromedian pronotal face in profile view about $1 / 4 \mathrm{x}$ mesoscutum height in profile view; lateral pronotal face concave posterad procoxal insertion. Mesoscutum considerably longer than broad in dorsal view (length 1.26-1.42 x width); anterior and posterolateral areas not swollen. Notauli distinct, fine, not cross-ribbed; meeting or barely meeting at midlength, but not extending to transscutal line. Parapsidal lines slightly longer than half mesoscutum length, slightly divergent. Parascutal carinae fine, weakly sinuate, situated so low on mesoscutum that carinae completely obscured by wing base. Scutoscutellar sulcus deeply impressed dorsally, V-shaped. Axillae enlarged, meeting at body midline. Mesoscutellum at same height as mesoscutum, dorsal margin linear in profile view. Metascutellum small, convex, not produced. Metanotal trough deep, long, elliptical, broader anteriorly. Mesopectus lacking oblique sulcus; subalar furrow very large, about same size as petiole. Spiracular sclerite absent. Lower metapleural area offset by upper metapleural area by sulcus; upper metapleural area anteroposteriorly narrow, convex, sclerite thinned and differentiated from lower metapleuron, mesopectus, and propodeum. Metapleural gland orifice conspicuous, wide open, directed laterally, slightly posteriorly. Propodeum parabolic in profile view, dorsal face shorter than and continuous with posterior face; propodeal spiracle circular, small, situated anteroventrally. Propodeal lobe reduced to small tubercle with dorsal, dorsoventrally-oriented carina; petiolar presclerites visible in profile view, unobscured by propodeal lobe.

Metasoma (Fig. 8C). Petiole wedge-shaped, weakly nodiform in profile view; anteriormost portion of petiolar tergum not offset by carina; petiolar tergum overlapping sternum; anterodorsal petiolar face weakly concave, curving into shallow node in profile view; node with poorly-developed posterodorsal face; petiolar sternum ventral margin convex in profile view, sternum with symmetrical curving longitudinal carinae forming concentric long ellipses; petiolar sternum lacking process. Abdominal segment III similar in size, shape, and sculpture to segment IV; helcium infraaxial, broad, presternite not visible ventrad pretergite; prora absent, transverse sulcus ventrad helcial sternum absent (present in worker). Abdominal terga IV-VIII and sterna IV-IX normally developed, not reduced or obscured in situ. Abdominal sternum IX apical margin obtusely triangular, not pronged or toothed. 
Forewing (Fig. 9A, see note below). Tegulum reduced, elliptical, much longer than broad. Wings hyaline, completely covered by fine setose layer. Pterostigma absent. Wing venation Ogata type IVa: one submarginal cell and marginal cell 1 closed, $1 \mathrm{~m}$-cu present, thus discal cell 1 closed. Costal vein tubular, contacting Rf distally. Cells clustered in basal half of wing, with only marginal cell extending into apical half. Rsf1 less than half length of Mf1; Rsf1 and Mf1 parallel. Rs+M sinuate (see note on wing venation below). 2r-rs slightly shorter than Mf1, directed posteroapically, oblique to long axis of wing. Rsf4-6 tubular, meeting Rf, enclosing marginal cell. Mf4-6 present, tubular for a short distance before disappearing. Crossvein cu-a tubular, situated distad Mf1. CuF slightly divergent with respect to Mf4-6. 1A extending distad 1m-cu but not enclosing subdiscal cell. Marginal and discal cells elongate; length of each cell considerably greater than half their width.

HINDwING (Fig. 9B). Venation reduced, only R+Rs tubular. Four hamuli present.

Genitalia (Fig. 9C-H). Pygostyles absent. Abdominal sternum IX hexagonal in outline; spiculum somewhat long, about four times longer than broad at base; anterior margins angle distinctly posterolaterally from spiculum; anterolateral margins weakly divergent; posterolateral margins extending to broadly rounded apex posteromedially. Anterolateral sternal corners hooked anteriorly. Cupula dorsal and ventral faces anteroposteriorly narrow; lateral face broad. Basimere ventromedially produced as lamina, concealing basivolsella in ventral view. Basimere and telomere continuous in profile view; telomere dorsoventrally narrow, dorsal telomeral margin concave, ventral margin convex, telomere weakly upturned, apex setose and evenly rounded. Basivolsella lateromedially narrow, oriented dorsoventrally; anterodorsal corner produced as dorsomedially-directed spur which abuts penisvalvar ventral margin base in situ; cuspis lobate, elongate, directed posterolaterad. Digitus elongate, arched, directed posteromesad, apex hooked. Penisvalvae dorsomedially fused from base to almost $3 / 4^{\text {ths }}$ their length, and fused anterodorsally with basimeres; valvura short, linear; valviceps dorsolateral face convex, lateral apodeme produced ventrolaterally, forming concave shell-like structure in which volsella may rest; ventral margin strongly concave, raised dorsally and only slightly differentiated from concave ventrolateral penisvalvar face; phallotreme situated apically, between dorsal penisvalvar margins where penisvalvar dorsal margins curve ventrally.

COLORATION. Body uniformly castaneous, legs yellowed.

SCULPTURATION. Body weakly sculptured, mostly smooth and shining except for the following features: head, mesonotum, metasoma posterad petiole, and legs covered with more-or-less even, somewhat dense piligerous punctures; subalar sulcus weakly longitudinally costulate.

Setation. All setae short to very short; head setae head coarse, decumbent to erect, evenly spaced, apices slightly overlapping bases; mesoscutal setae similar in form and density to head, sparser mediad parascutal carinae; mesoscutellar setae somewhat longer and more dilute than mesoscutal setae, but otherwise similar, absent on lateral mesoscutellar face; metascutellum with few, coarse setae; pronotum bearing comparatively fine setae anterolaterally, otherwise glabrous; mesopectus with comparatively fine, long, and dilute setae; metapleuron and lateral propodeal face glabrous, posterior propodeal face with setae similar to mesoscutellum; propleural and procoxal setae similar to head setae on anterior surfaces; leg setae coarse, short, pale, appressed on most surfaces but decumbent to subdecumbent on ventral femoral faces; only petiolar node bearing coarse setae; metasoma posterad petiole with setation similar to head and mesoscutum.

\section{Note}

Interpretation of the abscissae enclosing submarginal cell 1 is ambiguous. The crossvein $1 \mathrm{~m}$-cu may be apically displaced, producing a second Rs + M abscissa which splits into Rsf2 and Mf2, or 1m-cu 
BOUDINOT B.E., Contributions to the Formicidae
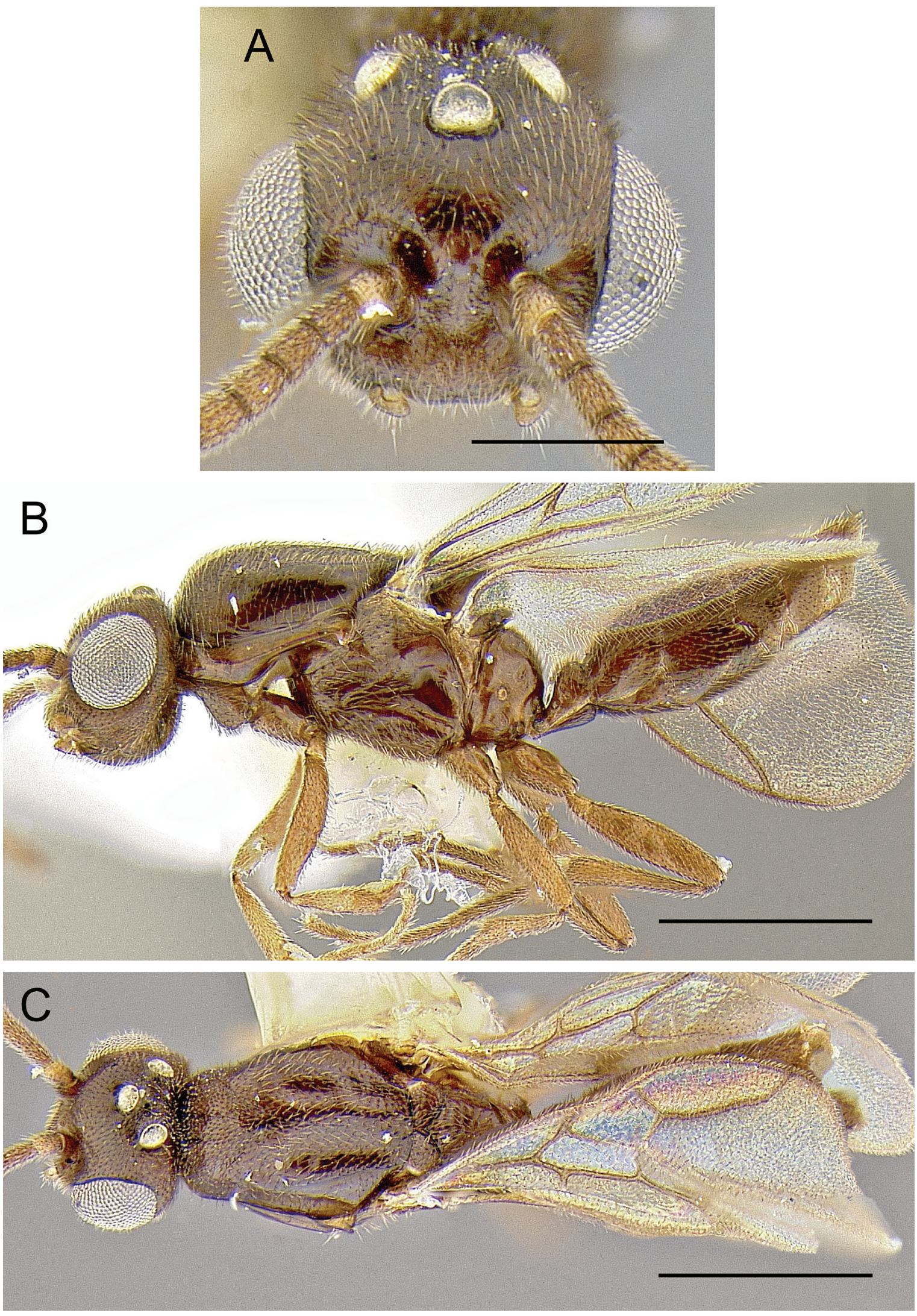

Fig. 8. Apomyrma CD01, male, photomicrographs (CASENT0086073, E. Prado). A. Head, frontal view. B. Body, lateral view. C. Body, dorsal view. Scale bars: A $=0.2 \mathrm{~mm}, \mathrm{~B}-\mathrm{C}=0.5 \mathrm{~mm}$. 

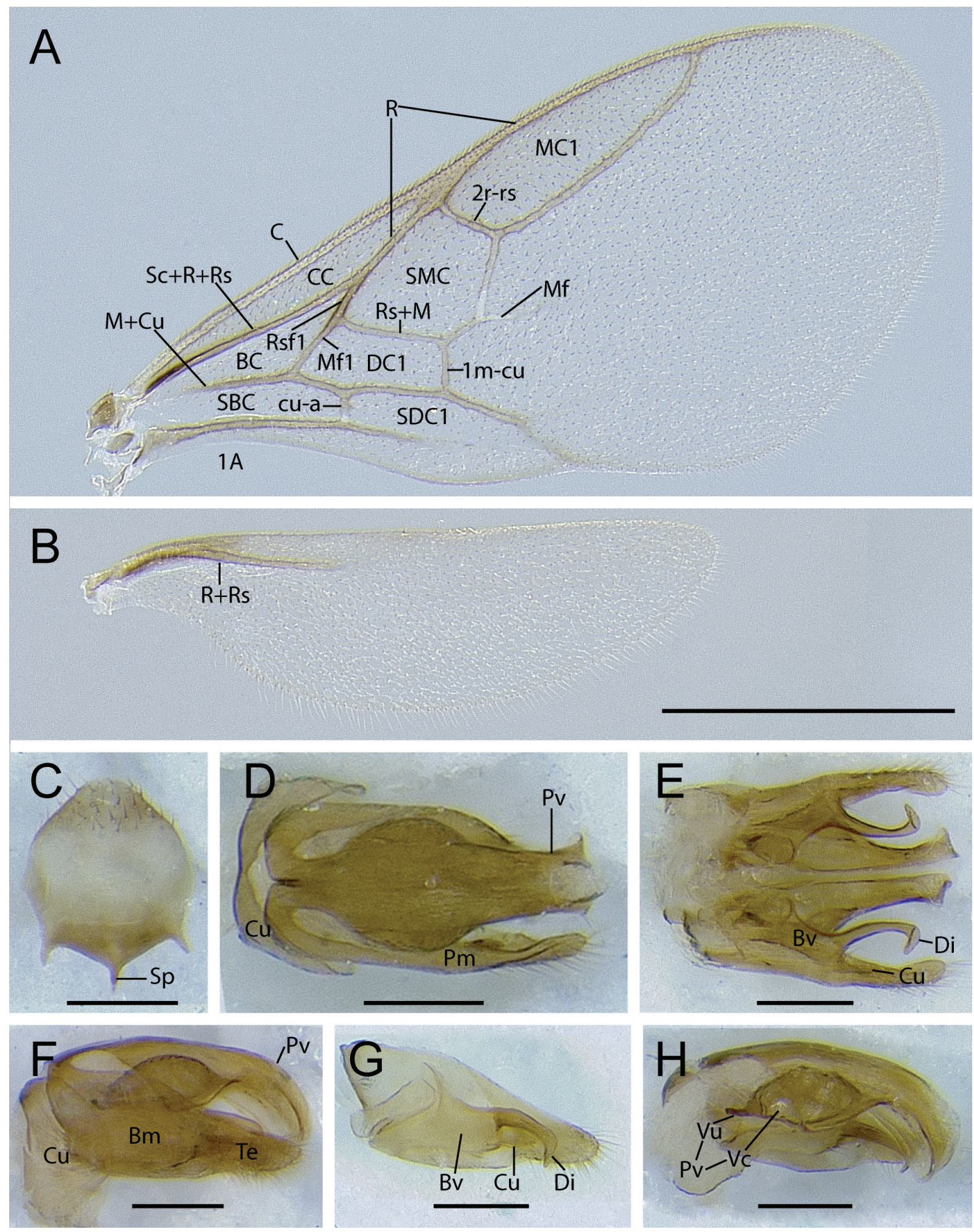

Fig. 9. Apomyrma CD01, male, photomicrographs. A. Forewing. B. Hindwing. C. Abdominal sternum IX, ventral view. D. Genital capsule, dorsal view. E. Genital valves, slightly splayed and without cupula, ventral view. F. Genital capsule, lateral view. G. Volsella and paramere, mesal view. H. Penisvalva in situ, mesal view. Scale bars: A-B $=0.5 \mathrm{~mm}, \mathrm{C}-\mathrm{H}=0.1 \mathrm{~mm}$. Abbreviations: see Material and Methods. 
may be unmoved and Rsf2 may be absent. Without a transitional series it is currently not possible to accurately determine these particular abscissal homologies, although the abscissa in question has a thyridium (weakening), suggesting that it is $2 \mathrm{rs}-\mathrm{m}$ (the latter case).

\section{Discussion}

The species-level identification of the males described here is uncertain, as unpublished molecular work on Apomyrma has revealed more than one species in the genus (P.S. Ward, unpubl. data). The male described here, "Apomyrma CD01", differs from other male-based Apomyrma morphospecies by the following characters: head capsule in full-face view shorter, compound eyes more strongly protuberant; and ocelli large (equal in size to morphospecies Apomyrma CF01). The morphospecies probably differ in morphometrics, wing venation, and genitalic morphology, but these character systems were not evaluated as no physical specimens of other morphospecies were available. It may be the case that of the specific lineages of Apomyrma, the male of A. stygia will remain unknown until another nest collection is made.

A strong morphological case could be made to revive the Apomyrminae and remove Apomyrma from the Amblyoponinae. Published molecular studies, however, recover Apomyrma within or sister to the Amblyoponinae, but with weakly supported relationships with either the XMAS (Brady et al. 2006; Moreau \& Bell 2013) or the OCP clade (Moreau et al. 2006; Rabeling et al. 2008). Given these results, Apomyrma is conservatively treated as an amblyoponine here, despite compelling morphological characters suggesting a relationship with the Leptanillinae, Opamyrma, and even Martialis (see "Shared apomorphies" section below). For further remarks on the similarities of Apomyrma to other taxa, see the Discussion section of the Martialis heureka species account below.

Subfamily Leptanillinae Emery, 1910

Figs 4F, 6F, 10

Leptanillini Emery, 1910: 32. Type-genus: Leptanilla.

Note

All diagnoses in the references below pertain to the tribe Leptanillini; males of Anomalomyrmini undescribed.

\section{Male references for subfamily}

Wheeler 1910: 138 (diagnosis [Leptanilla]); Wheeler \& Wheeler 1930: 193 (diagnosis [Leptanilla, Phaulomyrma]); Morley 1939: 114 (morphology comments); Kutter 1948: 293 (diagnosis); Bernard 1967: 90 (diagnosis [Leptanilla]); Petersen 1968: 577 (generic diagnoses, discussion); Gotwald 1969: 97 (mouthparts morphology); Wheeler \& Wheeler 1972: 37 (diagnosis); Baroni Urbani 1977: 430 (diagnosis, generic diagnoses); Bolton 1990b: 269 (diagnosis); Baroni Urbani et al. 1992: 316 (morphology); Ogata et al. 1995: 32 (diagnosis, genitalia); Bolton 2003: 39, 151 (diagnosis); Borowiec et al. 2011: 11 (venation comments [Anomalomyrmini]).

\section{Male diagnosis}

Male Leptanillinae are recognizable by the combination of nub-like mandibles, extremely reduced wing venation (three cells enclosed by tubular abscissae at most development: costal, basal, and subbasal cells; no cells enclosed by tubular abscissae at least development), and absence or inconspicuousness of propodeal lobes. Otherwise, male leptanillines are highly variable, often resembling "normal" poneroids, although some males are so derived as to be difficult to intuitively ascribe to the Formicidae; this modification includes even loss of abdominal segment II petiolation.

1. Mandibles strongly reduced, nub-like not meeting at head midline, or spatulate and hypertrophied (Scyphodon) (note 1). 
2. Palpal formula 4,1 or 1,1 (note 2).

3. Clypeus usually strongly reduced such that antennal toruli situated anteriorly, separated from anterior clypeal margin by much less than one torulus diameter; occasionally (Yavnella, Protanilla, Noonilla) antennal toruli situated about one torulus diameter from anterior clypeal margin (note 3 ).

4. Anterior clypeal margin without pegs.

5. Anterior tentorial pits usually situated lateral to lateral torular arch; occasionally (Yavnella) situated anterolaterad torular arch.

6. Frontal carinae and lobes absent.

7. Antenna 13-merous; funiculus filiform to submoniliform.

8. Occipital carina absent.

9. Oblique mesopleural sulcus present, anterior terminus contacting posterolateral pronotal corner or situated well ventral to pronotal corner.

10. Metapleural spiracular plate absent.

11. Propodeal lobes absent or very inconspicuous.

12. Metacoxal cavities closed.

13. Tibial spur formula $2 \mathrm{~s}, 2 \mathrm{~s} ; 1 \mathrm{~s}, 2(1 \mathrm{~s}, 1 \mathrm{p}) ; 1 \mathrm{~s}, 2 \mathrm{~s} ; 1 \mathrm{~s}, 1 \mathrm{~s} ; 0,1 \mathrm{p}$.

14. Metatarsus lacking posterolateral line of dense differentiated setae.

15. Pretarsal claws edentate.

16. Pterostigma usually strongly reduced, but may be enlarged (Anomalomyrma, some Protanilla) (note 4).

17. Ogata wing venation type IVb (Fig. 4F), but would be type IIIb should the maximum complement of spectral veins be hypothetically tubular; at most 3 closed cells present (costal, basal, subbasal); at the most extreme reduction only $\mathrm{Sc}+\mathrm{R}+\mathrm{Rs}$ and $\mathrm{Rf}$ present along anterior wing margin, with narrow stretch of membrane present anterobasally (notes 5,6).

18. Hindwing venation reduced: all abscissae absent, or $\mathrm{R}+\mathrm{R}$ s tubular and short, or $\mathrm{R}+\mathrm{Rs}$ and $1 \mathrm{~A}$ tubular and short.

19. Jugal lobe absent.

20. Petiolar laterotergite absent; tergum fused with sternum, suture visible.

21. Petiolar tergum not forming anteroventral collar around sternum.

22. Helcium axial or infraaxial.

23. Helcial sternite overlapped laterally by tergite, thus not visible in lateral view.

24. Abdominal segment III undifferentiated to somewhat constricted posteriorly to strongly differentiated with posterior constriction, forming postpetiole.

25. Abdominal segment IV as long as or infrequently distinctly longer than following abdominal segments; not vaulted.

26. Abdominal spiracles IV-VIII obscured by preceding tergites.

27. Pygostyles absent or present as extremely elongate rods.

28. Genitalia partially exserted; subject to extreme modification.

29. Basimere separated from telomere ventrally by corium or basimere and telomere fused.

30. Telomere highly variable; least modified telomeres are digitate to wedge-shaped; sometimes telomere laminar.

31. Basivolsella lateromedially narrow in ventral view, occasionally extremely elongated.

32. Cuspis present or absent; when present usually lobate and otherwise unmodified.

33. Digitus highly variable; least modified digiti are elongate and arched.

34. Valviceps highly variable; almost always with lateral apodeme produced laterally (note 7).

\section{Notes on diagnosis}

1. Mandibles also reduced and nub-like in Ponerini (Ponerinae), Apomyrma (Amblyoponinae), and some Myrmicinae (e.g., Acanthognathus, Daceton, the Adelomyrmex genus group, Myrmecina).

2. Some unidentified Protanilla males have higher palp counts, similar to workers. Future work should establish the extent of palpomere count variation inter- and intragenerically. 
3. Anteroposteriorly broad clypeus is pleisiomorphic for Leptanillinae, and is present in Protanilla and Yavnella.

4. The polarity of pterostigmal reduction is unclear, as Anomalomyrma and some Protanilla have an enlarged pterostigma; it seems likely though that this is a secondary development.

5. Wing venation also reduced to the Ogata type IVb pattern convergently in other groups, including some Myrmicinae (Strumigenys, the Adelomyrmex genus group, and the inquiline Pheidole acutidens) and some Proceratiinae (Probolomyrmex). These taxa may be distinguished from leptanillines by a suite of characters, including presence of the propodeal lobe. Contrary to the sentiment of Ogata et al. (1995) the reduced wing venation of the Leptanillinae is eminently valuable for diagnosis of the subfamily. While certainly this reduction in venation may be driven by functional constraints, the particular pattern occurring in the Leptanillinae is nearly globally unique. Although it has been indicated that the forewing venation of Leptanilla is completely absent (Wheeler 1910; Bernard 1968; Wheeler \& Wheeler 1972), no specimens were observed which had this state; at the least one compound abscissa was present along the leading wing margin.

6. Detailed forewing abscissal development description: Costal vein present or absent, when absent $\mathrm{Sc}+\mathrm{R}+\mathrm{Rs}$ very close to anterior wing margin (costal cell closed or open). Rsfl+Mf1 tubular or nebulous, indistinguishable from one another, or both abscissae absent (basal cell distally closed or open). Rs + M usually absent, infrequently spectral; Rsf $2+3$ absent (submarginal cell 1 open). Rsf4+ tubular, continuous with 2r-rs which is directed posteroapically, ending before wing apex, or Rsf4+ and 2r-rs absent (marginal cell 1 open). Mf2+ absent or spectral and 2rs-m absent (submarginal cell 2 absent). $1 \mathrm{~m}$-cu absent (discal cell 1 open). $\mathrm{M}+\mathrm{Cu}$ nebulous or absent (basal cell closed posteriorly or open). Cuf tubular to nebulous, short, or absent (subdiscal cell 1 absent). 1A tubular, partially nebulous, or absent (subbasal cell closed or open).

7. One morphogroup of South East Asian male Leptanillinae has lateromedially compressed valviceps, other morphogroups and genera have the lateral apodeme consistently laterally produced, and often modified.

Taxa examined $(q=$ queen, $\hat{O}=$ male $)$

Anomalomyrma indet. [: Indonesia]; Leptanilla africana Baroni Urbani [ổ: Nigeria]; L. bifurcata Kugler [ổ: Israel]; L. islamica Baroni Urbani [ỡ: Yemen]; L. israelis Kugler [ổ: Israel]; L. miniscula

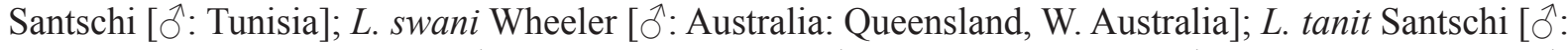
Tunisia]; L. tenuis Santschi [ô: Tunisia]; L. GR01 [ô: Greece]; L. GR02 [ổ: Greece]; L. GR03 [ô’:

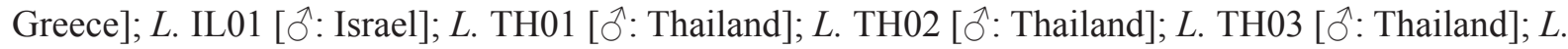

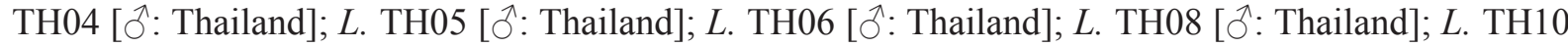

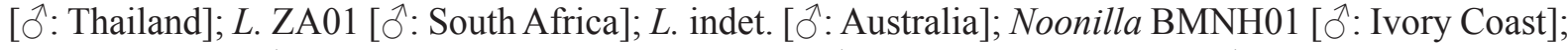

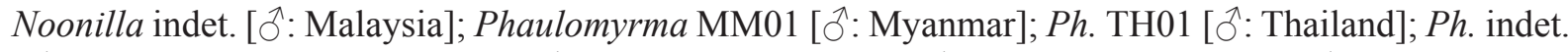

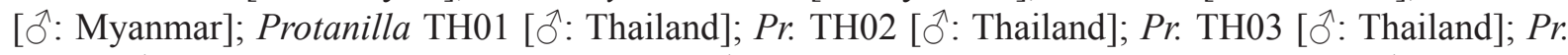
indet. [Ô: Indonesia]; Scyphodon cf. bruesi [ô: Indonesia]; Yavnella argamani Kugler [ô: Israel]; Y.

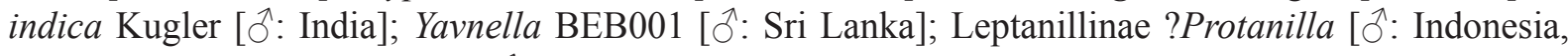
Malaysia]; Leptanillinae indet. [ô: Borneo, Democratic Republic of Congo, Indonesia, Malaysia, Papua New Guinea, Thailand].

\section{Distribution}

Old World: Palearctic (Europe, Southern Asia, and Northern Africa), Afrotropical, Australasian, and Australian regions.

\section{Discussion}

The Leptanillinae, based on males, is defined by the apomorphies presented in the diagnosis above (in italics). At present the subfamily is comprised of eight genera with the re-inclusion of the male- 
based taxa Noonilla Petersen, 1968 (stat. rev.) and Scyphodon Brues, 1925 (stat. rev.). Both N. copiosa Petersen, 1968 and S. anomalum Brues, 1925 are transferred to the Leptanillinae.

The Leptanillinae was first delimited as a tribe of Dorylinae by Emery (1910), but has consistently been considered a distinct subfamily since Wheeler (1923), except for Bernard's (1951) treatment of the "Formicoidea", in which the leptanillines were treated as a family. Opamyrma was described by Yamane et al. (2008) who assigned the genus to the Amblyoponinae using the concept of Saux et al. (2004) for
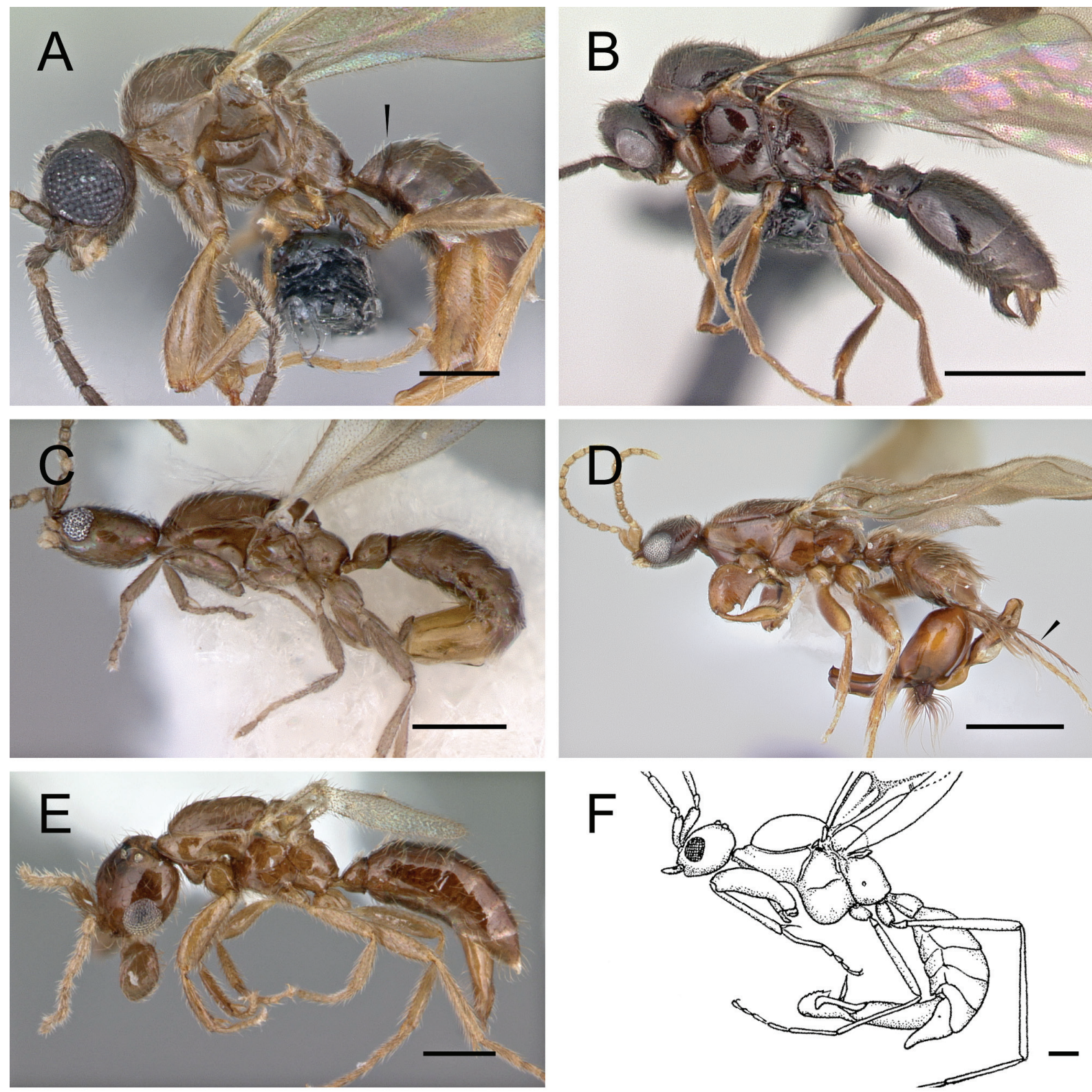

Fig. 10. Representative males of Leptanillinae, lateral view A. Protanilla "TH01" (Thailand, CASENT0119776, A. Nobile), arrow indicates loss of abdominal segment II petiolation. B. Protanilla "TH03" (Thailand, CASENT0119791, E. Prado). C. Leptanilla swani (Australia, CASENT0172318, A. Nobile). D. Protanilla sp. (Indonesia, CASENT0178838, A. Nobile), arrow indicates basolateral basimeral process. E. Scyphodon sp. (Indonesia, MCZ155112w, A. Nobile). F. Noonilla sp., used with permission from Petersen (1968). Scale bars: A, C, E-F $=0.2 \mathrm{~mm}, \mathrm{D}=0.5 \mathrm{~mm}, \mathrm{~B}=1.0 \mathrm{~mm}$. 
the subfamily, although they concomitantly referred to the genus as belonging to the Apomyrminae. Discovery of the male of Opamyrma and the larvae and gynes of Opamyrma and Martialis are anticipated to contribute to the resolution of the "basal ant problem".

As noted by prior authors (e.g., Baroni Urbani 1977; Bolton 1990b; Ogata et al. 1995), the Leptanillinae is unfortunately subject to parallel taxonomies, with two genera known only from workers (Anomalomyrma, Furcotanilla), four genera known only from males (Noonilla, Phaulomyrma, Scyphodon, Yavnella), and two genera known from both castes (Leptanilla, Protanilla). The Leptanillinae is in need of generic revision, especially given the highly variable morphologies of the males. As this is beyond the scope of the present paper, the male of Protanilla, although recently identified by the Ant Tree of Life Team (P.S. Ward et al., unpubl. data; AntWeb 2014), is not described. Moreover, there is a spectacular and perplexing diversity of leptanilline males from Southeast Asia, which await classification and association with workers (Fig. 10).

Except for the mandibles of Scyphodon and the sexual characteristics of Noonilla, these two are "typical" leptanillines (compare specimens in Fig. 10). They exhibit proposed formicid synapomorphies: the prodisticoxal cavity is closed, the propodeal spiracle is situated low on the propodeum, and the metasoma is petiolate. Placement of these genera in the Leptanillinae is supported by the presence of the following apomorphies: mandibles nub-like to spatulate (secondarily hypertrophied in Scyphodon); buccal cavity reduced; medial hypostoma vestigial; clypeus strongly reduced; and Ogata venation type IVb. The following characteristics support the placement: palpal formula 1,1; meso-segment of mesosoma elongated anteriorly; and abdominal tergum VIII enlarged (not present in all material attributed to Scyphodon). Of the formicid pleisiomorphies present in these genera, the most diagnostically valuable is absence of propodeal lobes.

Ogata et al. (1995) indicated several characters which were dubiously diagnostic for the Leptanillinae, specifically including: reduced palp formula; elongated pronotum; fore femora shape; reduced venation; metapleural gland absence; terminal abdominal segment reduction; cupula (= basal ring) absence; and cuspis absent. It is agreed that palpal formula may be reduced in other Formicidae, but reduction to 1,1 occurs in the Dorylinae (Aenictogiton), the Myrmicinae (e.g., Eurhopalothrix, Pheidole and Tetramorium-clade inquilines, Strumigenys, Rhopalomastix), and the Ponerinae (e.g., Hypoponera and Simopelta). It is evident that Scyphodon and Noonilla are not closely related to the genera indicated above. The elongate mesoscutum with concomitant posterior elongation of the pronotum is not present in all Leptanillinae and also occurs in Apomyrma (Amblyoponinae), but is otherwise unique among the Formicidae. The fore femoral modifications of Noonilla are autapomorphic, and are certainly sexual characters. As discussed in note 5 of the Leptanillinae diagnosis, the reduced venation of the Leptanillinae is highly diagnostic of the group. Certainly, of any of the dubious characters Ogata et al. indicated, the metapleural gland absence is the least valuable and in no way supports contentions about relationships in male ants. It is difficult to assess development of the cupula without dissecting the few specimens of Noonilla and Scyphodon available, so evaluation of these characters is set aside for future studies. Cuspides are present at least in some Protanilla males, and thus are not diagnostic for the Leptanillinae on the whole, but absence may be apomorphic for the remainder of the subfamily.

Subfamily Martialinae Rabeling \& Verhaagh 2008

Martialinae Rabeling \& Verhaagh, in Rabeling et al. 2008: 14913. Type-genus: Martialis. Monotypic.

\section{Apomorphies of Martialinae and Martialis}

Note: Character states indicated here are generally apomorphic for the Formicidae given Bolton's (2003) synthesis of plesiomorphies (appendix 3; presented below in brackets) and novel observations. These 
apomorphies may or may not be unique synapomorphies of $M$. heureka, but are of high diagnostic value. Worker-based states may also apply to the gyne, which at present is unknown. Larvae are unknown.

1. Mandibles more-or-less linear, elongate, not crossing at rest (worker), mandibles narrowly linear (male) (Fig. 11A-B) (note 1). [Mandibles triangular.]

2. Labrum with pair of trigger-hair-like setae at basolateral corners of sclerite, before margin curves distally, and situated at about lateral margin of lateral torular arch in anteroventral view; these setae directed dorsolaterally, contacting basal mandibular margin (worker) (note 2). [Labral trigger-hairs absent.]

3. Clypeus strongly reduced (worker) (note 3). [Clypeus well-developed.]

4. Medial clypeal portion covered with dense patch of erect, linear setae projecting anteriorly (worker) (note 3). [Dense setal patch absent.]

5. Antennal toruli exposed in dorsal view (worker) (note 4). [Antennal toruli partially concealed in dorsal view.]

6. Antennal toruli situated at and projecting anteriorly beyond anterior clypeal margin (worker) (note 5). [Antennal toruli distant from anterior clypeal margin.]

7. Antennal toruli situated anterior to line drawn between anterior tentorial pits (worker) (note 5). [Antennal toruli situated posterior to anterior tentorial pits.]

8. Antennal toruli dorsoventrally elongated (worker) (note 6). [Antennal toruli dorsoventrally short.]

9. Frons bulging medially posterior to posterior clypeal margin and between antennal toruli (worker). [Frons not bulging anteromedially.]

10. Compound eyes absent (worker) (note 7). [Compound eyes present.]

11. Petiole completely tergosternally fused, without externally visible suture (worker, male) (note 8) (Fig. 11C). [Petiole without tergosternal fusion.]

12. Abdominal segment III tergosternally fused (worker) (note 9).

13. Abdominal segment III reduced in size relative to segment IV, to which it is still broadly attached (worker) (note 10). [Abdominal segment III not reduced in size relative to segment IV.]

14. Abdominal segment IV presclerite differentiated from postsclerite (worker) (note 11). [Abdominal segment IV presclerite undifferentiated.]

\section{Notes on diagnosis}

1. Worker trait is character 1 of Rabeling et al.'s (2008) generic diagnosis.

2. The labrum of the worker is lateromedially broad, with the apical half populated by somewhat dense setae, while the basal half is glabrous except for a pair of elongate basolateral setae which are directed apicolaterally, toward the basal mandibular margins. These setae are reminiscent of the trigger-hairs of trap-jawed ants such as Strumigenys, the Daceton genus group, and the Odontomachus + Anochetus clade (although the setae of the ponerines occur on the mandibles). At first blush it seems unlikely that Martialis is a trap-jaw predator (Rabeling et al. 2008), as the most well-studied trap-jaw ants (Strumigenys, Daceton genus group, Odontomachus) all have mandibles, which are quite to very close-set compared to Martialis. This does not preclude mandibular snapping, however, as Mystrium (Moffett 1986; Gronenberg et al. 1998) and Protanilla (Hölldobler \& Wilson 1990) have mandibles capable of rapid, forceful closure. While no apparent mandibular locking mechanism has been identified for Martialis, a detailed study of its internal morphology has yet to be done. The putative trigger setae of Martialis do not resemble the trigger setae found in Protanilla (Hölldobler \& Wilson 1990).

3. Characters 3 and 4 above were treated as character 2 in the subfamilial diagnosis of Rabeling et al. (2008). Here they are considered independent.

4. Part of Rabeling et al. (2008) subfamilial character 5. 
5. In addition to Martialis, the only ants with antennal toruli situated anterior to the anterior tentorial pits are homoplastically derived in the proceratiine genera Probolomyrmex and Discothyrea (Keller 2011).

6. Rabeling et al. (2008) character 6 of the subfamilial diagnosis.

7. Character 3 of Rabeling et al.'s (2008) subfamilial diagnosis.

8. Worker trait is character 13 of Rabeling et al.'s (2008) subfamilial diagnosis

9. Part of Rabeling et al. (2008) character 14 of the subfamilial diagnosis; tergosternal fusion of abdominal segment III may be an apomorphy of the poneroids.

10. Part of Rabeling et al. (2008) character 14 of the subfamilial diagnosis.

11. Generic diagnosis character 8 from Rabeling et al. (2008).

\section{Additions to worker diagnosis of Rabeling et al. (2008)}

Note: Characters indicated here are segregated from the "Apomorphies of Martialinae ..." section above as they are of diagnostic value but are either plesiomorphies or of uncertain polarity, i.e., it is unclear whether these traits are apomorphic.

1. Scape conspicuously curved.

2. Meso- and metacoxae very closely situated (metapleuron foreshortened).

3. Metatibia with potentially glandular patch of discolored cuticle posterobasad ventroapical spur (note 1).

4. Aroliae reduced.

5. Petiolar peduncle anteriorly delimited by parabolic carina.

6. Subpetiolar process present as small anteroventral denticle.

7. Helcium axial.

8. AIII prora carinate, transverse, lip-shaped.

9. Anterior and posterior margins of AIII postsclerites not parallel in profile view, posterior margin of posttergite produced posteriorly.

10. Abdominal segments 4, 5, 6, and 7 about equal length.

\section{Note}

1. The potentially glandular patch of cuticle here identified is located on the apicoventral metatibial surface basad the tibial spur, in a similar position to the confirmed metatibial glands of other Formicidae. The cuticular patch was visible when backlit through the cleared leg of the holotype. Unlike the remainder of the leg cuticle, this patch was clearly thick and opaque. Recorded as absent by Baroni-Urbani et al. (1992), not recorded by Billen et al. (2013). Future specimens of Martialis workers should be subjected to detailed SEM and TEM study.

\section{Comments}

An attempt was made to discern the palpal count of the holotype worker, but the labrum is partially reflexed over the maxillolabial complex. It seems as if there are two maxillary palpomeres, but this could not be confirmed in any specimen orientation or lighting. The labial palps were not visible. Rabeling et al. (2008) recorded the propodeal lobes as absent in the worker; after comparative study of the male and worker it is apparent that weakly developed carinae are present in the area associated with propodeal lobes. These carinae are not obvious in perfect profile view. Their homology with propodeal lobes is uncertain.

\section{Male diagnosis}

Uniquely identified among the global fauna by the following character combination: mandibles linear, barely meeting at head midlength; clypeus reduced, with antennal toruli situated less than 1 antennal 
socket distance from anterior clypeal margin; notauli present; wing venation somewhat reduced, Ogata type IVa (five cells enclosed by tubular abscissae: costal, basal, subbasal, submarginal, and marginal cells closed); jugal lobe absent; petiolar tergum and sternum clearly fused; posterior petiolar foramen raised dorsad anterior foramen; helcium axial; abdominal segment III reduced relative to and differentiated from segment IV; abdominal segment IV with cinctus impressed yet indistinctly margined; pygostyles absent; and genitalia small, relatively unmodified.

1. Alate.

2. Mandalus enlarged (Fig. 11A-B).

3. Mandibles linear, lateral and medial margins weakly tapered to apex; barely meeting at head midline (Fig. 11A-B).

4. Palpal formula 2,1 .

5. Clypeus reduced, greatest anteroposterior length about 1.5 times antennal socket diameter; antennal toruli separated from anterior clypeal margin by less than 1 antennal socket diameter (Fig. 11A-B).

6. Anterior clypeal margin without pegs (Fig. 11A-B).

7. Anterior tentorial pits situated posteromediad antennal toruli (Fig. 11B).

8. Frontal carinae and lobes absent (Fig. 11A-B).

9. Antenna 13-merous; funiculus filiform.

10. Occipital carina reduced, not enclosing occiput.

11. Notauli present, meeting medially and extending posteriorly to transscutal line (Fig. 11C-D).

12. Scutoscutellar sulcus not ribbed (Fig. 11D).

13. Oblique mesopleural sulcus present, anterior terminus separated slightly ventrad posterolateral pronotal corner (Fig. 11C).

14. Metapleural spiracular sclerite absent (Fig. 11C).

15. Propodeal lobes present, weakly developed (Fig. 11C).

16. Metacoxal cavities narrowly closed.

17. Tibial spur formula $1 \mathrm{p}, 1 \mathrm{p}$.

18. Pretarsal claws edentate.

19. Pterostigma indistinct, nearly absent (Fig. 12A).

20. Ogata forewing venation type IVa (Fig. 12A): Submarginal cell $1+2$ closed by Rs $+\mathrm{M}+\mathrm{Mf2}-3 ; 2 \mathrm{rs}-\mathrm{m}$ present, Mf4-6 absent; marginal cell 1 closed; $1 \mathrm{~m}$-cu absent, thus discal cell 1 open; subdiscal cell 1 open.

21. Hindwing venation reduced (Fig. 12B): Only R+Rs and 1A tubular.

22. Jugal lobe absent (Fig. 12B).

23. Petiole nodiform, with indistinct posterior face; posterior foramen raised dorsally above longitudinal petiolar axis (note 1) (Fig. 11C).

24. Petiolar tergum with anterior parabolic carina (basipetiolar carina).

25. Petiolar tergum and sternum fused; laterotergite absent (Fig. 11C).

26. Petiolar tergum not forming anteroventral collar around sternum.

27. Helcium axial, broad (Fig. 11C).

28. Helcial sternite projecting ventrad lateral tergite margins.

29. Abdominal segment III weakly reduced relative to and differentiated from segment IV (Fig. 11C).

30. Prora of abdominal sternum III weak, transversely parabolic (Fig. 11C).

31. Abdominal tergum IV neither vaulted nor elongated relative to following segments (Fig. 11C).

32. Abdominal spiracle 4 exposed, 5-8 concealed by preceding tergites (Fig. 11C).

33. Abdominal sternum IX acutely triangular, apex nearly pointed; neither pronged nor toothed (Fig. 12C).

34. Pygostyles absent.

35. Genitalia small, partially exserted (Fig. 11C).

36. Cupula anteroposteriorly narrow along all faces (Fig. 12D-F).

37. Basimere continuous with telomere (Fig. 12D-H). 
38. Telomere short, digitate, extending anteroventrad beneath basimere (Fig. 12F).

39. Cuspis absent (Fig. 12E).

40. Valviceps dorsomedially fused, lobate, longer than tall, apex downturned, two sides forming tube (Fig. 12D, H).

\section{Note}

1. The posterior petiolar foramen is convergently raised above the anterior petiolar foramen in Tatuidris (Agroecomyrmecinae).

Genus Martialis Rabeling \& Verhaagh, 2008

Martialis Rabeling \& Verhaagh, in Rabeling et al. 2008: 14914. BRAZIL. Type-species: Martialis heureka, by original designation. Monotypic.

Martialis heureka Rabeling \& Verhaagh, 2008

Figs $11-12$

Martialis heureka Rabeling \& Verhaagh, in Rabeling et al. 2008: 14914, figs. 1-2 (worker). BRAZIL, Amazonas: Manaus, Headquarters of Empresa Brasileira de Pesquisa Agropecuária (EMBRAPA) Amazônia Ocidental, kilometer 28 highway AM 010, 253’'S, 5959’ W, elev. 40-50 m, 9 May 2003, ex leaf litter at dusk, primary tropical lowland rainforest. (C. Rabeling) [MZSP].

\section{Male description}

Measurements (n=3). HL 0.35-0.42, HW1 0.35-0.40, HW2 0.44-0.49, MAL 0.04-0.06, MDL 0.10 0.11, SL 0.20-0.23, PDL 0.10-0.13, A3L 0.17-0.21, AAL 0.17-0.21, EL 0.17-0.19, EW 0.14-0.17, OOD 0.14-0.15, LOD 0.04-0.05, MOD 0.04-0.05, ML 0.64-0.78, MLL 0.16-0.18, MLW 0.17-0.20, MTL 0.29-0.37, MTW 0.36-0.45, PFL 0.39-0.48, MFL 0.43-0.53, PTH 0.16-0.19, PTL 0.20-0.23.

INDICES. CI 0.94-1.02, CS 0.35-0.41, SEI 83.6-86.2, SI 55.6-58.4, EI 83.0-85.6, EYE 88.1-88.7, MI 26.7-27.8, OBI 80.1-82.8, OMI 3.46-4.74, MNI 2.00-2.26, MTI 79.9-83.2, FI 88.3-91.3, PTI 76.983.2. Small, but body variable in overall size (Fig. 11C).

HEAD (Fig. 11A-B). In full-face view head about as broad as long excluding eyes, broader than long including eyes. Palpal formula 2,1; palps short, not reaching hypostomal margin. Stipes simple, lacking carinae on medial surface. Labrum very small, medially emarginate, setose; lateral margins distant from mandibular bases by somewhat less than maximum lateromedial labrum length; labrum lacking basolateral trigger setae observable in workers. Mandibles linear, narrow; lateral and medial margins weakly tapering to apex; masticatory mandibular margin reduced, bidentate; apical tooth asymmetrical, larger than symmetrical basal tooth; mandalus enlarged, diameter equal to maximum mandible width. Clypeus reduced; anterior margin broadly emarginate; medial clypeal portion maximum anteroposterior length about 1.5 maximum antennal socket diameters; posterior clypeal margin produced between antennal toruli. Supraclypeal area arc-shaped, anteroposteriorly longer than maximum antennal socket diameter. Antennal toruli situated anteriorly, with anteriormost portion of torular arch anterad anterior tentorial pit. Frons and ocellar area bulging. Occipital carina present, weakly developed, obscured in full-face view by vertex, not enclosing occiput. Compound eyes bulging strongly; medial margin weakly convex; posterior margin weakly emarginate; compound eye narrower dorsally than ventrally. Ocelli small, situated distant from compound eye. Hypostomal margin reduced, lacking lamina. Antenna 13-merous; scape longer than maximum compound eye diameter and slightly more than $2 \mathrm{x}$ pedicel length; pedicel cylindrical, long, about $4 / 5 \mathrm{x}$ antennomere 3 length; funiculus filiform, elongate, reaching metasoma when laid against mesosoma. 
Mesosoma (Fig. 11C-D). Pronotal neck continuous with remainder of sclerite in dorsal view; main portion of pronotum swollen, muscular; anteromedian pronotal face convex in profile view, short, dorsoventral height of pronotum from pronotal neck about $1 / 3 \times$ mesoscutum height in profile view; lateral pronotal face concave. Mesoscutum broader than long in dorsal view (length $0.80-0.83 \mathrm{x}$ width); anterior and posterolateral areas swollen. Notauli distinct, crossribbed, meeting at body midline, not extending to transscutal line although narrow longitudinal line present from notauli to transscutal line. Parapsidal lines impressed, slightly divergent. Parascutal carinae nearly linear; weakly sinuate. Scutoscutellar sulcus unimpressed. Axillae small and widely situated. Mesoscutellum high and convex in profile view; not modified. Metascutellum small, lateromedial width slightly less than one half anteroposterior length; in profile view metascutellum strongly produced. Metanotal trough deep, small, circular. Mesopectus with oblique longitudinal sulcus, anterior terminus of sulcus nearly contacting posterolateral pronotal corner. Spiracular sclerite inconspicuous. Lower metapleural area strongly offset from upper metapleural area by deep, broad, margined sulcus. Metapleural gland orifice occluded; presence of internal metapleural gland not visible through metapleural sclerite. Propodeum parabolic in profile view, dorsal face about as long as and continuous with posterior face; propodeal spiracle circular, small; propodeal lobe weakly developed, carinate, clearly visible in anterolateral oblique view.

Metasoma (Fig. 11C). Petiole nodiform, pedunculate; anteriormost portion of petiolar tergum offset by parabolic carina; petiolar tergum and sternum fused, longitudinal lateral carinae not suggestive of suture; petiolar node shallow, in profile view anterodorsal face nearly linear, dorsum weakly convex, posterior face very weak; petiolar sternum linear for most of length, posteriorly narrowed, ventral petiolar surface with paired diverging carinulae; subpetiolar process absent. Abdominal segment III slightly reduced and differentiated from segment IV; helcium axial, sternal presclerite visible in profile view, not obscured by tergal presclerite; abdominal posttergite and poststernite III not fused; abdominal sternum III prora present as anterolateral bosses subtending helcium, anteromedian area of sternum concave. Abdominal terga IV-VIII and abdominal sterna IV-IX normally developed, not reduced or obscured in situ. Abdominal tergum VIII posterior margin unmodified. Abdominal sternum IX apically ligulate, narrow, posterior margin very narrowly convex, nearly triangular.

ForeWING (Fig. 12A). Tegulum reduced, subrectangular, longer than broad. Wings weakly infuscated, completely covered in fine setose layer. Pterostigma poorly-developed, only anterior enclosing abscissa tubular. Wing venation Ogata type IVa: Submarginal cell 1+2 and marginal cell 1 closed, $1 \mathrm{~m}$-cu absent, thus discal cell 1 open. Costal vein tubular to pterostigma. Rsf1 slightly more than $1 / 2 \mathrm{x}$ length of and meeting Mfl obliquely. Rs $+\mathrm{M}$ continuous with undifferentiated Mf2-3 until meeting very short 2rsm. Rsf2+3 absent. 2r-rs very long, longer than combined lengths of Rsf1 and Mf1; 2r-rs directed posteroapically, not orthogonal with anterior wing margin. Rsf4-6 tubular to Rf, enclosing marginal cell. Mf4-6 absent. Crossvein cu-a incompletely tubular, situated basad Mf1. Cuf divergent with respect to Rs $+\mathrm{M}+\mathrm{Mf2}+3$. 1A extending only slightly beyond cu-a, not enclosing subdiscal cell 1 .

HINDwING (Fig. 12B). Hindwing venation reduced, only R+Rs and $1 \mathrm{~A}$ tubular; R not reaching anterior wing margin; $1 \mathrm{~A}$ short, weakly indicated. Three hamuli present. Claval region poorly developed.

Genitalia (Fig. 12C-H). Pygostyles absent. Abdominal sternum IX spiculum short; anterior margin linear, curving posterolaterally near lateral margins; lateral margins short, slightly divergent; posterolateral margins weakly concave, tapering strongly to acute, narrowly rounded apex. Cupula dorsal and lateral faces about as broad as telomeral base; lateral face narrowing ventrally to narrow bar-like ventral face. Basimere and telomere more-or-less continuous, basimere weakly shouldered dorsomedially anterad telomeral base; dorsomedian margins of basimeres parallel for about half length of paramere; telomere acutely triangular in profile view; basimere and telomere with ventrolateral layer of posteroventrallydirected setae. Basivolsella lateromedially broad; base transversely connected with basimere; cuspis 
absent; digitus clavate, apex swollen and directed ventrally; digital stem short. Valvura short, linear, directed anteriorly and situated at about $2 / 3$ valviceps height; valviceps linear, dorsoventrally short; valviceps dorsomedially fused for most of length; in profile view dorsal valviceps margin weakly convex, ventral margin concave, edentate, valviceps apex weakly convex, subrectangular, produced ventrally; dorsolateral valviceps face convex, margined by lateral apodeme which extends almost to apex before curving ventrad and contacting ventral margin; ventrolateral valviceps face concave; phallotreme situated at aedeagal apex, sclerotic aperture formed by valviceps circular.

Coloration. Body almost uniformly brown to brownish yellow; extremities slightly lighter colored.

SCULPTURATION. Body weakly sculptured overall; head with fine piligerous punctae; mesonotal piligerous punctae coarser, posterolateral mesoscutal area above parascutal carina roughened; dorsomedian scutoscutellar area finely and densely anteroposteriorly striate; mesoscutellum weakly roughened; metascutellum with fine transverse carina subtending posteriorly produced portion of disc; mesopectus and metapleuron smooth, shining, slightly rough; propodeum finely striate, striae extending from anterior margin down along lateral faces, dorsal propodeal face weakly rugose, posterior face mostly smooth; petiole mostly smooth and shining, with lateral longitudinal carinulae; abdominal segment III mostly smooth and shining; abdominal segments posterior to segment III weakly sclerotized.

SEtation. Head, median pronotal portion including pronotal neck, mesonotum, and procoxae covered by dense layer of somewhat short, uniform, weakly curved, erect to suberect setae, longer setae present on these areas very sparsely; clypeus lacking clypeal brush of worker, although setal layer denser than on remainder of head capsule; setae sparse and subdecumbent to nearly appressed on pronotal lateral face, mesopectus, metapleuron, and propodeum; setae somewhat denser on metasoma, but not as dense as on head and mesonotal dorsum; petiolar setae elongate, linear, setae on remaining segments shorter and curved; setae on legs, including meso- and metacoxae, about as dense as on metasoma, mostly subdecumbent with a few longer suberect setae present.

\section{Distribution}

Neotropical: Known only from the Amazon basin near Manaus (Amazonas, Brazil).

\section{Discussion}

Described from a single stray worker from the Amazon just north of Manaus, Brazil, Martialis heureka Rabeling \& Verhaagh, 2008 is one of the most significant taxa in the Formicidae described in recent years. Displaying a bizarre mixture of pleisiomorphic and autapomorphic traits, the species was attributed to its own subfamily, the Martialinae. This decision was supported by further morphological study (Brandão et al. 2010) and multi-locus molecular phylogenetic reconstruction (Rabeling et al. 2008; although see Kück et al. 2011). Rabeling et al. (2008) recovered Martialis as the sister to all remaining extant ants including the Old World subfamily Leptanillinae, while a reanalysis by Kück et al. (2011) found the converse. Given this debate and the mysterious biology of the species, Martialis is of high interest. Here the male of Martialis is described for the first time based on material from the Biological Dynamics of Forest Fragments Project (BDFFP [English], PDBFF [Portuguese]) study region, about $50 \mathrm{~km}$ north of the type locality.

The male of Martialis differs from the worker by standard intercaste dimorphism, e.g., eyes welldeveloped, ocelli and notauli present, alate, flight sclerites developed, mesosoma musculated for flight, but the male also differs notably in several specific characters: mandibles far shorter, reduced relative to worker; labral trigger setae absent; clypeal brush absent; antennal toruli situated more anteriorly; forelegs weak; metatibial gland absent; petiolar node weakly developed; helcium broader; abdominal tergum and sternum III of equal length; cinctus between pre- and postsclerites IV not developed. On 
the other hand, the male of Martialis displays numerous similarities with the worker, such as linear mandibles, reduced palpal count (although worker count unconfirmed, but certainly less than 3,3), clypeus poorly developed, anterior tentorial pits posteriorly-situated, antennal toruli well-developed (but not quite as cup-like as in worker), scapes long, pedicel elongate, frontal carinae absent, propodeal lobes weakly developed (contra the initial worker diagnosis), tibial spur formula 1,1, basipetiolar carina present, petiolar tergum and sternum fused, abdominal segment III differentiated from IV, and sculpture and setation remarkably similar, although the somatic sclerites of the male are generally less strongly sclerotized. The two castes are similar in several other specifics, but this brief list captures most of the significant features.

Specimens were examined from collecting events in January, February, April, and October of 1985. The BDFFP study region displays weak seasonality of rainfall and day length, with the months of June through December roughly representing the "dry season", July through September being the driest (Bierregaard Jr. et al. 2001). It is possible that Martialis flights occur year-round, although the sampling of BDFFP material examined for this study is too small to confidently assert the flight phenology. While the range of Martialis has only been extended by about $50 \mathrm{~km}$ by the discovery of the male, the quantity of males recovered exceeds that of workers by an order of magnitude ( 25 males $v s .3$ workers). Thus, Martialis may be recovered via alates more readily than workers. The use of Malaise traps and flight intercept traps should be encouraged for studies of ant diversity, particularly for species with cryptic habits. Although our knowledge of flight phenology is poor, tropical rainforests may be particularly amenable to these studies due to the relatively more year-round flights of Neotropical (Kaspari et al. 2001a, 2001b) than of Nearctic ants (Dunn et al. 2007).

As the Manaus region is considered the ecological "crossroads" of the Amazon where a high proportion of species ranges overlap (Bierregaard Jr. et al. 2001), it will be valuable to sample for Martialis in other Amazonian regions. Moreover, it is of interest whether the fragmented populations of Martialis in the BDFFP plots have survived the intervening 30 years. This may not be the case, as ant communities have been observed to hemorrhage in BDFFP study plots (Vasconcelos et al. 2001), although hypogaeic ants may be less sensitive to habitat changes than epigaeic ants. The placement of the Malaise samples relative to the edges of the study plots is unknown. As well, the gyne of Martialis remains unknown. It is possible that this caste will be ergatoid, but the presence of alate gynes cannot be ruled out. In general, the male of a given ant species is more frequently collected via Malaise traps than females; thus it is possible that although only males were encountered, alate gynes could still be present. Regardless, the natural history of Martialis will be fascinating to uncover.

\section{Material examined}

Holotype worker examined at MZSP. Specimen was cleared by non-destructive extraction of DNA, which allowed for examination of internal characters. All males were examined from the following collecting events at the Fazenda Esteio study area of the Biological Dynamics of Forest Fragments Project in Amazonas, Brazil, with an elevation of about $90 \pm 10 \mathrm{~m}$, collected by Bert Klein (WWF) via Malaise trap in 1985: Plot 1112 "Cidade Powell", $2.38692^{\circ} \mathrm{S}, 59.87494^{\circ} \mathrm{W}, \pm 100 \mathrm{~m}, 26$ Feb. (5 specimens) and 1 Oct. ( 1 specimen), 1 hectare Amazonian rainforest fragment; plot 1208 "Cidade Powell”, $2.37204^{\circ} \mathrm{S}, 59.87252^{\circ} \mathrm{W}, \pm 250 \mathrm{~m}, 22$ Oct. (1 specimen), 10 hectare Amazonian rainforest fragment; plot 1301 "Florestal", $2.38897^{\circ} \mathrm{S}, 59.85012^{\circ} \mathrm{W}, \pm 500 \mathrm{~m}, 23$ Jan. (4 specimens), 24 Apr. (7 specimens), and 2 Oct. (7 specimens), 100 hectare Amazonian rainforest fragment. (Note: data extrapolated from Bierregaard Jr. et al. 2001, and PDBFF \& INPA-SI 2014; latitude and longitude recorded from Google Earth with error estimates to account for uncertainty of exact plot location; half the male material examined remains at INPA.) 
BOUDINOT B.E., Contributions to the Formicidae
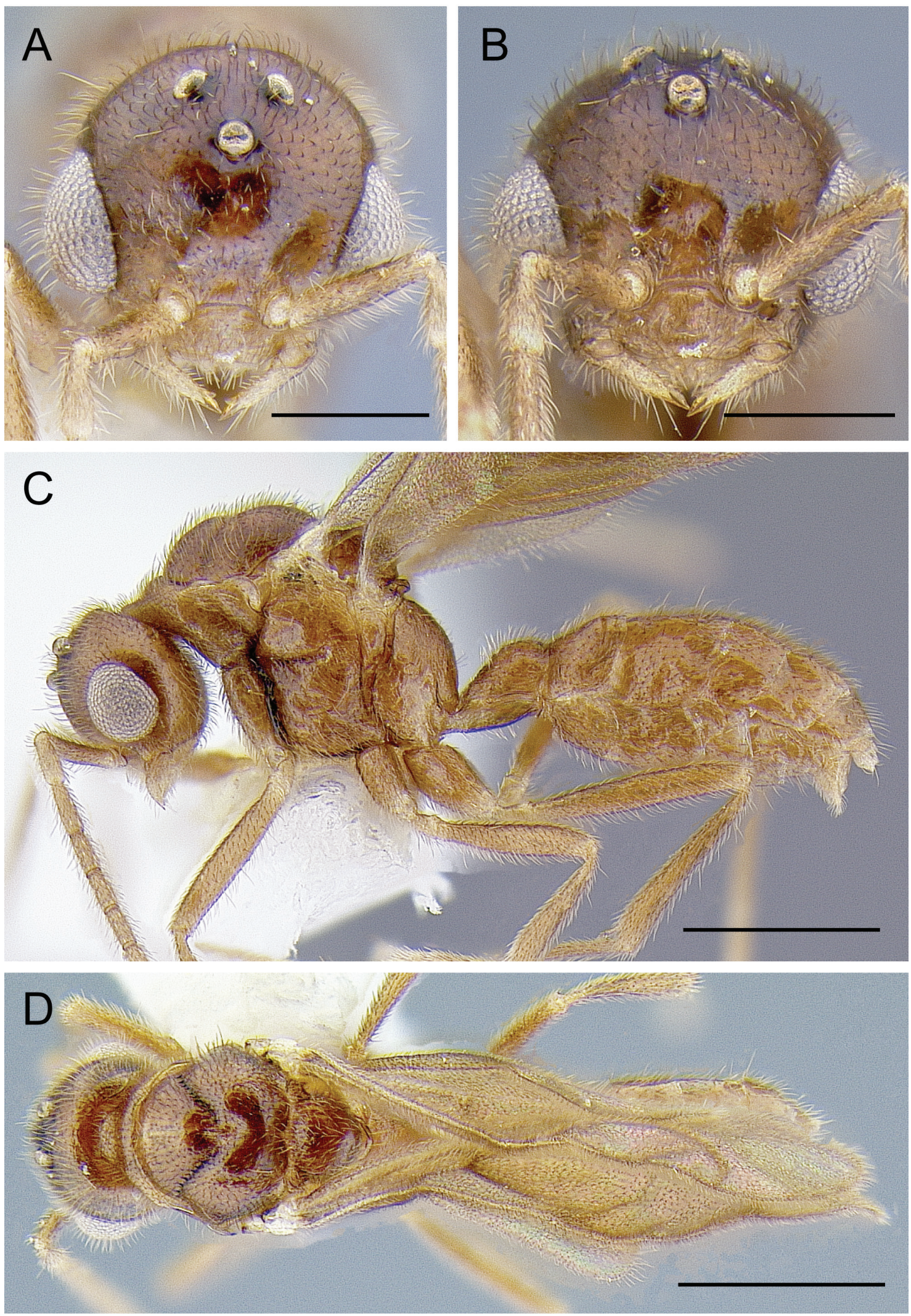

Fig. 11. Martialis heureka Rabeling \& Verhaagh, 2008, male, photomicrographs. A. Head, frontal view. B. Head, anteroventral oblique view. C. Body, lateral view. D. Body, dorsal view. Scale bars: A-B $=0.2$ $\mathrm{mm}, \mathrm{C}-\mathrm{D}=0.5 \mathrm{~mm}$. 

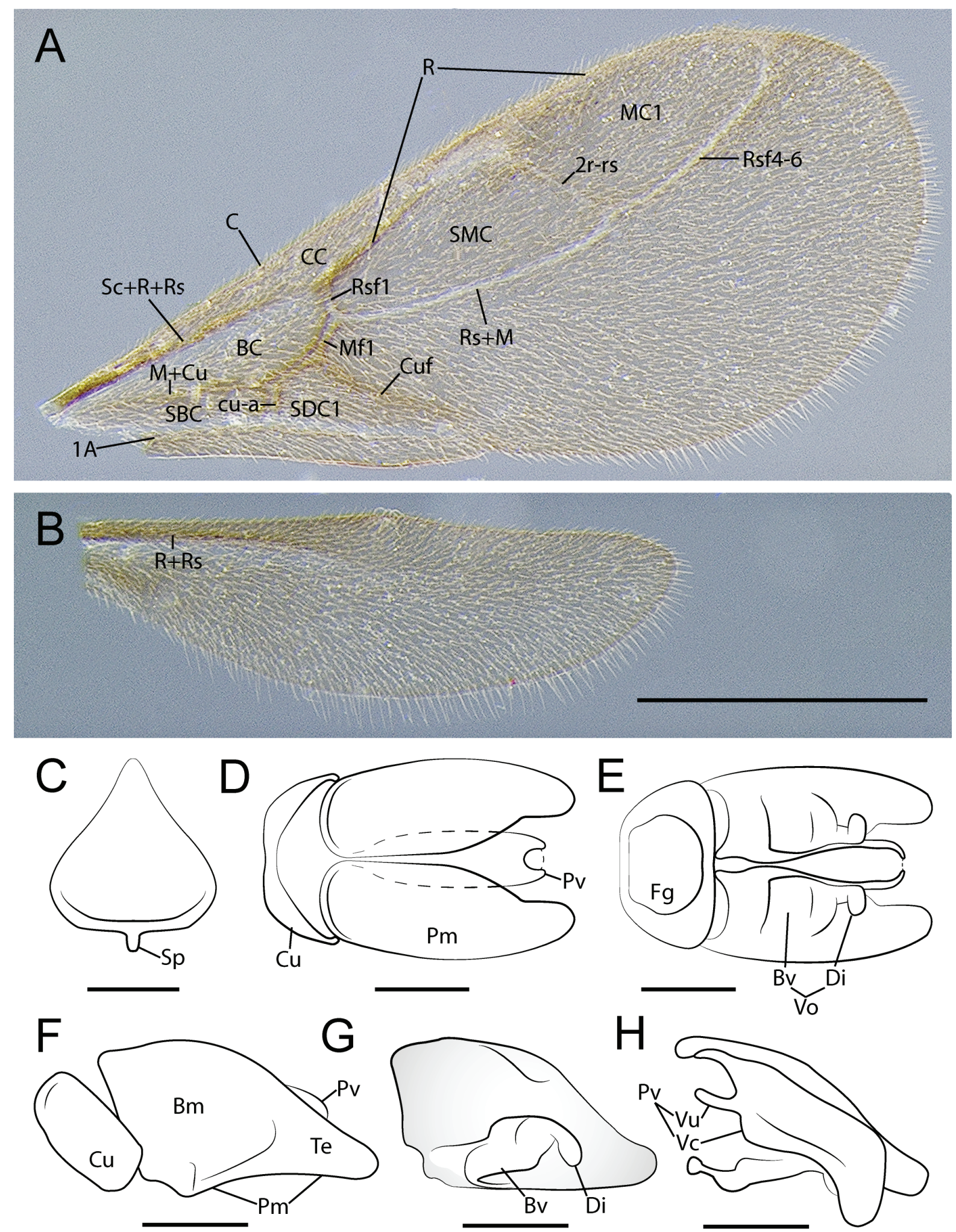

Fig. 12. Martialis heureka Rabeling \& Verhaagh, 2008, male, wing photomicrographs and genitalia illustrations, genital membranes not shown. A. Forewing. B. Hindwing. C. Abdominal sternum IX, ventral view. D. Genital capsule, dorsal view. E. Genital capsule, ventral view. F. Genital capsule, lateral view. G. Volsella and paramere, mesal view. H. Penisvalva in situ, mesal view. Scale bars: A-B $=0.5$ $\mathrm{mm}, \mathrm{C}-\mathrm{H}=0.1 \mathrm{~mm}$. Abbreviations: see Material and Methods. 


\section{Shared apomorphies of the basal ants}

Of particular interest for the "basal ant" problem (Brady et al. 2006; Rabeling et al. 2008; Kück et al. 2011) is the relationship of the Leptanillinae, Martialinae, and the Amblyoponinae. While the relationships within the formicoid clade (Dorylinae, myrmeciomorphs, dolichoderomorphs, Formicinae, ectaheteromorphs, Myrmicinae) have crystallized in the past decade (Moreau et al. 2006; Brady et al. 2006, 2014; Ward et al. 2015), the relationships of the "poneroids" (Agroecomyrmecinae, Amblyoponinae, Paraponerinae, Ponerinae, and Proceratiinae) are still unresolved (Ward 2014). The poneroids may constitute a clade or a grade, depending on placement of the root on the ant tree of life (Brady et al. 2006).

The dilemma of rooting the ant tree of life was highlighted by the discovery of $M$. heureka, which has been recovered as sister to the remainder of the extant Formicidae (Rabeling et al. 2008), a result contested by Kück et al. (2011), who recovered Leptanillinae as sister to the extant Formicidae. These results not only disagree in topology, but may be subject to the biases of long-branch attraction and CG-bias (Ward 2014). As summarized by Ward (2014), one of the major questions of ant systematics is whether Martialis and/or the Leptanillinae are sister to the extant Formicidae or whether they are highly derived poneroids. Unpublished molecular phylogenetic analyses by P.S. Ward (discussed in Ward 2014), in which the outgroups are excluded, recover Martialis and the Leptanillinae as part of a bipartition comprising part of the poneroids; moreover, these analyses recover Opamyrma as sister to the Leptanillinae. Considerable uncertainty thus exists, even with molecular data. The present work seeks, in part, to render this problem more tractable by providing novel morphological characters that are shared by Martialis, Apomyrma, Opamyrma, the Leptanillinae, and the Amblyoponinae.

The male of Martialis is more generalized morphologically than most Leptanillinae, although some Protanilla display a mosaic of generalized and specialized characteristics. Martialis males differ from all known male Leptanillinae by the following characters: mandibles linear, meeting at head midline, bidentate apically; antennal toruli situated posterad anterior portion of antennal torulus; lower metapleuron dorsoventrally longer than anteroposteriorly broad; metanotal trough pit-like (vs. oblong); propodeal lobe present; first submarginal cell enclosed by tubular abscissa; marginal cell 1 closed; petiole pedunculate; genitalia more generalized. The worker of Martialis is superficially similar to Protanilla and Anomalomyrma. The natural history of all three of these taxa is virtually unknown.

Male Martialis, in comparison with those of the Amblyoponinae, excluding Apomyrma, differ by lacking several amblyoponine apomorphies, such as the anteroventral petiolar tergum collar, modified peg-like setae on clypeus and labrum. Martialis further differs from the Amblyoponinae without Apomyrma by the following characters: mandibles linear (rather than curved and subfalcate); clypeus reduced; antennal toruli strongly developed, conspicuous (vs. inconspicuous); metascutellar trough pit-like; petiolar tergum and sternum fused; helcium axial; and helcial sternite projecting ventrad helcial tergite in profile view.

The male of the amblyoponine Apomyrma, however, displays several characters that are on the one hand very leptanilline in nature and on the other are similar to Martialis. Apomyrma has reduced, nub-like mandibles, lacks propodeal lobes, and has an infraaxial petiole, as in the Leptanillinae. Additionally, the pro- and mesonotum is elongated, similar to most of the Leptanillini. The petiole of Apomyrma is unlike other Amblyoponinae, as it is infraaxial and lacks the anterior tergal collar, but the petiole differs from Martialis in being tergosternally unfused. Unlike Martialis, Apomyrma has a distinct metapleural gland orifice and short, robust legs. Martialis is easily distinguished from Apomyrma. The male of Opamyrma is unknown, but would inevitably be valuable to describe and compare.

Are the workers of Apomyrma, Opamyrma, and the Leptanillinae convergently similar due to subterranean habits? Nothing is known yet of the habits of Martialis. The workers are superficially similar to the 
Sphecomyrminae in mesosoma and metasoma form relative to the Leptanillinae and Amblyoponinae, although several sphecomyrmine genera have peg-like setae as in the Amblyoponinae. Martialis males are superficially similar to males tentatively identified as Sphecomyrma (Grimaldi et al. 1997), differing mainly in having antennae situated anteriorly, reduced venation, tergosternal petiolar fusion, a tibial spur formula of 1,1, and having abdominal segment III reduced. The extinct genus Baikurus differs similarly, except the mandibles are curved and palps are longer; the petiole is not visible in the specimen illustrated by Grimaldi et al. (1997).

Below is presented a list of apparent morphological apomorphies shared among the Amblyoponinae (excluding Apomyrma and Opamyrma), Martialinae, Apomyrma, Opamyrma, and Leptanillinae, with groups presented by increasing qualitative similarity. Pleisiomorphic conditions are presented in brackets next to the respective apomorphic conditions.

Apomorphies shared among all five taxa:

1. Compound eyes reduced (worker) (note 1). [Compound eyes not reduced in most Formicidae.]

2. Petiole anteriorly tergosternally fused (worker, gyne) (note 2). [Petiole anteriorly tergosternally unfused in Formicidae.]

Notes:

1. Proposed by Ward (1994) as a putative synapomorphy of the Amblyoponinae, Leptanillinae, and Apomyrma, but prone to homoplasy.

2. Ward (1994) proposed this as a putative synapomorphy of the Amblyoponinae, Leptanillinae, and Apomyrma.

Apomorphies shared by Martialis, Opamyrma, Apomyrma, and the Leptanillinae:

1. Frontal carinae lost (worker, gyne) (note 1). [Frontal carinae present, lobe-like in Amblyoponinae and other poneroids, excepting Proceratiinae.]

2. Antennal toruli directed dorsally or anterodorsally rather than laterally (female castes) (note 1). [Antennal toruli directed more-or-less laterally in Amblyoponinae and other poneroids, excepting Proceratiinae.]

3. Compound eyes completely absent (worker). [Compound eyes present in most Formicidae.]

4. Occiput enclosed by occipital carina (worker, gyne) (note 2). [Occipital carina not enclosing occiput in other Formicidae.]

5. Occiput enlarged, such that it is visible in full-face view (worker, gyne). [Occiput smaller, not visible in full-face view in other Formicidae.]

6. Parascutal carina situated very low on mesoscutum, almost completely obscured by wing base and thus inconspicuous (male). [Parascutal carina raised on mesoscutum, near height of mesoscutal dorsum, only partially obscured by wing base, conspicuous; in Formicidae.]

7. Spiracular sclerite absent, metapleural spiracle unconcealed (male) (note 3). [Spiracular sclerite present, concealing metapleural spiracle; in Formicidae.]

8. Pygostyles absent (male) (note 4). [Pygostyles present for Formicidae; see note below.]

9. Valviceps linear to arched, with concave ventral and convex dorsal margin in ectal view (male). [Valviceps more-or-less elliptical, with both dorsal and ventral margins convex in ectal view in other poneroids.]

10. Valviceps lateral apodeme evenly linear, extending almost to valviceps apex before curving ventrad, delimiting convex dorsolateral and concave ventrolateral face (male). [Lateral apodeme sinuate, wavy, extending to valviceps apex but not curving ventrad; dorsolateral and ventrolateral faces more or less flat in other poneroids.]

11. Valviceps ventral margin edentate (male) (note 5). [Valviceps ventral margin dentate in other poneroids.] 
12. Valviceps dorsomedially fused (male). [Valviceps unfused and articulating dorsomedially in most other Formicidae.]

13. Characters of the sting apparatus (worker, gyne) (note 6).

Notes:

1. Also observed in Dorylinae.

2. The genus Apomyrma is an exception as no occipital carina occurs.

3. The spiracular sclerite has been lost in various lineages of Formicidae, including the entire Myrmicinae and Tatuidris.

4. Pygostyles have been lost in numerous lineages of Formicidae and thus constitute a relatively weak character. Within the poneroid group, the Agroecomyrmecinae, Ponerinae, and Paraponerinae retain pygostyles; in the Proceratiinae, only Probolomyrmex has lost pygostyles. The Amblyoponinae are somewhat more complicated, with loss of pygostyles occurring at least twice: one or more times in the XMAS clade (Myopopone, Mystrium + Xymmer), and once outside of the XMAS clade. Pygostyles are retained in the OCP clade and in Stigmatomma and Adetomyrma of the XMAS clade, thus spanning the root of the Amblyoponinae. In formicoids, loss of the pygostyles has been adduced as an apomorphy of the Dorylinae (Bolton 1990c). The bizarre, elongate, filamentous structures of some unassociated leptanilline males are, amazingly, appendages of the basimere (Fig. 10D).

5. Absence of ventral valviceps teeth has evolved several times, including the amblyoponine genus Adetomyrma (Yoshimura \& Fisher 2012b).

6. Kugler (1992) indicated as synapomorphic a set of sting apparatus characters applying to Apomyrma, Protanilla, and Leptanilla; these characters also seem to occur in Martialis. These characters are, in short, lack of medial lobe on quadrate plate, fulcral arm short and lacking lateral extensions. Notably, the anal plate of Apomyrma and Protanilla is absent and no anal plate was found for Martialis (Brandão et al. 2010); this may, however, be an artefact of the poor preservation of the Martialis specimen examined by Brandão et al., and waits to be confirmed for Protanilla (Kugler 1992). The present author admittedly has insufficient expertise with the sting apparatus to critically evaluate these characters, however. Future researchers are encouraged to examine the sting apparati of the poneroids, as knowledge of this group is poor (Kugler 1992) and as understanding the sting apparatus might assist in providing a more detailed picture of the evolution of the early branching ant lineages.

Apomorphies shared by Opamyrma, Apomyrma, and the Leptanillinae:

1. Lateral bases of mandibles set deep in pits, suggestive of a trap-jaw mechanism (female castes). [Pleurostoma posterad mandibular insertion without a deep pit for reception of mandible; mandibles without trap-jaw mechanism in other poneroids, excepting Mystrium.]

2. Clypeus raised dorsally, distinctly margined posteriorly (worker, gyne). [Clypeus flush with frons, lacking posterior margination in other Formicidae.]

3. Entire clypeus anteriorly produced (not just median portion), with rectangular anterolateral margins (worker, gyne) (note 1). [Clypeus not produced anteriorly; anterolateral corner obtuse in other Formicidae.]

4. Labrum with peg-like setae (worker, gyne) (note 2). [Labrum without dentiform setae in other Formicidae, excepting Amblyopone.]

5. Thickened setae present on ventromedial mandibular face (worker, gyne). [Thin setae present on ventromedial mandibular face in other poneroids, with some exceptions.]

6. Male mandibles strongly reduced, nub-like (male) (note 3). [Mandibles long, falcate to linear in Amblyoponinae and Martialis.]

7. Basivolsella lateromedially narrow in ventral view (male) (note 4). [Basivolsella lateromedially broad in ventral view in other poneroids, excepting various proceratiine species.] 
8. Digital stem elongate and strongly arched (male) (note 4). [Digital stem short, linear to weakly curved in other Formicidae.]

9. Larva elongate, slender, and club-shaped ("leptanilloid" in terminology of Wheeler \& Wheeler 1976) (note 5). [Larva pogonomyrmecoid, myrmecioid, or platythyreoid in other poneroids; see Wheeler \& Wheeler 1976 for definition of larval forms.]

Notes:

1. The clypeus of Leptanilla is strongly produced as a subrectangular median process in addition to the anterior clypeal migration.

2. Polymorphic in Leptanillinae: present at least in Anomalomyrmini. Also present in Amblyopone, Onychomyrmex.

3. Mandibles secondarily elongated in Noonilla and enlarged in Scyphodon.

4. The genitalia of Leptanillinae are subject to extreme modification, but this state is visible in species with more-generalized genitalia. The male of Opamyrma is unknown.

5. May apply to Martialis; larval caste unknown for Martialis and Opamyrma.

Apomorphies shared by Opamyrma and Apomyrma:

1. Promesonotal flexion extreme (worker, gyne?) (note 1). [Promesonotal articulation flexible, but not enhanced.]

2. Propleurae bulging in profile view (worker, gyne?) (note 2). [Propleurae flat, only weakly produced anteriorly beyond pronotum, if at all.]

3. Scapes clavate (worker, gyne?).

4. Petiolar tergum extending anteroventrally and fusing medially, forming collar (worker, gyne?) (note $3)$.

Notes:

1. Promesonotal flexion is enhanced in other Formicidae, including some Leptanilloides (Dorylinae), and the Leptanillini.

2. Also present in Leptanillini, Xymmer (Amblyoponinae), and Leptanilloides.

3. The tergal-tergal fusion "collar" around the petiolar base is not present in the male of Apomyrma, whereas such a collar is present in both the male and worker of Xymmer.

\section{Brief global diagnoses of subfamilies, based on males}

\section{Note}

The treatment of the subfamilies below follows the current systematic classification of the Formicidae (Bolton 2003; Brady et al. 2006, 2014; Ward et al. 2015). The subfamilies are organized by the systematic results of Brady et al. (2006) and Ward et al. (2015), with the "poneroids" in alphabetical order first, followed by the formicoid clade comprised of the Dorylinae, myrmeciomorph clade (Myrmeciinae, Pseudomyrmecinae), dolichoderomorph clade (Aneuretinae, Dolichoderinae), Formicinae, ectaheteromorph clade (Ectatomminae, Heteroponerinae), and Myrmicinae.

Subfamily Agroecomyrmecinae Carpenter, 1930

Figs 5F, 13A-B

\section{Diagnosis}

Uniquely identified globally by petiolation of abdominal segment III (post petiole) and supraaxial helcium. Furthermore, the petiolar comformation seems to be globally unique, with the posterior petiolar foramen raised completely dorsad the anterior foramen. Identification may be confirmed with the following combination of characters: mandibles reduced, edentate; antennal toruli situated distant 
from anterior clypeal margin; antenna 12-merous; meso- and metatibia with one ventroapical spur each; forewing with five closed cells; jugal lobe absent; petiolar tergum and sternum distinct; abdominal segment IV pre- and postsclerites separated by cinctus; abdominal tergum IV vaulted; abdominal tergum VIII not spiniform; abdominal sternum IX apex rounded.

\section{Comments}

Two extant genera are known in the Agroecomyrmecinae, the Neotropical Tatuidris and Afrotropical Ankylomyrma (Ward et al. 2015). The male of Ankylomyrma is unknown and will be a notable discovery.

Subfamily Paraponerinae Emery, 1901

Figs 1, 2C, 3C, 4D, 13C-D

\section{Diagnosis}

The hatchet-shaped petiole (Fig. 4D) and the morphology of abdominal sternum IX are both globally unique among the Formicidae. The ninth abdominal sternum of Paraponera is strongly produced posteriorly as an apically bidentate linear process. These characters may be supplemented by the following combination: mandibles triangular, unidentate; clypeus well-developed, antennal toruli situated distant from anterior clypeal margin; antenna 13-merous; meso- and metatibiae with two ventroapical spurs each; eight closed cells present on forewing; jugal lobe present; petiolar tergum and sternum distinct; abdominal segment IV pre- and postsclerites separated by cinctus; abdominal tergum IV not vaulted; abdominal tergum VIII not spiniform.

\section{Comment}

One species of the Paraponerinae is extant, Paraponera clavata. This species dwells in rainforests and is known from Honduras through Central America into tropical South America.

Subfamily Ponerinae Lepeletier de Saint-Fargeau, 1835

Figs 4C, 5H, 6B, D-E, I, 7D, 13E-F

\section{Diagnosis}

Ponerinae share the following characters: antennal toruli situated well-posterad anterior clypeal margin (except Dolioponera); at least 4 closed cells present on forewing (Dolioponera with 3); propodeal lobes usually present; jugal lobe usually present; petiolar tergum and sternum distinct; cinctus between abdominal pre- and posttergites IV usually present; and abdominal sternum IX unpronged and edentate. Three final sets of characters are required for identification: 1) (Platythyreini) mandibles triangular, tibial spur formula 2,2; 2) (Ponerini) mandibles spatulate, linear, or nub-like and mesonotum not anteriorly elongated; and 3) (Ponerini, Dolioponera) forewing with three closed cells, propodeal lobes present, antennal toruli situated at anterior extreme of head, oblique mesopleural sulcus absent, and cinctus present. The eighth abdominal tergum of male Ponerinae may be spiniform, a unique state among the Formicidae, but this character is not present in all genera and may be interspecifically variable. The spur formula of Ponerini is variable.

\section{Comments}

The Ponerinae is global in distribution and has recently been provided a molecular phylogeny (Schmidt 2013) and a global generic revision (Schmidt \& Shattuck 2014), which did not treat males; the subfamily is now comprised of 47 valid genera. Males are unknown for 9 genera (Asphinctopone, Austroponera, Boloponera, Feroponera, Fisheropone, Iroponera, Loboponera, Odontoponera, Promyopias); the males of Belonopelta, Emeryopone, Myopias and Simopelta will be described in forthcoming publications (B. 
Boudinot in prep. and R.S. Probst et al. in prep.). The male of Dolioponera was discovered by the author during the review period of the present work.

Unlike the female castes, which have the lateral torular arch fused with the frontal carina (Bolton 2003), no single character was found to distinguish male Ponerinae from other subfamilies. The Platythyreini and Ponerini share numerous characteristics but are easier to key separately due to the informatively variable development of male mandibles. The Ponerini themselves are challenging to key as the males of some genera are highly derived, such as Simopelta, which lacks the mesopleural sulcus and the cinctus of abdominal segment III, and Dolioponera, which also lacks the mesopleural sulcus and has the antennal toruli situated near the anterior head margin. A polythetic definition of the Ponerini is thus required. Fortunately, some of the derived character states of the Ponerini also serve to distinguish them from the "generalized" ants, including the Formicinae and Dolichoderinae.

Yoshimura \& Fisher (2007) and previously Yoshimura \& Onoyama (2002) used the scutoscutellar sulcus and conformation of the mesopleural sulcus to diagnose the Ponerinae for the Malagasy and Japanese regions, respectively. These structures are variably developed on the global level, with several genera presenting unsculptured scutoscutellar sulci, and as noted above the mesopleural sulcus is not always present. In general, presence of the abdominal segment III cinctus is more stable than these sulci. Understanding the generic boundaries of male Ponerinae will be most difficult in the Afrotropics, where the most genera occur and where the least number of genera have males described. A key to the New World genera, including Ponerinae, is in the works (B. Boudinot, in prep.).

Subfamily Proceratiinae Emery, 1895

Figs $6 \mathrm{~A}, 14 \mathrm{~A}-\mathrm{B}$

\section{Diagnosis}

All proceratiine genera share the following characters which are required for identification: oblique mesopleural sulcus present; mesotibia with one or no apicoventral spurs, metatibia with one apicoventral spur; propodeal lobe present; three to five closed cells present on forewing; jugal lobe absent; petiolar tergum and sternum distinct; abdominal sternum IX unpronged and edentate. Two conditional sets of characters are required in conjunction with those indicated above: 1) if mandibles triangular then antennal toruli situated well-posterad anterior clypeal margin and crossvein 1m-cu absent; and 2) if mandibles reduced then antennal toruli situated at or produced anterad anterior clypeal margin; $1 \mathrm{~m}-\mathrm{cu}$ may be present or absent. Additionally, proceratiine males may or may not have vaulted fourth abdominal terga, and the eighth abdominal tergum is never spiniform.

\section{Comments}

Yoshimura \& Fisher's (2009) key to the Malagasy Proceratiinae has global applicability. The three genera of Proceratiinae, Discothyrea, Probolomyrmex, and Proceratium, seem to be well-defined taxa.

Subfamily Dorylinae Leach, 1815

Figs 5A-B, E, 6C, 14C-D

\section{Diagnosis}

Most Dorylinae are uniquely identified by the bidentate or pronged ninth abdominal sternum, lack of pygostyles, and poorly developed clypeus. Males of the Leptanilloides genus group are highly derived and are identifiable by the following combination of characters: antennal toruli abutting or very nearly abutting anterior clypeal margin; oblique mesopleural sulcus absent; four closed cells present on forewing; cinctus between abdominal pre- and postsclerites IV absent. 


\section{Comments}

The males of the Dorylinae have a long history of treatment due to the conspicuousness and remarkable morphology of several constituent genera (Dorylus, Aenictus, Anictogiton, the Eciton genus group). Indeed, the first male-based ant taxon described was Dorylus helvolus (L., 1764). The concept of the Dorylinae has shifted greatly over the past two hundred years; a very recent molecular phylogeny (Brady et al. 2014) has redefined the Dorylinae in a broad sense, including the formerly accepted subfamilies (as of Bolton 2003) Aenictinae, Aenictogitoninae, Cerapachyinae, Ecitoninae, and Leptanilloidinae, which themselves include several family-level synonyms. Little further will be said of the Dorylinae here as a generic revision of the subfamily is being prepared which will treat both males and females, and which will significantly clarify the generic limits of this diverse subfamily (M.L. Boroweic, in prep.).

Subfamily Myrmeciinae Emery, 1877

Figs $5 \mathrm{C}-\mathrm{D}, 6 \mathrm{H}, 14 \mathrm{E}-\mathrm{F}$

\section{Diagnosis}

Uniquely identified by the combination of petiolation of abdominal segment III (Myrmeciini), retention of the jugal lobe and of two ventroapical spurs on each meso- and metatibia, and complete fusion of the petiolar tergum and sternum anteriorly (Prionomyrmecini). The third abdominal segment of the male of Nothomyrmecia (Prionomyrmecini) is incompletely petiolated, although it is still recognizable by the other states indicated above.

\section{Comment}

Extant Myrmeciinae are restricted to Australia and New Caledonia, and are comprised of two monogeneric tribes, Myrmeciini (Myrmecia) and Prionomyrmecini (Nothomyrmecia). Ward \& Brady (2007) provided keys to the extant and extinct genera of Myrmeciinae, including males, although the two extant genera may also be separated by the key presented above.

Subfamily Pseudomyrmecinae M.R. Smith, 1952

Figs 5B, E, 15A-B

\section{Diagnosis}

Pseudomyrmecine males are uniquely identified by the absence of the jugal lobes in combination with the following character combination: cuticle soft, flexible, weakly-sculptured; frontal carinae inconspicuous or absent; meso- and metatibia each with two ventroapical spurs; more than three forewing cells closed; abdominal segment III petiolated; abdominal sternum IX unpronged.

\section{Comments}

The Pseudomyrmecinae is comprised of three genera, the widespread New World Pseudomyrmex, the Amazon endemic Myrcidris, and the Old World genus Tetraponera. Ward (1990) provided a male-based key to the genera for the subfamily.

\section{Subfamily Aneuretinae Emery, 1913}

Figs $7 \mathrm{~A}, 15 \mathrm{C}$

\section{Diagnosis}

The male of Aneuretus simoni is uniquely identified by the exceedingly long and thin petiolar peduncle and the unpetiolated third abdominal segment. The species is further identified by the following combination of characters: oblique mesopleural sulcus present; seven closed cells present on forewing; jugal lobe absent; abdominal segment IV without cinctus between pre- and postsclerites; abdominal 
sternum IX unpronged and edentate; telomere extending anteroventrad basimere. Additional characters for distinguishing A. simoni from the Dolichoderinae and Formicinae are indicated in couplets 19 and 20 above.

\section{Comments}

The sole extant member of the Aneuretinae, A. simoni, is restricted to Sri Lanka, and is the survivor of a lineage which has a somewhat diverse fossil record (LaPolla et al. 2013). The subfamily is of considerable interest as it is sister to the Dolichoderinae (Brady et al. 2006). Eight fossil genera are ascribed to the Aneuretinae based on the work of several authors (e.g., Dlussky \& Rasnitsyn 2009). Some taxa, based on workers, are definitely members of the Aneuretinae, i.e., $\uparrow$ Paraneuretus and $\dagger$ Protaneuretus from Baltic amber (37-42 My; Wheeler 1915; LaPolla et al. 2013), while others are less certain, i.e., $\uparrow$ Pityomyrmex (also from Baltic amber, Wheeler 1915; placed in Aneuretinae by Dlussky \& Rasnisyn 2009) and $\uparrow$ Aneuretellus (Sakhalin amber, 56-59 My; Dlussky 1988; LaPolla et al. 2013). The impression-fossil taxa $\uparrow$ Britaneuretus (see Antropov et al. 2014) and $\uparrow$ Mianeuretus (see Carpenter 1930) may not be members of the Aneuretinae. Because of the occurrence of definitive aneuretines in Baltic amber, it will be critical to carefully study the reproductives occurring in these fossils to determine whether any may be placed in the Aneuretinae.

Two fossil "aneuretine" taxa are worth discussing specifically. The affinities of $\uparrow$ Burmomyrma $(\sim 98 \mathrm{My}$, Burmese amber; Dlussky 1996; LaPolla et al. 2013) and †Cananeuretus (78-19 My, Canadian amber; Engel \& Grimaldi 2005; LaPolla et al. 2013) with Aneuretus simoni are uncertain. The description and illustration of $\uparrow$ Burmomyrma in Dlussky (1996) provide no characters which support a relationship of the fossil taxon with Aneuretus; the diagnosis includes one extreme autapomorphy and several characters which are pleisiomorphic for the family or are broadly shared among several subfamilies. The character combination indicated by Dlussky (1996) to assign †Burmomyrma to the Aneuretinae is weak, especially given that Aneuretus has complete ("ancestral") wing venation while $\uparrow$ Burmomyrma lacks almost all vein abscissae. Placement of $\uparrow$ Burmomyrma within the Leptanillinae, and indeed other aculeate hymenopteran families, cannot be ruled out. No taxonomic action is taken here, however.

$\dagger$ Cananeuretus, on the other hand, cannot be so easily considered distantly related to the Aneuretinae. The Grassy Lake deposit of Canadian amber includes representatives of the Sphecomyrminae, Ectatomminae, and critically, the Dolichoderinae (LaPolla et al. 2013). While the placement of the fossil dolichoderine $\dagger$ Chronomyrmex (see McKellar et al. 2013) in the Leptomyrmecini (sensu Ward et al. 2010) is debatable, co-occurrence of these subfamilies in this deposit suggests the placement of $\uparrow$ Cananeuretus is plausible. As the diagnosis of the Aneuretinae provided here and previously (Wilson et al. 1956; Bolton 2003) is based largely on pleisiomorphic characters, other characters should be considered. For example, future studies of Canadian amber should be sensitive to specific traits occurring in Aneuretus and extant Dolichoderinae. Aneuretus shares, among other characters, a deep median notch on the anterior clypeal margin and fine serrations intercalated among larger denticles on the masticatory mandibular margin, both of which occur in the Tapinomini, the tribe sister to the remaining Dolichoderinae (Ward et al. 2010). Reconsideration of the fossil record of Aneuretinae will be valuable for improving our concepts of both the Aneuretinae and Dolichoderinae.

Subfamily Dolichoderinae Forel, 1878

Figs 7E, 15D-E

\section{Diagnosis}

The Dolichoderinae are uniquely identified by the telomere, which is strongly reduced and does not extend anteroventrad the basimere. Males of the subfamily are further identified by the following combination of characters: oblique mesopleural sulcus present; seven or fewer closed cells present on forewing; jugal lobe absent; petiolar peduncle short or absent; abdominal segment III unpetiolated; 
abdominal segment IV without cinctus between pre- and postsclerites; abdominal sternum IX unpronged and edentate. Additional characters for distinguishing males of the Dolichoderinae from the Aneuretinae and Formicinae are indicated in couplets 19 and 20 of the key above.

\section{Comments}

The Dolichoderinae is one of the major ant lineages, with over 700 described species distributed in 28 valid genera. Males are unknown for four genera (Ecphorella, Gracilidris, Loweriella, Nebothriomyrmex). One of the historically intractable problems of myrmecology has been the separation of male Dolichoderinae and Formicinae. Here, the telomeral character described by Yoshimura \& Fisher (2011) is confirmed as a diagnostic synapomorphy of the subfamily on a global scale, while the antennal torulus to clypeus distance character was first described to the author's knowledge in Czechowski et al. (2012). Several other characters were found to distinguish male Dolichoderinae and Formicinae, as indicated in the key and this diagnosis. Genera of Dolichoderinae have been keyed globally by Shattuck (1992), although this key stands in need of updating. A key to the New World dolichoderine genera is in preparation (B. Boudinot, in prep.).

Subfamily Formicinae Latreille, 1809

Figs 5I, 7B, F, 16A-B

\section{Diagnosis}

The Formicinae are uniquely identified by the following combination of characters: mandibles never serrate; antennal toruli usually situated posterad posterior clypeal margin; antenna 8-13-merous; oblique mesopleural sulcus present; at most six closed cells present on forewing; jugal lobe absent; petiolar peduncle short to absent; petiole narrowly attached to abdominal segment III; abdominal segment III unpetiolated; abdominal segment IV without cinctus between pre- and postsclerites; abdominal sternum IX unpronged and edentate.

\section{Comments}

In terms of both number of described species $(\sim 3,000)$ and genera (51), the Formicinae is one of the most diverse lineages of ants. Genera of the Formicinae are relatively easily delimitable based on males (B. Boudinot, in prep.), but little work has been done to render males identifiable. Males are unknown or at least undescribed for seven genera (Agraulomyrmex, Alloformica, Bregmatomyrmex, Forelophilus, Pseudonotoncus, Santschiella, Teratomyrmex), and the identity of Echinopla and Phasmomyrmex is uncertain.

\section{Ectaheteromorph clade}

Fig. 16B-C

\section{Diagnosis}

Male ectaheteromorphs are uniquely identified by the following combination of characters: mandibles triangular, multidentate; antennal toruli situated posterad anterior clypeal margin; tibial spur formula 1,1 or 2,2 (if 2,2 then prora anteriorly directed); crossvein $1 \mathrm{~m}$-cu present; abdominal segment III unpetiolated; cinctus present between the pre- and postsclerites of abdominal segment IV; abdominal sternum IX unpronged and edentate. The jugal lobes may be present or absent.

\section{Comments}

No nomothetic (single unique) character separates the males of Ectatomminae Emery, 1895 and Heteroponerinae Bolton, 2003, which are better distinguished genus-by-genus. In brief, Typhlomyrmex may be distinguished by the scapes, which are longer than the compound eye; Acanthoponera males have 

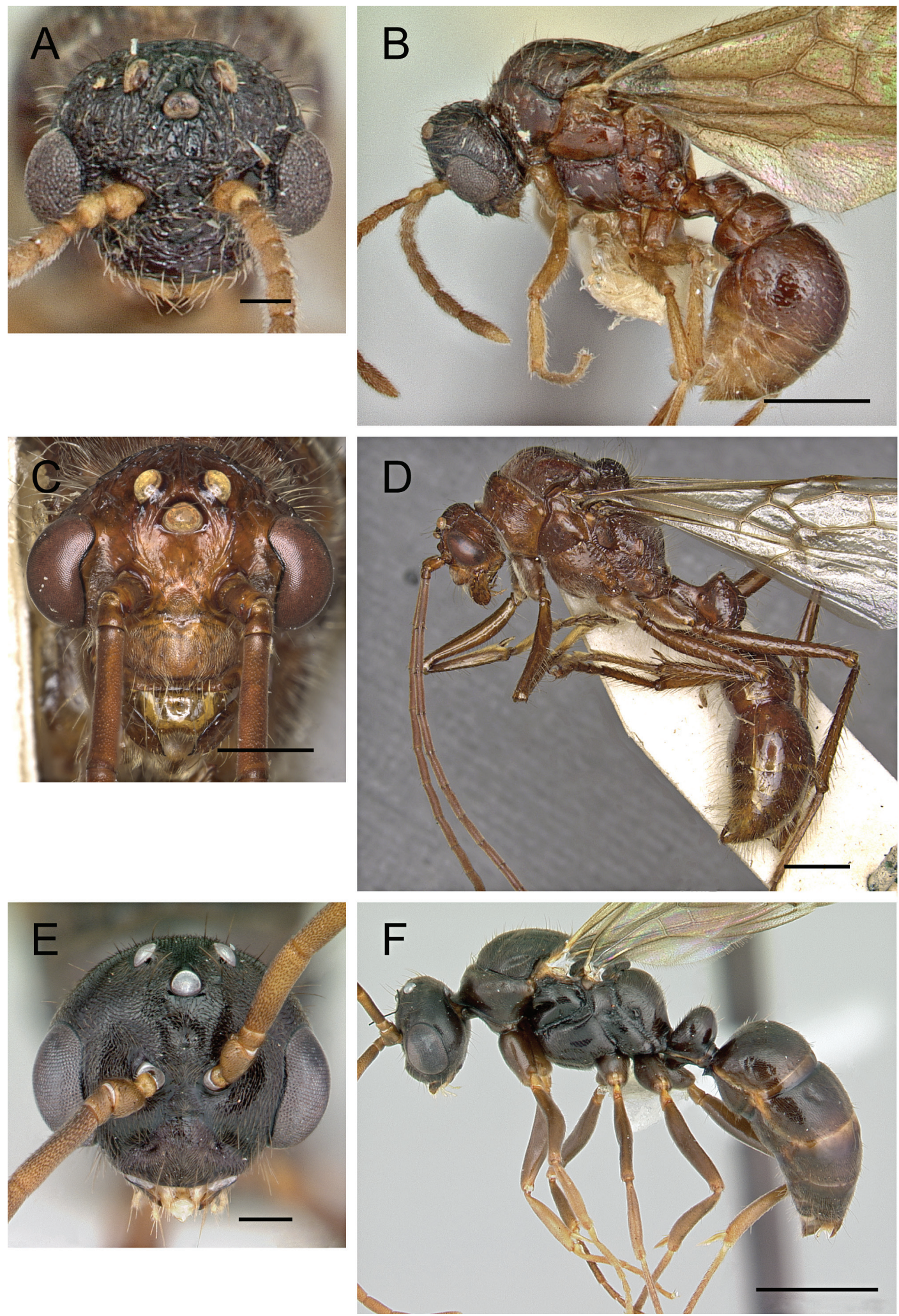

Fig. 13. Male representatives of three subfamilies. A, C, E. Frontal view. B, D, F. Lateral view. A-B. Tatuidris tatusia, Agroecomyrmecinae (Panama, CASENT0178870, E. Prado). C-D. Paraponera clavata, Paraponerinae (Guyana, CASENT0902407, R. Perry). E-F. Pseudoponera stigma, Ponerinae (Paraguay, CASENT0178182, A. Nobile). Scale bars: A $=0.1 \mathrm{~mm}, \mathrm{~B}=0.5 \mathrm{~mm}, \mathrm{C}, \mathrm{F}=1.0 \mathrm{~mm}, \mathrm{D}=2.0$ $\mathrm{mm}, \mathrm{E}=0.2 \mathrm{~mm}$. 


\section{BOUDINOT B.E., Contributions to the Formicidae}
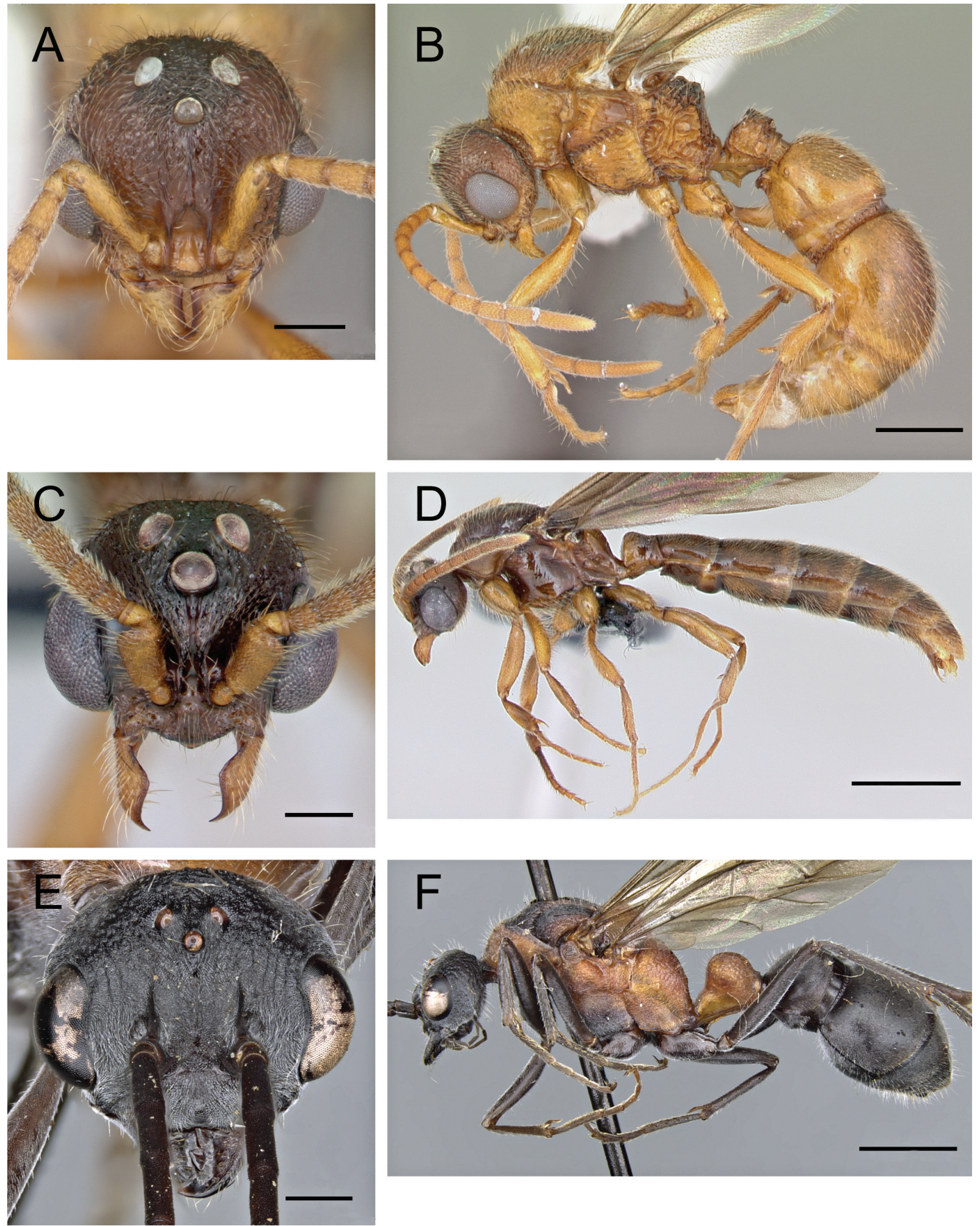

Fig. 14. Male representatives of three subfamilies. A, C, E. Frontal view. B, D, F. Lateral view. A-B. Proceratium creek, Proceratiinae (U.S.A., CASENT010441, A. Nobile). C-D. Acanthostichus, Dorylinae (French Guiana, CASENT0056970, A. Nobile). E-F. Myrmecia chasei, Myrmeciinae (Australia, CASENT0903663, W. Ericson). Scale bars: A, C $=0.2 \mathrm{~mm}, \mathrm{~B}, \mathrm{E}=0.5 \mathrm{~mm}, \mathrm{D}=1.0 \mathrm{~mm}, \mathrm{E}$ $=2.0 \mathrm{~mm}$. 

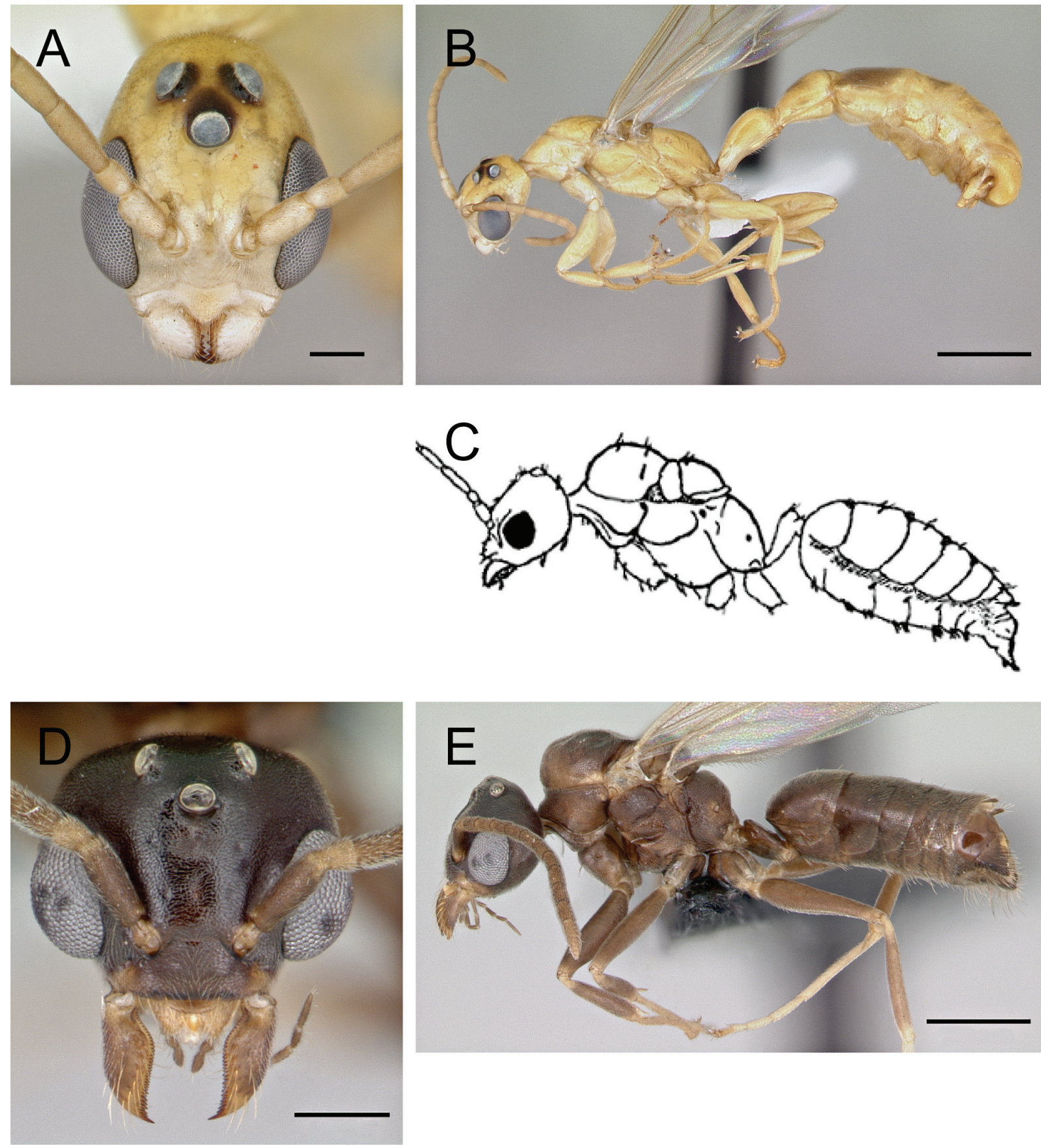

Fig. 15. Male representatives of three subfamilies. A, D. Frontal view. B-C, E. Lateral view. - A-B. Pseudomyrmex holmgreni, Pseudomyrmecinae (Paraguay, CASENT0173758, A. Nobile). C. Aneuretus simoni, Aneuretinae, used with permission from Wilson et al. (1956). D-E. Technomyrmex difficilis, Dolichoderinae (Madagascar, CASENT0049968, A. Nobile). Scale bars: A, D $=0.2 \mathrm{~mm}, \mathrm{~B}=1.0 \mathrm{~mm}$, $\mathrm{E}=0.5 \mathrm{~mm}$, no scale available for $\mathrm{C}$. 

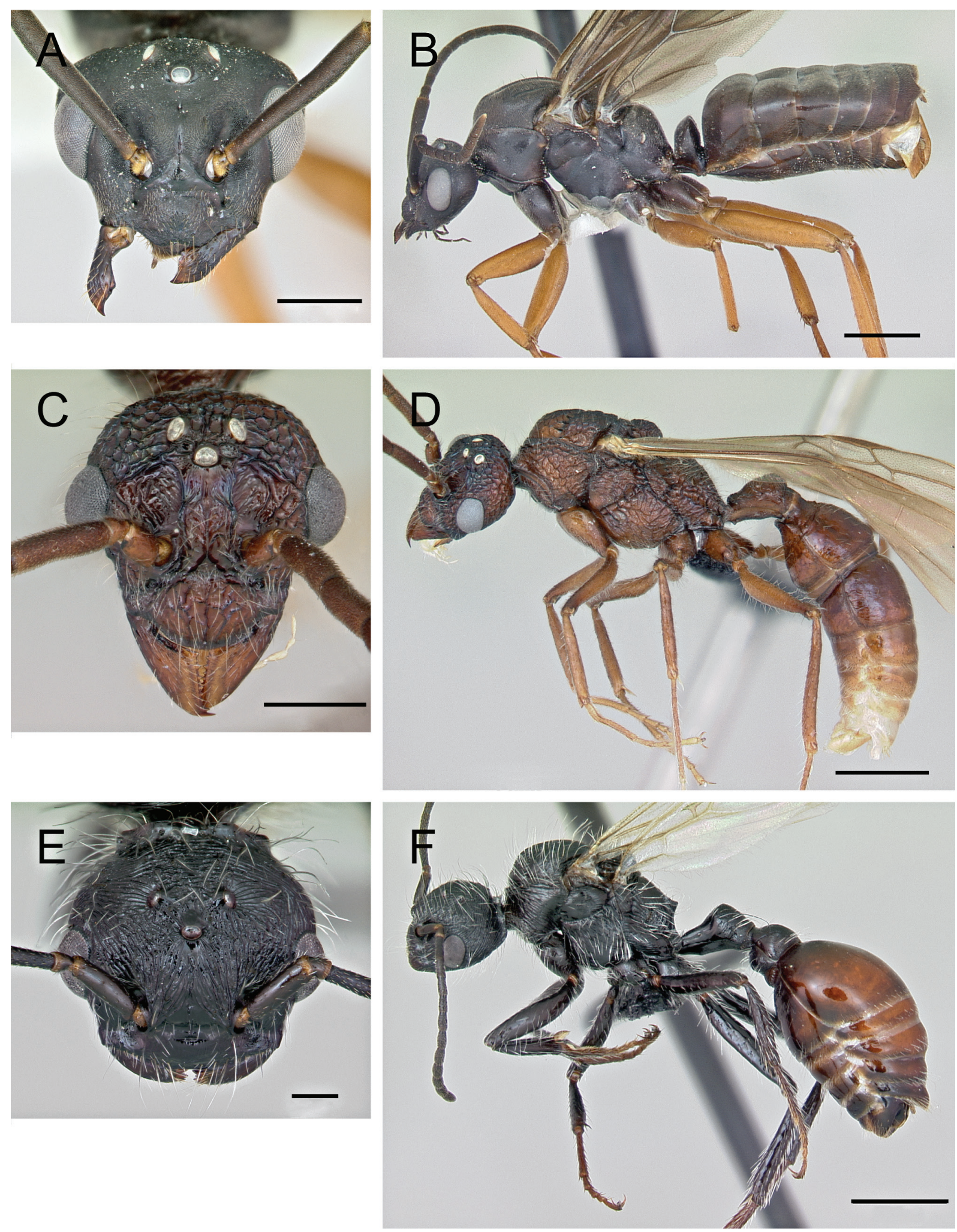

Fig. 16. Male representatives of three subfamilies. A-B. Formica wheeleri, Formicinae (U.S.A., CASENT0173024, A. Nobile). C-D. Rhytidoponera, Ectatomminae, ectaheteromorph clade (Australia, CASENT0004610, A. Nobile). E-F. Pogonomyrmex rastratus (Argentina, CASENT0172673, A. Nobile). Scale bars: A, C $=0.5 \mathrm{~mm}, \mathrm{~B}, \mathrm{D}, \mathrm{F}=1.0 \mathrm{~mm}, \mathrm{E}=0.2 \mathrm{~mm}$. 
long maxillary palps, which almost reach the postocciput; Ectatomma (Neotropical) and Rhytidoponera (Australasian) are large and have jugal lobes. Heteroponera and Gnamptogenys are distinguishable globally only using conditional statements. Characters have been found to do this, and will be described in a forthcoming publication on the New World genera (B. Boudinot in prep.). The male of Aulacopone is unknown.

Subfamily Myrmicinae Lepeletier de Saint-Fargeau, 1835

Figs 4H, 5A, G, 16D-E

\section{Diagnosis}

Male Myrmicinae are uniquely identified by the strongly petiolated third abdominal segment (postpetiole), axial helcium, 1,1 maximum ventroapical tibial spur count, unvaulted abdominal tergum IV, and presence of propodeal lobes. All myrmicines lack jugal lobes and have posteriorly-situated antennal toruli, but are highly variable otherwise: mandibles fully-developed to nub-like; antenna 8-13-merous; forewing with (0)1-8 eight closed cells; and petiole sessile to long-pedunculate. Some myrmicines, e.g., Adelomyrmex and Acanthognathus, have extremely reduced wing venation similar to Leptanillinae; all myrmicine taxa examined during this study with reduced wing venation have conspicuous propodeal lobes, differentiating them easily from Leptanillinae despite secondary petiolation of abdominal segment III in some leptanillines.

\section{Comments}

Of all the ant subfamilies, the Myrmicinae will be the grand challenge to understand with respect to males. At the time of writing, 139 valid genera and 6,500 valid species are described. Males of at least 30 genera are unknown, but as generic delimitation is still very active in the Myrmicinae some uncertainty exists for this number. Based on a study of the New World genera (B. Boudinot, in prep.), distinctions between genera may be weak and in many cases genera will have to be keyed multiple times due to variability. The recent subfamily-wide phylogeny of Ward et al. (2015) will contribute significantly to improving the classification of the Myrmicinae.

\section{Acknowledgments}

First I want to extend my gratitude to Dr Philip S. Ward (UCD) for his advice, for his support for my Brazil museum trip (which precipitated the present work), for his critical review of the manuscript, and valuable discussions of this research through its various phases. I want to also extend my gratitude to Dr. John (Jack) T. Longino (University of Utah) for diverting my attention to entomology, critically encouraging my interest in the Formicidae, and providing a valuable review of this manuscript. This work would not be possible without Barry Bolton's extensive and influential literature. I want to thank my Brazilian colleagues, who supported my trip to Brazil in several functions. At the INPA, I thank Dr. Marcio Oliveira, Thiago Mahlmann, and Itanna Fernandes; at the MZSP, I thank Dr. C. Roberto (Beto) F. Brandão, Rodolfo da S. Probst, Thiago S. R. da Silva, Mônica Ullyssea, and Lívia Prado; and at the DZUP, I thank Dr. Rodrigo M. Feitosa, Gabriela Camacho, and the rest of the Feitosa lab. At UC Davis, I thank Dr. Lynn Kimsey for a valuable loan and discussion of non-formicid Aculeata; Marek Borowiec for use of Leptanillinae on loan from Lund, for lending books on the European myrmecofauna, and for providing discussion of the "basal ant problem"; and Drs. Steve Heydon and Lynn Kimsey for helping discover non-formicid literature. Thanks to Dr. Brian Fisher and Michele Esposito for AntWeb; Stan Blum, Barry Bolton, and the AntCat community for online taxonomic catalog resources. An anonymous reviewer provided some useful comments. This work was supported by National Science Foundation grant DEB-1354739 (Project ADMAC), a UC Davis Jastro grant, and an Ernst Mayr grant from the MCZ for the project "Male ants of Central America", which has expanded to "Male ants of the New World". 


\section{References}

Antropov A.V., Belokobylskij S.A., Compton S.G., Dlussky G.M., Khalaim A.I., Kolyada V.A., Kozlov M.A., Perfilieva K.S. \& Rasnitsyn A.P. 2014. The wasps, bees and ants (Insecta: Vespida = Hymenoptera) from the insect limestone (Late Eocene) of the Isle of Wight, UK. Earth and Environmental Science Transactions of the Royal Society of Edinburgh 104: 335-446.

AntWeb. 2014. AntWeb v5.17.1 [online]. Available from http://www.antweb.org/ [accessed 29 Oct. 2014].

Arakelian G.R. 1994. Fauna of the Republic of Armenia. Hymenopterous Insects. Ants (Formicidae). [In Russian] Erevan, Gitutium.

Arnol'di K.V. \& Dlussky G.M. 1978. Superfam. Formicoidea. 1. Fam. Formicidae - ants. [In Russian] Opredeliteli Faune SSSR 119: 519-556.

Baroni Urbani C. 1977. Materiali per una revisione della sottofamiglia Leptanillinae Emery Hymenoptera: Formicidae. Entomologica Basiliensia 2: 427-488.

Baroni Urbani C., Bolton B. \& Ward P.S. 1992. The internal phylogeny of ants (Hymenoptera: Formicidae). Systematic Entomology 17: 301-329. http://dx.doi.org/10.1111/j.1365-3113.1992.tb00553.x

Bernard F. 1951. Hyménoptères, super-famille des Formicoidea Ashmead 1905. In: Grassé P.P. (ed) Traité de Zoologie. Tome X. Fasc. II: 997-1104. Masson et Cie, Paris.

Bernard F. 1967 [1968]. Faune de l'Europe et du Bassin Méditerranéen. 3. Les fourmis Hymenoptera Formicidae d'Europe occidentale et septentrionale. Masson, Paris.

Bierregaard R.O. Jr., Gascon C., Lovejoy T. \& Mesquita R.C.G. (eds) 2001. Lessons from Amazonia: The Ecology and Conservation of a Fragmented Forest. Yale University Press, New Haven.

Billen J., Bauweleers E., Hashim R. \& Ito F. 2013. Survey of the exocrine system of Protanilla wallacei (Hymenoptera: Formicidae). Arthropod Structure \& Development 42: 173-183. http://dx.doi. org/10.1016/j.asd.2013.01.001

Bolton B. 1990a. Abdominal characters and status of the cerapachyine ants (Hymenoptera, Formicidae). Journal of Natural History 24: 53-68. http://dx.doi.org/10.1080/00222939000770051

Bolton B. 1990b. The higher classification of the ant subfamily Leptanillinae (Hymenoptera: Formicidae). Systematic Entomology 15: 267-282. http://dx.doi.org/10.1111/j.1365-3113.1990.tb00063.x

Bolton B. 1990c. Army ants reassessed: the phylogeny and classification of the doryline section (Hymenoptera, Formicidae). Journal of Natural History 24: 1339-1364. http://dx.doi. org/10.1080/00222939000770811

Bolton B. 1994. Identification Guide to the Ant Genera of the World. Harvard University Press, Cambridge.

Bolton B. 2003. Synopsis and classification of Formicidae. Memoirs of the American Entomological Institute 71: 1-370.

Bolton B. 2014. AntCat: An Online Catalog of the Ants of the World [online]. Available from http:// www.antcat.org/ [accessed 29 Oct. 2014].

Borowiec M.L., Schulz A., Alpert G.D. \& Baňař P. 2011. Discovery of the worker caste and descriptions of two new species of Anomalomyrma (Hymenoptera: Formicidae: Leptanillinae). with unique abdominal morphology. Zootaxa 2810: 1-14. 
Boudinot B.E. 2013. The male genitalia of ants: musculature, homology, and functional morphology (Hymenoptera, Aculeata, Formicidae). Journal of Hymenoptera Research 30: 29-49. http://dx.doi. org/10.3897/jhr.30.3535

Boudinot B.E., Sumnicht T.P. \& Adams R.M.M. 2013. Central American ants of the genus Megalomyrmex (Hymenoptera: Formicidae): six new species and keys to workers and males. Zootaxa 3732: 1-82. http://dx.doi.org/10.11646/zootaxa.3732.1.1

Brady S.G., Schultz T.R., Fisher B.L. \& Ward P.S. 2006. Evaluating alternative hypotheses for the early evolution and diversification of ants. Proceedings of the National Academy of Sciences of the United States of America 103: 18172-18177. http://dx.doi.org/10.1073/pnas.0605858103

Brady S.G., Schultz T.R., Fisher B.L. \& Ward P.S. 2014. The rise of army ants and their relatives: diversification of specialized predatory doryline ants. BMC Evolutionary Biology 14: 93. http://dx.doi. org/10.1186/1471-2148-14-93.

Brandão C.R.F., Diniz J.L.M. \& Feitosa R.S.M. 2010. The venom apparatus and other morphological characters of the ant Martialis heureka (Hymenoptera, Formicidae, Martialinae). Papeis Avulsos de Zoologia 50: 413-423.

Brothers D.J. 1975. Phylogeny and classification of aculeate Hymenoptera, with special reference to Mutillidae. The University of Kansas Science Bulletin 50: 485-648.

Brown W.L. Jr. 1958. A review of the ants of New Zealand. Acta Hymenopterologica 1: 1-50.

Brown W.L. Jr. \& Nutting W.L. 1949. Wing venation and the phylogeny of the Formicidae (Hymenoptera). Transactions of the American Entomological Society 75: 113-132.

Brown W.L. Jr., Gotwald W.H. Jr. \& Lévieux J. 1971 [1970]. A new genus of ponerine ants from West Africa (Hymenoptera: Formicidae) with ecological notes. Psyche 77: 259-275.

Czechowski W., Radchenko A., Czechowska W. \& Vepsäläinen K. 2012. The ants of Poland with reference to the myrmecofauna of Europe. Fauna Poloniae 4. Warsaw, Natura Optima Dux Foundation.

Deyrup M. \& Cover S. 2004. A new species of Odontomachus ant (Hymenoptera: Formicidae) from inland ridges of Florida, with a key to the Odontomachus of the United States. Florida Entomologist 87: 136-144. http://dx.doi.org/10.1653/0015-4040(2004)087[0136:ANSOOA]2.0.CO;2

Dlussky G.M. 1975. Superfamily Formicoidea Latreille, 1802. Family Formicidae Latreille, 1802. [In Russian] In: Rasnitsyn, A. P. Hymenoptera Apocrita of Mesozoic: 114-122. Trudy Paleontologicheskogo Instituta, Akademiya Nauk SSSR.

Dlussky G.M. 1983. A new family of Upper Cretaceous Hymenoptera: an "intermediate link" between ants and the scoliids. [In Russian] Paleontologicheskii Zhurnal 1983(3): 65-78.

Dlussky G.M. 1988. Ants of Sakhalin amber (Paleocene?). [In Russian] Paleontologicheskii Zhurnal 1988 (1): 50-61.

Dlussky G.M. 1996. Ants (Hymenoptera: Formicidae) from Burmese amber. Paleontological Journal 30: 449-454.

Dlussky G.M. 1999. The first find of the Formicoidea (Hymenoptera) in the lower Cretaceous of the northern hemisphere. [In Russian] Paleontologicheskii Zhurnal 1999 (3): 62-66.

Dlussky G.M., Brothers D.J. \& Rasnitsyn A.P. 2004. The first Late Cretaceous ants (Hymenoptera: Formicidae) from southern Africa, with comments on the origin of the Myrmicinae. Insect Systematics and Evolution 35: 1-13. 
Dlussky G.M. \& Fedoseeva E.B. 1988. Origin and early stages of evolution in ants. [In Russian] In: Ponomarenko A.G. (ed.) Cretaceous Biocenotic Crisis and Insect Evolution: 70-144. Nauka, Moskva.

Dlussky G.M. \& Rasnitsyn A.P. 2009. Ants (Insecta: Vespida: Formicidae) in the Upper Eocene amber of central and eastern Europe. Paleontological Journal 43: 1024-1042.

Dunn R.R., Parker C.R., Geraghty M. \& Sanders N.J. 2007. Reproductive phenologies in a diverse temperate ant fauna. Ecological Entomology 32: 135-142. http://dx.doi.org/10.1111/j.13652311.2006.00839.x

Emery C. 1910. Hymenoptera. Fam. Formicidae. Subfam. Dorylinae. Genera Insectorum 102: 1-34. http://www.biodiversitylibrary.org/bibliography/45481\#/summary

Engel M.S. \& Grimaldi D.A. 2005. Primitive new ants in Cretaceous amber from Myanmar, New Jersey, and Canada (Hymenoptera: Formicidae). American Museum Novitates 3485: 1-23.

Forel A. 1893. Sur la classification de la famille des Formicides, avec remarques synonymiques. Annales de la Société Entomologique de Belgique 37: 161-167.

Gauld I. \& Bolton B. (eds.) 1988. The Hymenoptera. Oxford University Press, Oxford.

Gotwald W.H. Jr. 1969. Comparative morphological studies of the ants, with particular reference to the mouthparts (Hymenoptera: Formicidae). Cornell University Agricultural Experiment Station 408: $3-150$.

Goulet H. \& Huber J. 1993. Hymenoptera of the World: an Identification Guide to Families. Agriculture Canada, Ottawa.

Grimaldi D., Agosti D. \& Carpenter J.M. 1997. New and rediscovered primitive ants (Hymenoptera: Formicidae) in Cretaceous amber from New Jersey, and their phylogenetic relationships. American Museum Novitates 3208: 1-43.

Gronenberg W., Hölldobler B. \& Alpert G.D. 1998. Jaws that snap: control of mandible movements in the ant Mystrium. Journal of Insect Physiology 44: 241-253. http://dx.doi.org/10.1016/S0022$\underline{1910(97) 00145-5}$

Harris R.A. 1979. A glossary of surface sculpturing. California Department of Food and Agriculture. Laboratory Services, Entomology. Occasional Papers 28: 1-31.

Hölldobler B. \& Wilson E.O. 1990. The Ants. Harvard University Press, Cambridge.

Johnson B.R., Borowiec M.L., Chiu J.C., Lee E.K., Atallah H. \& Ward P.S. 2013. Phylogenomics resolves evolutionary relationships among ants, bees, and wasps. Current Biology 23: 2058-2062. http:// dx.doi.org/10.1016/j.cub.2013.08.050

Johnson N.R. 1988. Midcoxal articulations and phylogeny of the order Hymenoptera. Annals of the Entomological Society of America 81: 870-881.

Kaspari M., Pickering J., Longino J.T. \& Windsor D. 2001a. The phenology of a Neotropical ant assemblage: Evidence for continuous and overlapping production. Behavioral Ecology and Sociobiology 50: 382-390. http://dx.doi.org/10.1007/s002650100378

Kaspari M., Pickering J. \& Windsor D. 2001b. The reproductive flight phenology of a Neotropical ant assemblage. Ecological Entomology 26: 245-257. http://dx.doi.org/10.1046/j.1365-2311.2001.00320.x

Keller R.A. 2011. A phylogenetic analysis of ant morphology (Hymenoptera: Formicidae) with special reference to the poneromorph subfamilies. Bulletin of the American Museum of Natural History 355: 1-90. 
Kück P., Hita Garcia F., Misof B. \& Meusemann K. 2011. Improved phylogenetic analyses corroborate a plausible position of Martialis heureka in the ant tree of life. PLOS ONE 6: e21031. http://dx.doi. org/10.1371/journal.pone.0021031

Kugler C. 1992. Stings of ants of the Leptanillinae (Hymenoptera: Formicidae). Psyche 99: 103-115.

Kutter H. 1948. Beitrag zur Kenntnis der Leptanillinae Hym. Formicidae. Eine neue Ameisengattung aus Süd-Indien. Mitteilungen der Schweizerischen Entomologischen Gesellschaft 21: 286-295.

LaPolla J.S., Dlussky G.M. \& Perrichot V. 2013. Ants and the fossil record. Annual Review of Entomology 58: 609-630. http://dx.doi.org/10.1146/annurev-ento-120710-100600

MacGown J.A., Boudinot B.E., Deyrup M. \& Sorger D.M. 2014. A review of the Nearctic Odontomachus (Hymenoptera: Formicidae: Ponerinae) with a treatment of the males. Zootaxa 3802: 515-552. http://dx.doi.org/10.11646/zootaxa.3802.4.6

McKellar R.C., Glasier J.R.N. \& Engel M.S. 2013. New ants (Hymenoptera: Formicidae: Dolichoderinae) from Canadian Late Cretaceous amber. Bulletin of Geosciences 88: 583-594. http://dx.doi.org/10.3140/ bull.geosci. 1425

Michener C.D. 1981. Comparative morphology of the middle coxae of Apoidea. Journal of the Kansas Entomological Society 54: 319-326.

Moffett M.W. 1986. Mandibles that snap: notes on the ant Mystrium camillae Emery. Biotropica 18: $361-362$.

Moreau C.S., Bell C.D., Vila R., Archibald S.B. \& Pierce N.E. 2006. Phylogeny of the ants: diversification in the age of angiosperms. Science 312: 101-104. http://dx.doi.org/10.1126/science.1124891

Morley B.D.W. 1939. The phylogeny of the Cerapachyinae, Dorylinae, and Leptanillinae (Hym. Formicidae). Bulletin de la Société Entomologique de France 44: 114-118.

Ogata K. 1991. A generic synopsis of the poneroid complex of the family Formicidae in Japan (Hymenoptera). Part II. Subfamily Myrmicinae. Bulletin of the Institute of Tropical Agriculture, Kyushu University 14: 61-149.

Ogata K., Terayama M. \& Masuko K. 1995. The ant genus Leptanilla: discovery of the worker-associated male of L. japonica, and a description of a new species from Taiwan (Hymenoptera: Formicidae: Leptanillinae). Systematic Entomology 20:27-34. http://dx.doi.org/10.1111/j.1365-3113.1995.tb00081.x

PDBFF \& INPA-SI. Projeto Dinâmica Biológica de Fragmentos Florestais [online]. Available from http://pdbff.inpa.gov.br [accessed 21 Aug. 2014].

Petersen B. 1968. Some novelties in presumed males of Leptanillinae (Hym., Formicidae). Entomologiske Meddelelser 36: 577-598.

Pilgrim E.M., Dohlen C.D. von \& Pitts J.P. 2008. Molecular phylogenetics of Vespoidea indicate paraphyly of the superfamily and novel relationships of its component families and subfamilies. Zoologica Scripta 37: 539-560. http://dx.doi.org/10.1111/j.1463-6409.2008.00340.x

Rabeling C., Brown J.M. \& Verhaagh M. 2008. Newly discovered sister lineage sheds light on early ant evolution. Proceedings of the National Academy of Sciences B 105: 14913-14917. http://dx.doi. org/10.1073/pnas.0806187105

Radchenko A.G. 1994. Identification table for the ants (Hymenoptera, Formicidae) of southern Siberia. [In Russian.]. Trudy Zapovednika "Daurskii" 3: 1-147.

Radchenko A. 2005. Monographic revision of the ants (Hymenoptera: Formicidae) of North Korea. Annales Zoologici 55: 127-221. 
BOUDINOT B.E., Contributions to the Formicidae

Saux C., Fisher B.L. \& Spicer G.S. 2004. Dracula ant phylogeny as inferred by nuclear 28S rDNA sequences and implications for ant systematics (Hymenoptera: Formicidae: Amblyoponinae). Molecular Phylogenetics and Evolution 33: 457-468. http://dx.doi.org/10.1016/j.ympev.2004.06.017

Schmidt C. 2013. Molecular phylogenetics of ponerine ants (Hymenoptera: Formicidae: Ponerinae). Zootaxa 3647: 201-250. http://dx.doi.org/10.11646/zootaxa.3647.2.1

Schmidt C.A. \& Shattuck S.O. 2014. The higher classification of the ant subfamily Ponerinae (Hymenoptera: Formicidae), with a review of ponerine ecology and behavior. Zootaxa 3817: 1-242. http://dx.doi.org/10.11646/zootaxa.3817.1.1

Shattuck S.O. 1992. Generic revision of the ant subfamily Dolichoderinae (Hymenoptera: Formicidae). Sociobiology 21: 1-181.

Smith M.R. 1943. A generic and subgeneric synopsis of the male ants of the United States. The American Midland Naturalist 30: 273-321.

Vasconcelos H.L., Carvalho K.S. \& Delabie J.H.C. 2001. Landscape modifications and ant communities. In: Bierregaard Jr., Gascon C., Lovejoy T.E. \& Mesquita R.C.G. (eds) Lessons from Amazonia: The Ecology and Conservation of a Fragmented Forest: 199-207. Yale University Press, New Haven.

Vilhelmsen L., Mikó I. \& Krogmann L. 2010. Beyond the wasp-waist: structural diversity and phylogenetic significance of the mesosoma in apocritan wasps (Insecta: Hymenoptera). Zoological Journal of the Linnean Society 159: 22-194. http://dx.doi.org/10.1111/j.1096-3642.2009.00576.x

Ward P.S. 1990. The ant subfamily Pseudomyrmecinae (Hymenoptera: Formicidae): generic revision and relationship to other formicids. Systematic Entomology 15: 449-489. http://dx.doi. org/10.1111/j.1365-3113.1990.tb00077.x

Ward P.S. 2014. The phylogeny and evolution of ants. Annual Review of Ecology, Evolution, and Systematics 45: 2.1-2.21. http://dx.doi.org/10.1146/annurev-ecolsys-120213-091824

Ward P.S. \& Brady S.G. 2007. Phylogeny and biogeography of the ant subfamily Myrmeciinae (Hymenoptera: Formicidae). Invertebrate Systematics 17: 361-386. http://dx.doi.org/10.1071/IS02046

Ward P.S., Brady S.G., Fisher B.L. \& Schultz T.R. 2010. Phylogeny and biogeography of dolichoderine ants: effects of data partitioning and relict taxa on historical inference. Systematic Biology 59: 342-362. http://dx.doi.org/10.1093/sysbio/syq012

Ward P.S., Brady S.G., Fisher B.L. \& Schultz T.R. 2015. The evolution of myrmicine ants: Phylogeny and biogeography of a hyperdiverse ant clade (Hymenoptera: Formicidae). Systematic Entomology 40: 61-81. http://dx.doi.org/10.1111/syen.12090

Wheeler G.C. \& Wheeler E.W. 1930. Two new ants from Java. Psyche 37: 193-201.

Wheeler G.C. \& Wheeler E.W. 1976. Ant larvae: Review and synthesis. Memoirs of the Entomological Society of Washington 7: 1-108.

Wheeler G.C. \& Wheeler J. 1972. The subfamilies of Formicidae. Proceedings of the Entomological Society of Washington 74: 35-45.

Wheeler G.C. \& Wheeler J. 1985. A simplified conspectus of the Formicidae. Transactions of the American Entomological Society 111: 255-264.

Wheeler W.M. 1910. Ants: Their Structure, Development and Behavior. Columbia University Press, New York.

Wheeler W.M. 1915 (1914). The ants of the Baltic Amber. Schriften der Physikalisch-Ökonomischen Gesellschaft zu Königsberg 55: 1-142. 
Wheeler W.M. 1923. Social life among the insects. New York, Harcourt, Brace and Co.

Wilson E.O. 1955. A monographic revision of the ant genus Lasius. Bulletin of the Museum of Comparative Zoology 113: 1-201.

Wilson E.O. 1985. Ants from the Cretaceous and Eocene amber of North America. Psyche 92: 205-216.

Wilson E.O., Carpenter F.M. \& Brown W.L. Jr. 1967. The first Mesozoic ants, with a description of a new subfamily. Psyche 74: 1-19.

Wilson E.O., Eisner T., Wheeler G.C. \& Wheeler J. 1956. Aneuretus simoni Emery, a major link in ant evolution. Bulletin of the Museum of Comparative Zoology 115: 81-99.

Yamane S., Bui T.V. \& Eguchi K. 2008. Opamyrma hungvuong, a new genus and species of ant related to Apomyrma (Hymenoptera: Formicidae: Amblyoponinae). Zootaxa 1767: 55-63.

Yoshimura M. \& Fisher B.L. 2007. A revision of male ants of the Malagasy region (Hymenoptera: Formicidae): key to subfamilies and treatment of the genera of Ponerinae. Zootaxa 1654: 21-40.

Yoshimura M. \& Fisher B.L. 2011. A revision of male ants of the Malagasy region (Hymenoptera: Formicidae): Key to genera of the subfamily Dolichoderinae. Zootaxa 2794: 1-34.

Yoshimura M. \& Fisher B.L. 2012a. A revision of male ants of the Malagasy Amblyoponinae (Hymenoptera: Formicidae) with resurrections of the genera Stigmatomma and Xymmer. PLoS ONE 7: e3325. http://dx.doi.org/10.1371/journal.pone.0033325

Yoshimura M. \& Fisher B.L. 2012b. A revision of the Malagasy endemic genus Adetomyrma (Hymenoptera: Formicidae: Amblyoponinae). Zootaxa 3341: 1-31.

Yoshimura M. \& Onoyama K. 2002. Male-based keys to the subfamilies and genera of Japanese ants (Hymenoptera: Formicidae). Entomological Science 5: 421-443.

Manuscript received: 4 November 2014

Manuscript accepted: 27 January 2015

Published on: 20 April 2015

Topic editor: Koen Martens

Desk editor: Kristiaan Hoedemakers

Printed versions of all papers are also deposited in the libraries of the institutes that are members of the EJT consortium: Muséum National d'Histoire Naturelle, Paris, France; Botanic Garden Meise, Belgium; Royal Museum for Central Africa, Tervuren, Belgium; Natural History Museum, London, United Kingdom; Royal Belgian Institute of Natural Sciences, Brussels, Belgium; Natural History Museum of Denmark, Copenhagen, Denmark. 